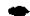

\title{
Biological Dose and Radiological Activity from Nuclear Reactor or Nuclear Weapon Fission Products
}

\author{
R. O. Chester
}

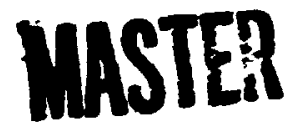


. 
Prirted in the United States of America. Available from National Technical Information Service

\section{U.S. Departmem of Commerce}

5285 Port Roval Road, Springfield. Virginia 22161

Price: Printed Copy S5.45; Microfiche $\$ 2.25$

This report wa prepered as an zecount j" work spersoned by the United Seats

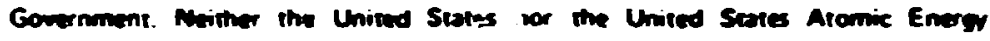

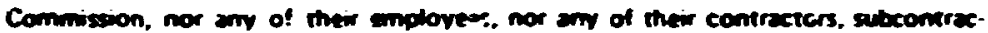
tors. or their emploves. mekes am terranry. exporess or inglind, or axemes any

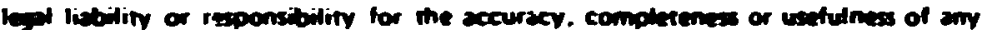
information, apperstus. product or process destead, or represents then its use noudo not intringe privetely awned rights. 
:RLL-4996
UC-32 - Yathematics and Computers

Contract MO. W-7to5-eng-25

HEALTY PHYSICS DTVISIOA

BIOLOGTCAL DOSE FND RADIOLOGICAL ACTVITI FROA MURLEAR REACTOR OR MUCLENR VEAP:N FISSIOA PRODUCTS

R. 0. Crester

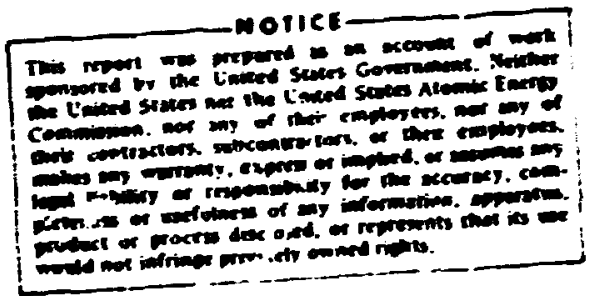

OAK RIDGE MTIOAAL LABORATORY Oak Ridge, Terinesuee 37830 operated by UNTON CARBIDE CORPORATION for the

U.S. ATOMIC ENERG COAAISSTON 
Abstrect - - - - - - - - - - - - - - 1

Introduction - - - - - - - - - - - - - 1

Use of the code, IIRIS - - - - - - - - - - 2

Bormal Use - - - - - - - - - - - - 2

Mon-Standard Use - $-\quad$ - - - - - - - 2

Bxarples of nuran Use - - - - - - - - 3

Buanple 1: Activity - - - - - - - 3

Bazple 2: Total Eersy Release - - - - - - 3

Buaple 3: Lifetime Thyroid Dose - - - - - - 3

Bupple 4: Gam Ray Dose Above a Conteninated Plane - 13

Barple 5: Lifetive Iung Dose - - - - - - 14

Barfle 6: Whole-Body Dase - - _ - _ - - 15

3aple 7: Dose to a Multisection Mosystea - - - 15

Calculatior Method - - - - - - - - - - - 17

Basic Jecay Chain - - - - - - - - - - - 17

Discussion - - - - - - - - - - - 17

Illustration of the Basis Method - - - - - - 19

Bffect: of a Biological system - - - - - - - 21

Basic Bquations - - - - - - - - 21

Approximation - - - - - - - - - - 22

Use of Alpha, Beta, ard Gama Ray Energies- - - - - 25

Alphe and Gama Ray Rnergies - - - - - - - 23

Average Beta Energy - - - - - - - - 23

Dose Calculations - - - - - - - - - - - $\geq 4$

Case I: Total Enerc/ Absorption - - - - - - 25

Case II: Garma Ray Dose Ahove a Plane - - - - 25

Case III: Doss Trom Ingestion ant Inhalation - - - 26

Case IV: Optional Input - - - - - - - 27

Continuous Release of Fission Products- - - - - - 27

Appendix A - Non-Standard Use of the Code, YEELD - - - - 29

Appendix B - Input Caras - - - - - - - - - -

Appendix C - Detafls of Decay Lhain Date - - - - - -

Append1X D - Complete Listing of YIELDS Code - - - - - 
BIOLOGICAL DOSE HW PADICTEGTCAL ACTIVITY FRQ NUCLEAR REAETCR QR NUCI GAR WBAPON FISSION FRODJCTS

R. 0. Cizester

ABSTRA:T

This report describes the use of a conputer code, YIEIDS, that pertors rapid, accurate calculation of dose and activity from the fission products in s suclear reactor core or from nuclear weapon. For example, if a dispersal model is assumed, calculations can be rade of contaminated area, dose from inhaled or ingerted i'ission products to each part of a biolozical system, or dose from external pission products, from 2 dispersed reacto- core, or nuclecr weapon fallout. Individual bete and gawra ray energies for each isotope are included, permitting detailer calculation of biological dose or other runctions of these energies vs time. The calculation method facilitates the handling of complicated radiological decay chains ccupled witr. multisection biological systems. The option of sorting the output by isotopes or chemical species is available.

\section{INTRODUCTIOR}

This report discusses a compliter code written primarily to describe the aftereffects of a nuclear power reactor core meltdown. The code also is used to calculate the effects of nuclear fission weapon fallout.

Time-dependent dose and activiะy frow each isotope in the 1issionproduct decay chairs were the originas of fectives. However, this method. applies equaliy well to actinide deray chains, as will be fllustrated in an example. It became necessiry tc acit the detalls of multisection tiological systems for accurate dose calculations. The resultant computational method car, utilize a differert mulisisection biological system for each isotope in the radiological decay chain.

Alphe, beta, and gamma ray energies have separate calculation procedures for absorpticn and dose determination. Hence, effects of one or more of the different emissions prese.tt ran be singled out of the calcule:tons. Standard options permit calcuiation of activity vs time, total energi released vs ifime, dose or dose rate in a single or multisention biological syst,en vs time, and goma rav dose rate one meter above a uniformly contaminated sxooth plane. 


\section{? \\ USB OP IHE CODE, MIEDS}

Noreal Use

Fo: a reactor, the core is assuned tc have three sections and one section is refueled eriery 16 eonths. Reastor shutdown is assuned to occur just before refueling. Activity is output "s tive after shutdoun. Por reactor fission-product activity that is released from the inmaliate core area, either a single "purf-type" release or a continuous release can be included in the calcuiations.

For both the reactor and the weapon, three basic types of calculation can be ade: (1) activity iin curies, (2) an energy-activity product, or (3) an energy-activity product integrated over tine. Changina an input parameter will produce an sutput in curies, MeV-curies, lifetime dase in reas tc an organ weighing a speciffed nuber of gran, gana-ray

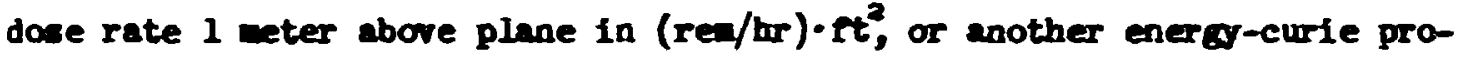
duct where the average enerfy per disintegration for fission-product 1sotopes is an Input parricieter.

Further, a complicated biological systen can be zpecified for each isotope so that a wore accurate dose to a blological syaten can be calculated than with the radiological half-life alone.

\section{Ron-Standar's Use}

The reactor refueling schedule can be easily modified. The type of core can be chiangec and even a single sution with continuous reprocessing can be used. The bulldup of fission produs is in the cor: during reactor operation can $\varepsilon_{0}$ so be inclujed in the output.

The routines that calculate "ine average beta ray energy aid the attenuation coefficients for gama rays are accessible to modify the energyactivity calculations.

Pission products have provision for sorting by chemical species but the atoaic weight is also available and can te used to sort isotopes.

Decay chains other than those for fission products can be supplied, as long as the basic equations to be solved are the same. The fissionable material is assumed to be ${ }^{235}$ If but this assumption can be changed by changing the fisston ylelds for sach decay cliain. 
Detailed instruction for all these charges aye also discussed is: Apperdix A.

\section{Buaples of Mormal lise}

Sarsar examples are listed below. The output from the exanples are plo.ted in Figs. I through 9. A list of the friput cerds for tinese examples is in Appendix $\mathrm{B}$.

\section{Eanple 1: Activity}

Aetivity in curies vs time for the fission products ir a 1000-Ne (3-j-yt) Boilirig Water Reactor core after resctor shutdowr. and a 1-zegator nuclear weapor after detoration are presented ir: Fig- i.

The printed output fros ihe calculations for titis examis contains a cosple ie list of the fissior -product isotopes ard their injividial activity os lise in acidion to the total activity.

\section{Exaple 2: Total Enercy Release}

HeV-curies froa beta ray ard ganat ray eriergies vi tine sfter shutdown for the fission products of the reactor in Bxample 1 are plotted i:: Pig. 2 .

This example gives the average rate of beta ard gana ray energy release $\mathrm{fy}$ fission products in the reactor core. The results for all the fission prodscts in the core are given as well as the results for the fission pruduc:s whose oxides have a volatility less than that of uranium oxide. These fission products are the most likely to remain in the vicin$i$ ty of the core vuring a core meltdown. The rate of energy production in megaustts is given on a second abscissa.

\section{Example 3: Lifetime Thyroid Dose}

The lifetime thyroid dose from the ingestion of radiolodine produced by the resctor in Example 1 is plotted in Fig. 3. The dose is a function of time elapsed after shutdown tefore ingestion. The contribution to the total dose by each isotope is also plotted. A 138-day biological halfiffe for lodine was assured in the calculation. 


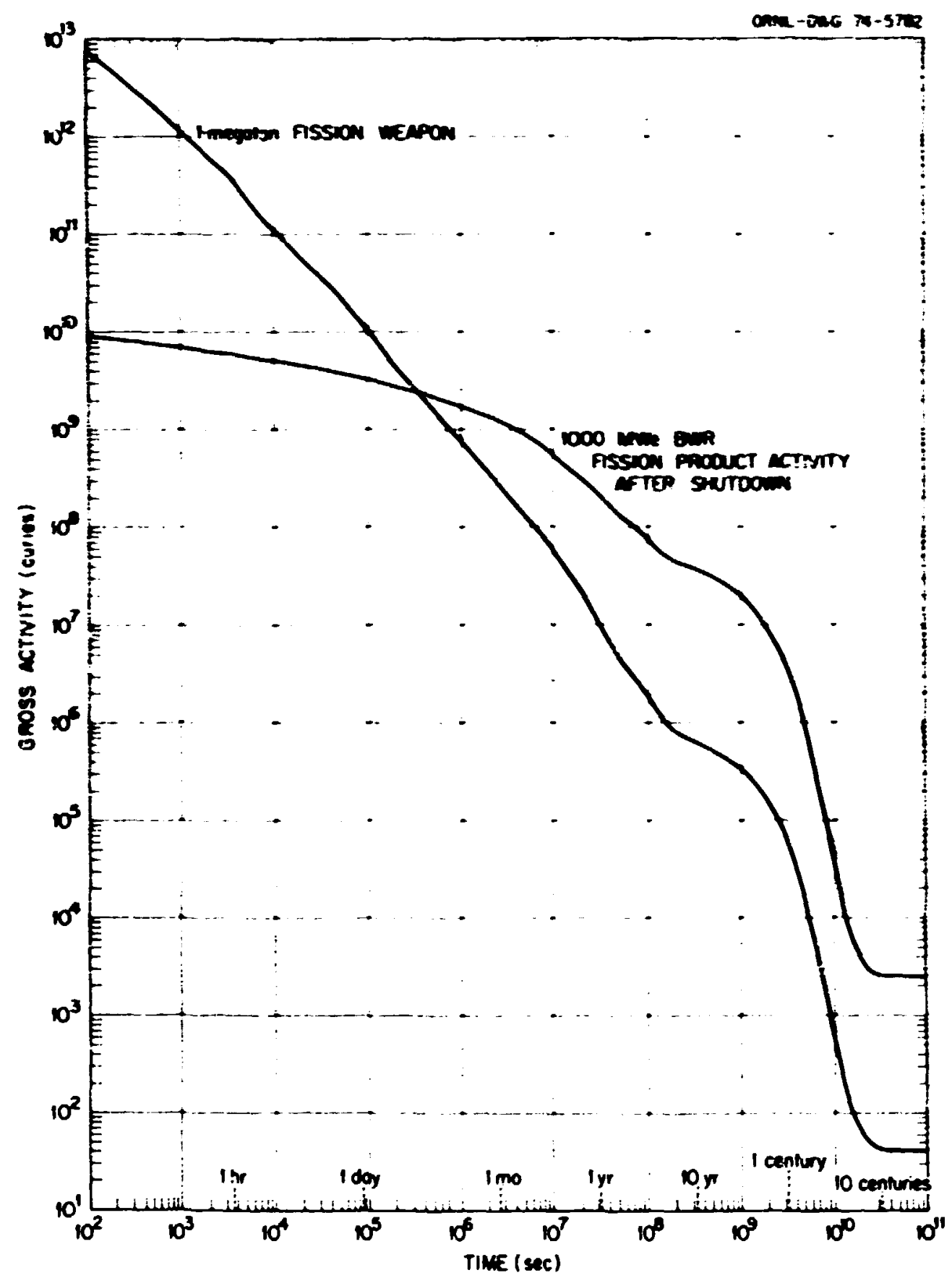

Fig. 1. Gross activity vs time. 
ONNL-OWO RA-5TO3

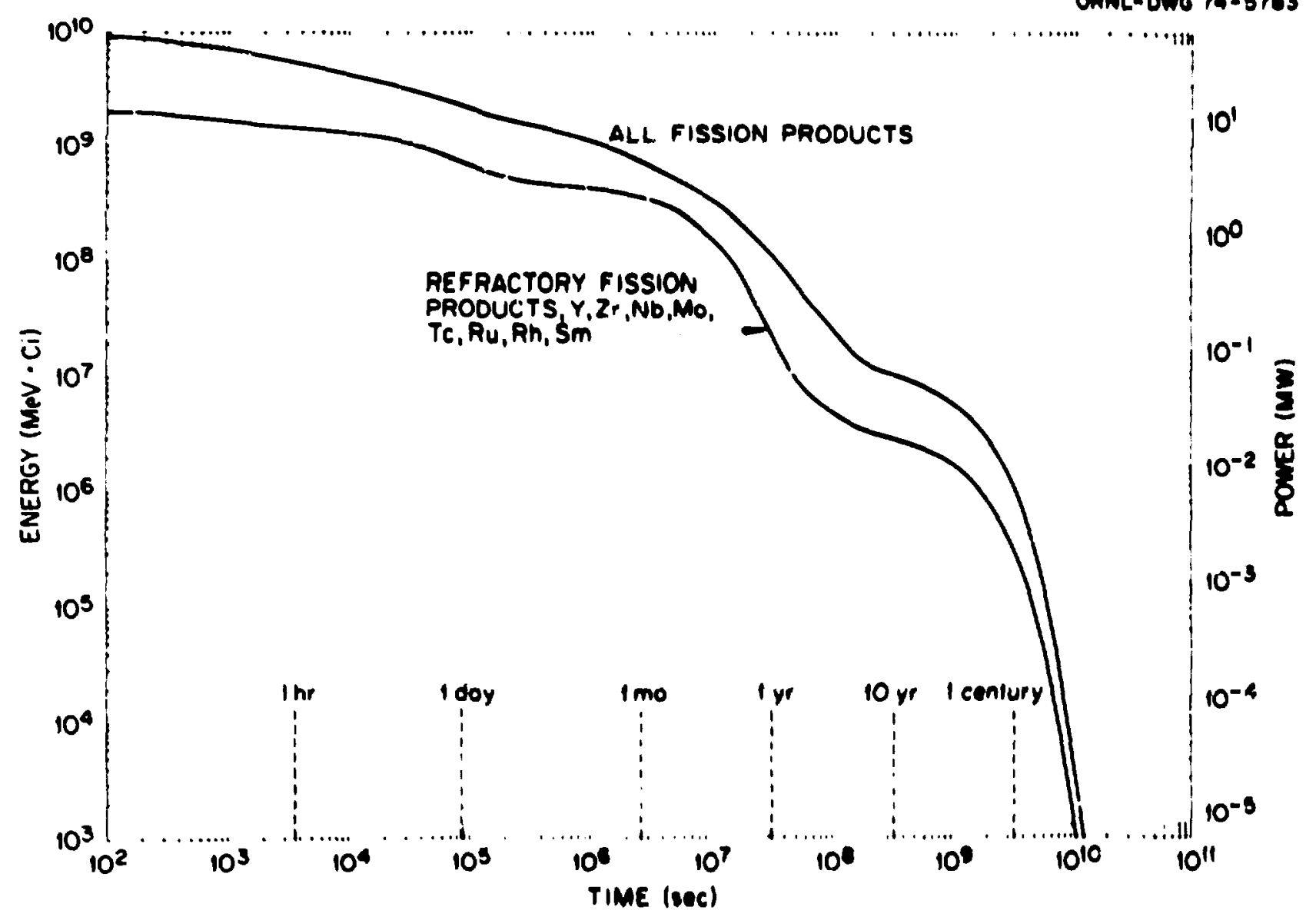

F1g. 2. Bete and sammi enerey in rieston producte after shutdown for 1000 MWe BNR. 


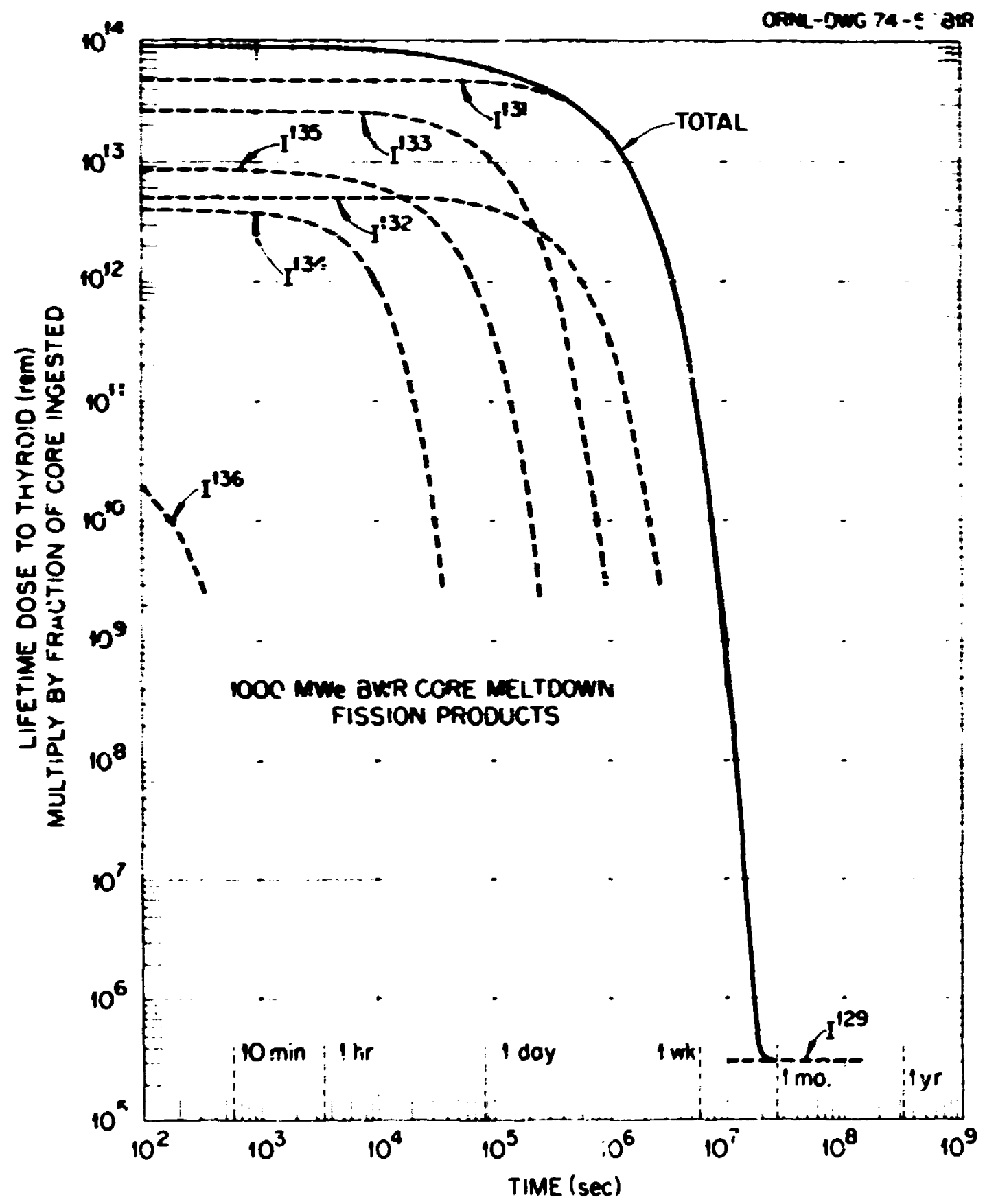

Fig. 3. Lifetime dose to adult thyroid vs time of ingestion. 


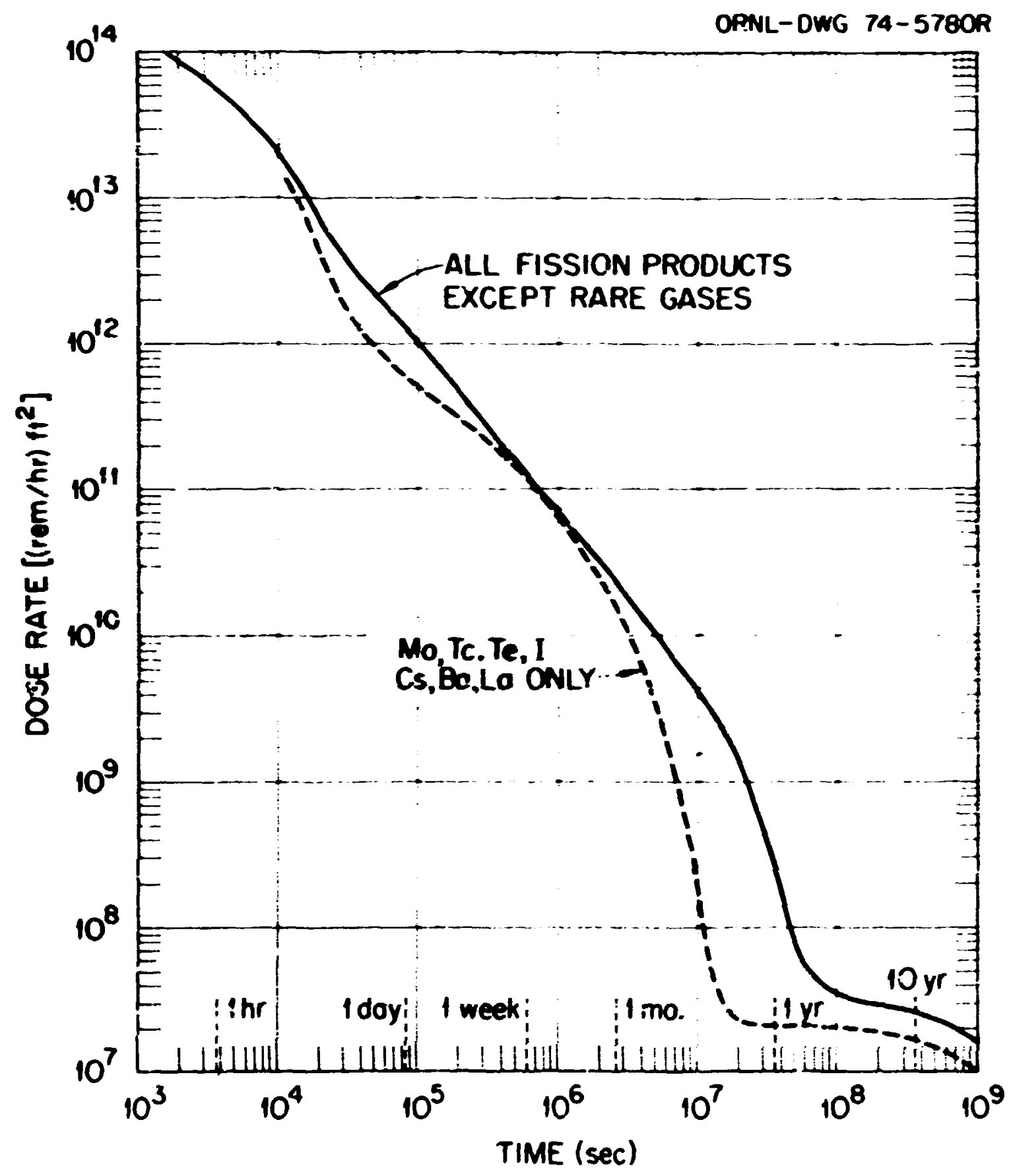

Pig. 4. Gamma dose rate at 1 meter above smooth plane, 1-megaton weapon fission product. 


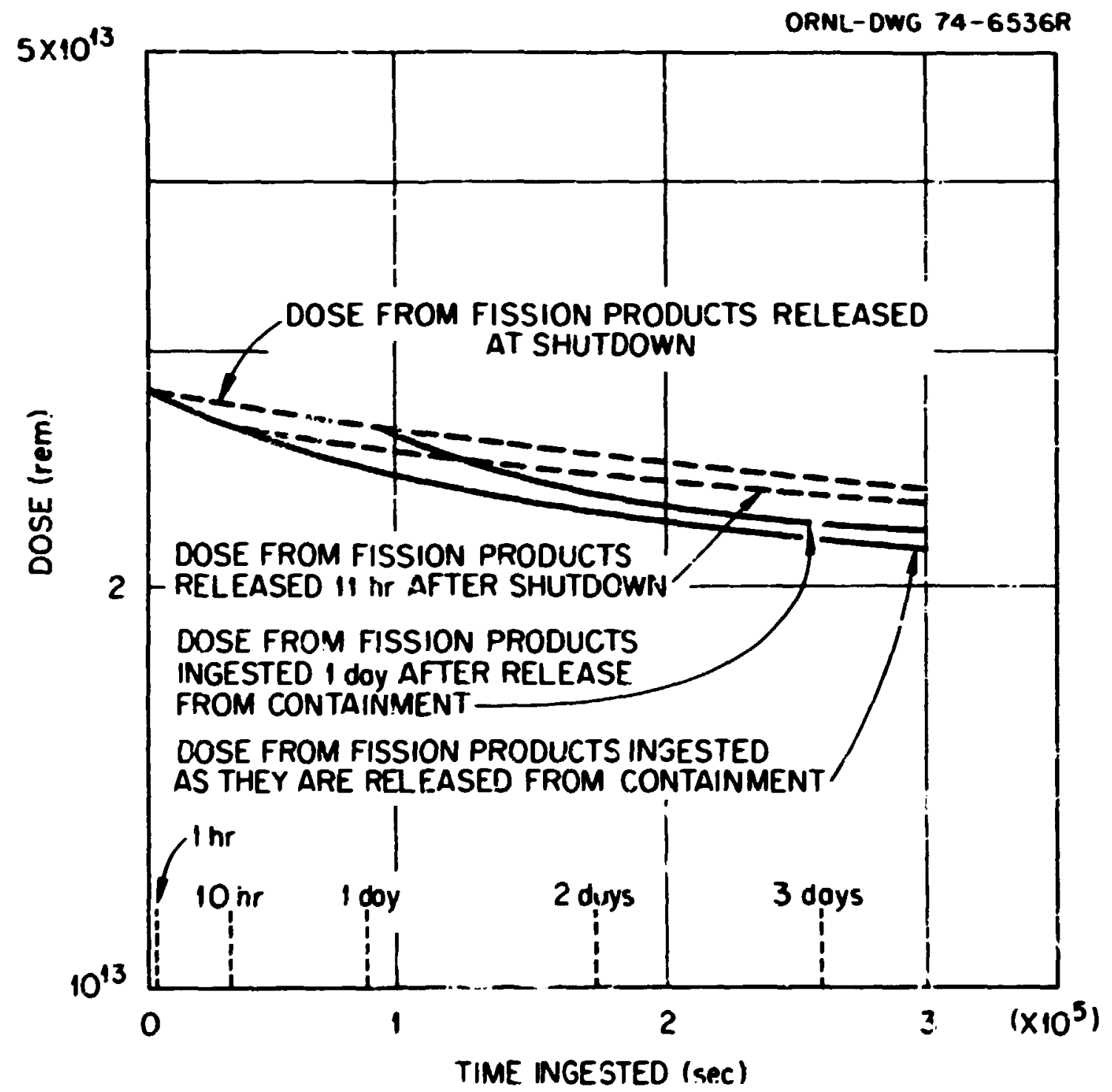

Fis. 5. Dose t lungs, $r$, volatile, insoluble fission pi: anin:s frou reacior core meltdown 1000 MNe BNR. Multiply by fractior of cor: ingested. 


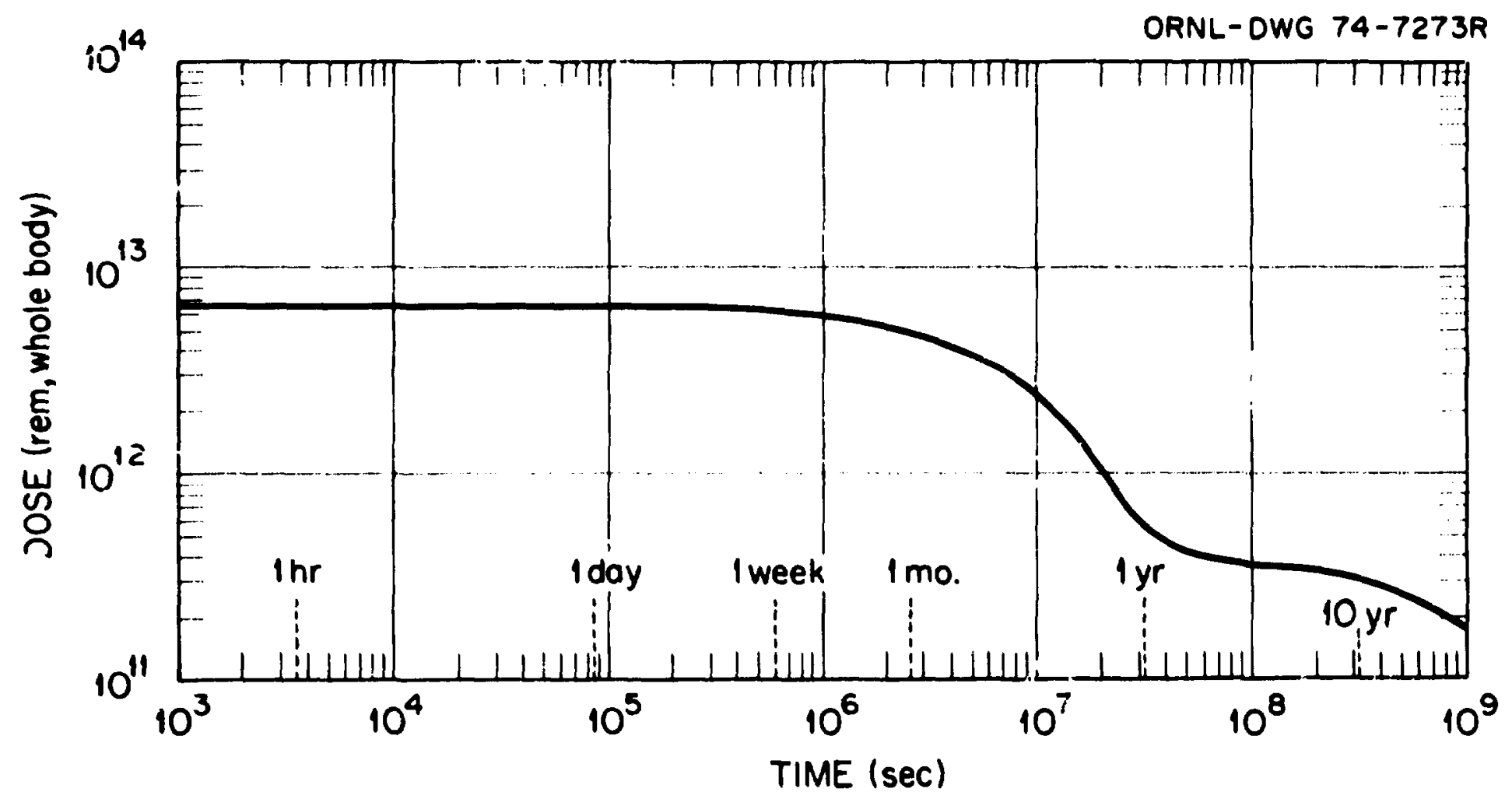

Fig. ó. Inhaled whole-body dose from fission products in 1000. MWe BWR core vs time after shutdown. Multiply Graph by fraction of core retsined in lungs. 


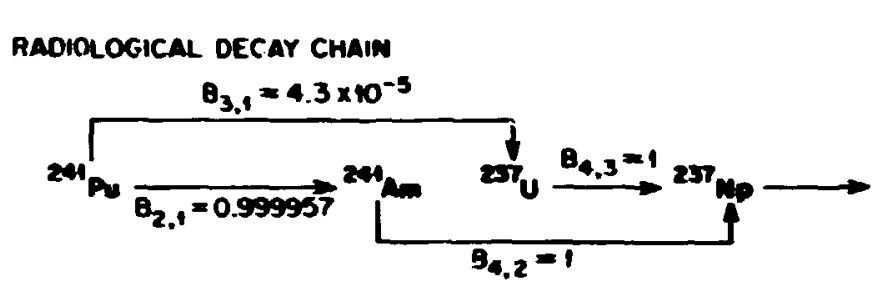

ANOLOGKAL SYSTËM

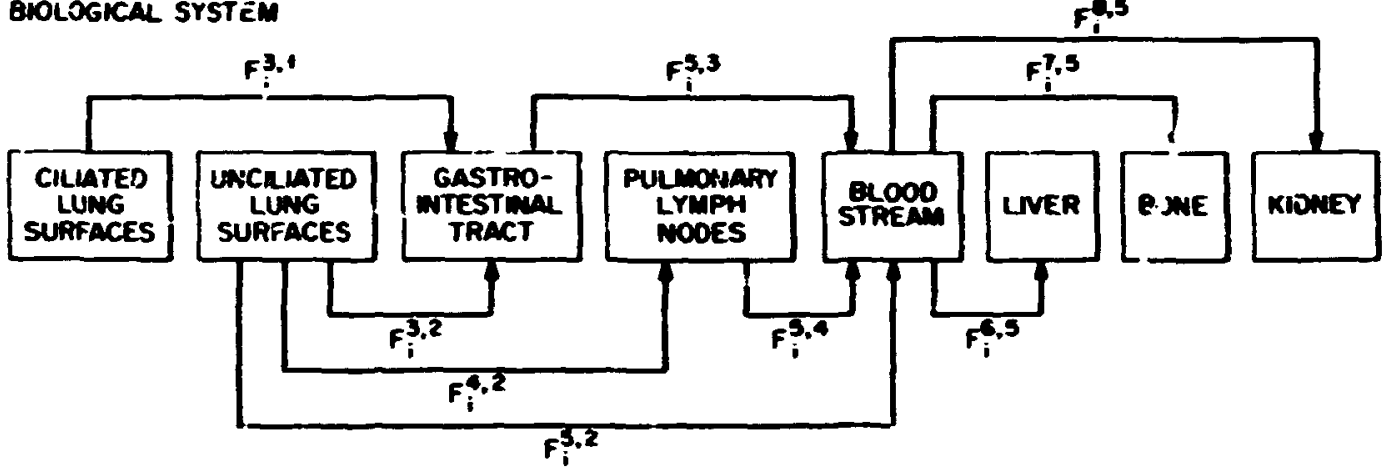

SIMPLIFIED BPLOGICAL SYSTEM

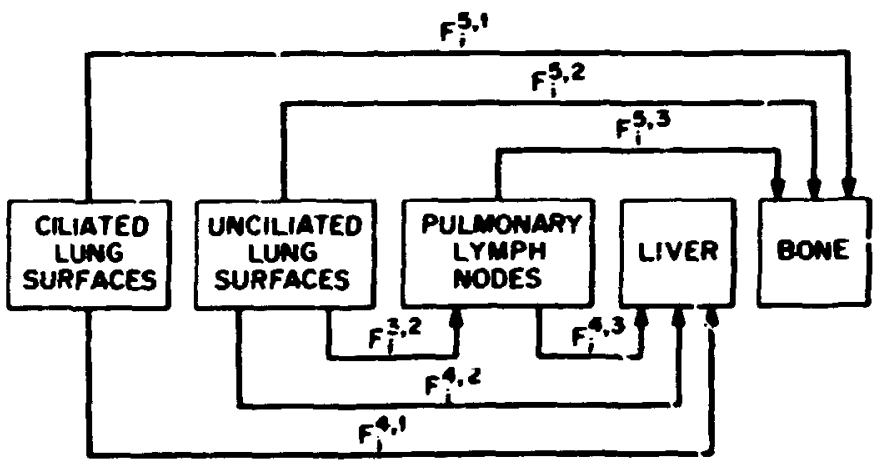

Fig. 7. Radiological decay chain and multisectiun biolcicical syistem for example?. 



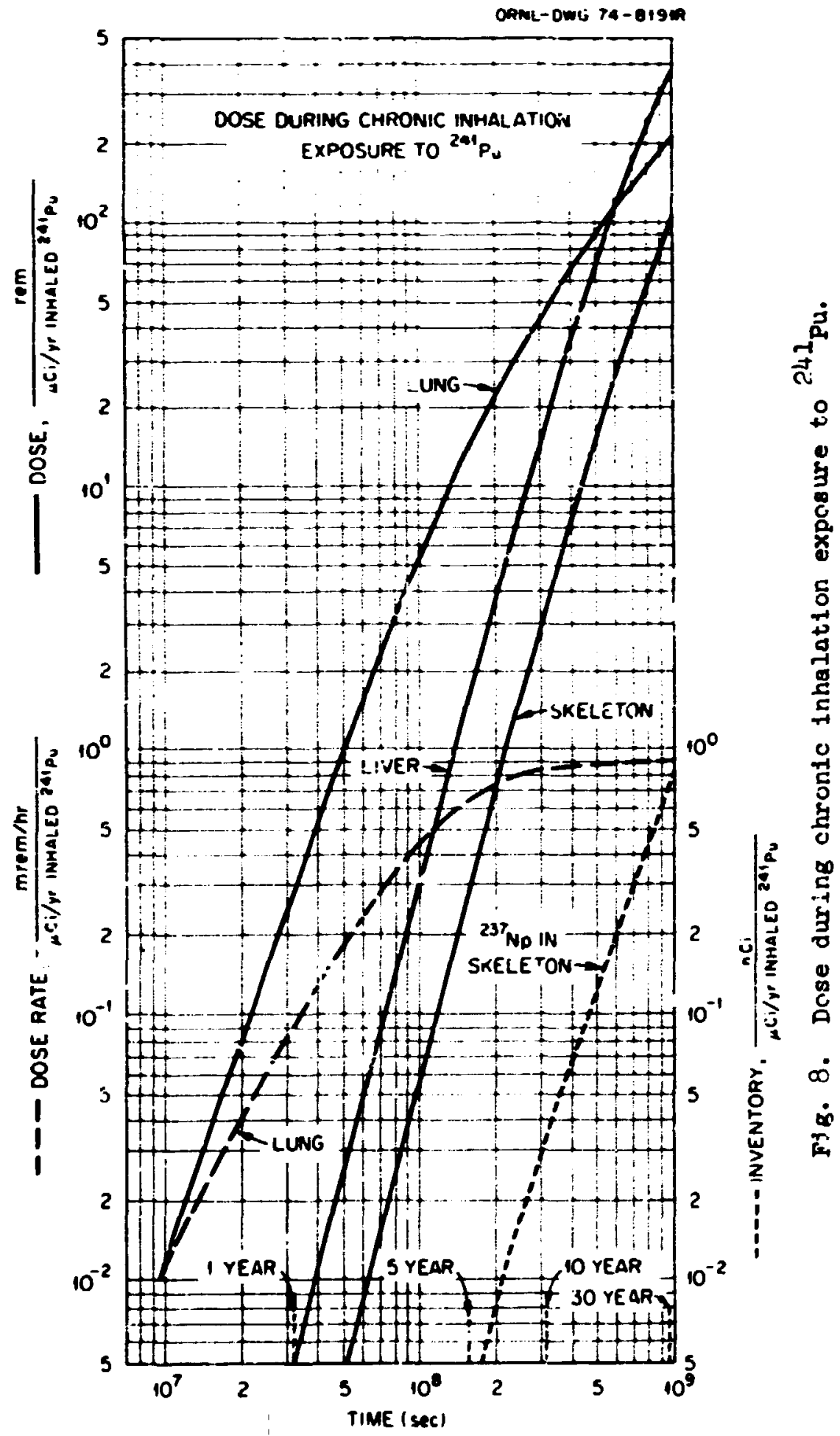




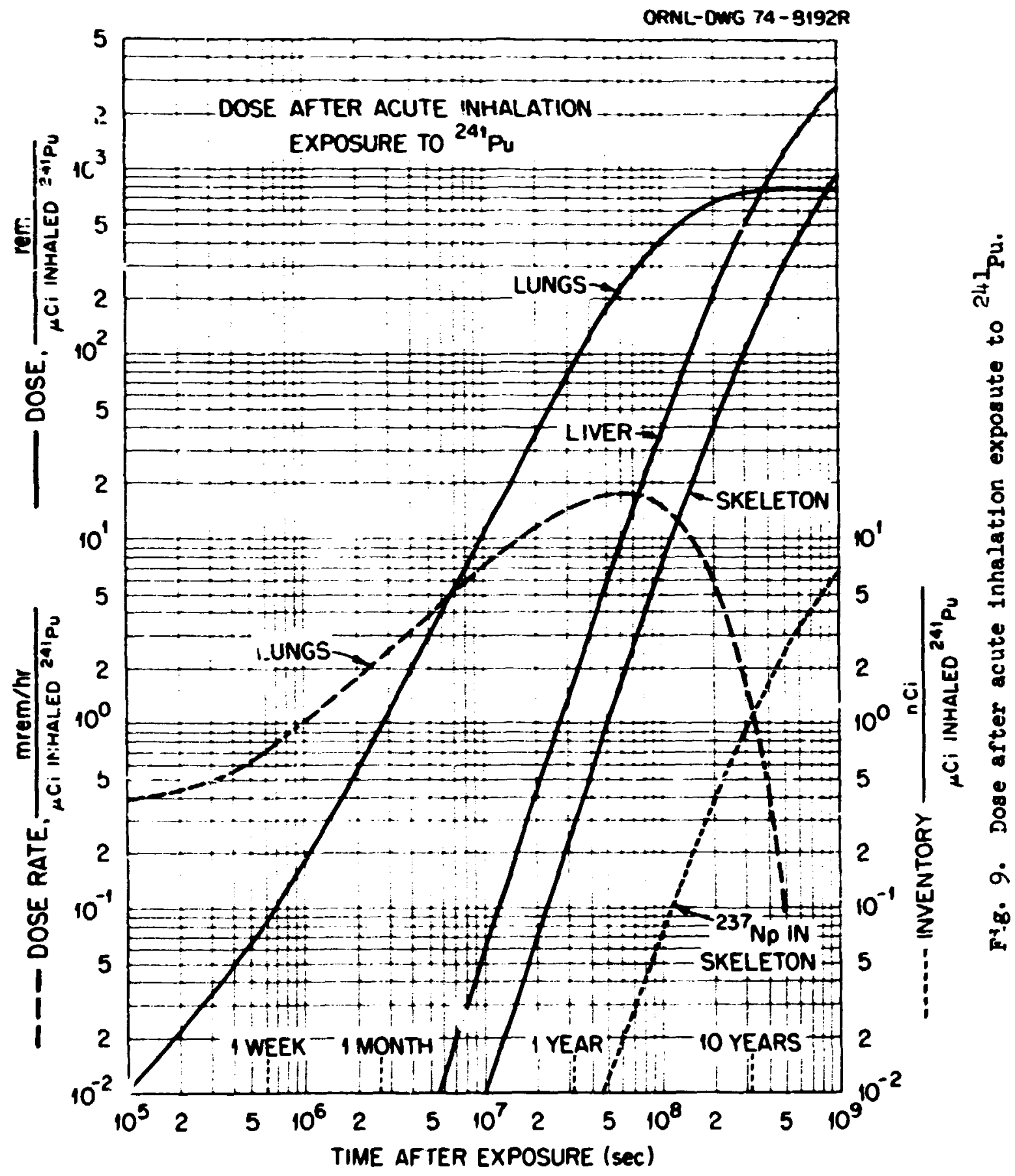


The curves in Fig. 3 sust be auliplied by the fraction of the reactor core ingested to give the dose to a single aduit thyroid. For example, assume $10^{t}$ curies of mixed iodine isotopes are relsased from the reactor containaent. Tixis is about $10^{-9}$ of the core inventory. By the time the radioactive meterial has been noved by atmospheric prasesses to the boundary of the plant a-ea, it ay be spread over volume a half-mile in diameter. Assuming a breathing rate of $3.3 \times 10^{-4} \mathrm{~m}^{3} / \mathrm{sec}$, a 1/2-hour exposure, and that $1 / 5$ of the ingestsd iodine collects in the thyroid, the dose to the individual ihyroid is

$$
10^{-5} \times \frac{1}{\left(0.5 \times 1.6 \times 10^{3}\right)^{-3}} \times 3.3 \times 10^{-4} \times \frac{3.6 \times 10^{3}}{2} \times \frac{1}{5} \times \text { curve in Fig. } 3 .
$$

If ingestion takes place from 2 to $2-1 / 2$ hu'rs after shutdown, the lifetime thyroid dose is about $2.3 \times 10^{-15} \times 0.35 \times 10^{4 *}=0.20 \mathrm{rem}$.

Example 4: Gemma Ray Dose Abrve a Contaminated Plane

The gama ray dose rate, in (rem/hr). $\mathrm{ft}^{2}, 1$ meter above a swooth plane is olotted in Fig. 4. All the fission products except the rare gases from detonation of a 1-megaton nuclear weapor. are assumed distributed on the plane in one curve. A second curve gives the dose rate irom just the fission products, Mo, TC, Te, I, Cs, Ba, and La.

The plotted results must be divided by the number of square feet over which the fission products are spread. For example, an airburst, l-megaton weapon detonated in Asia might deposit 1/j0 of the weapon's total activity over an area of 1000 miles by 1500 miles in North America. In this case, the curves in Fig. 4 must be maltiplied by

$$
\frac{1}{50} \times \frac{1}{1005 \times 1500} \times \frac{1}{5280 \times 5280}=4.8 \times 10^{-16} .
$$

At two weeks the dose rate from all but the rare gas fission products would then be $4.8 \times 10^{-1.7} \times 0.56 \times 10^{11}=2.7 \times 10^{-5} \mathrm{rem} / \mathrm{hr}$. Some measurements of trans-pacific fallout two weeks after detonation indicate she depositea isotopes are primarily Mo, Rc, Te, I, Cs, Ba, and La. This mixture is used to giv: the resuits plotted in curve 2. At two weeks the calculated dose rate is $4.8 \times 10^{-16} \times 0.49 \times 10^{2.1}=2.4 \times 10^{-6} \mathrm{rem} / \mathrm{hr}$. 
An inspection of the detailed output for this exacple shows the difference is due primarily to the isotopes ${ }^{95} \mathrm{Zr},{ }^{95} \mathrm{mb}$, and ${ }^{103} \mathrm{Ru}$.

\section{Exarple 5: Lifetive Lung Dose}

Figure 5 presents the lifetite lung dose in rems $\mathrm{from}$ Te and $\mathrm{Ru}$, if they are released continuously from the cuntainaent of the reactor in Brample 1. These fission products have axides that are more volatile than iran: oxide but relatively insoluble in ling iluids. The results ese plotted as a function of time elepsed after silutdown before ingestion and time elapsed efter shutdown bofore release of the fission froducts fron containment. These calculations assure that. beture zelease, the ifsaion piufucts jecay according to their indivisul decay chains. Thei-sfore, the release at different times will contain different amounts of each isotope. The nist effect is that the overall decay and biologica: effects if each release will be different.

The cirves in Fig. 5 must be multiplied by the fraction of the core that is ingested. If the oxides are in an airborne aerosol, roughly $1 / 4$ of the irhaled aerosol is retained in the lungs and, of the retained material, approximately $2 / 3$ is deposited on noncilliated lung surfaces. The clearance half-life for these surfaces is about 500 days. The weight of the lungs is assured to be about $1 \mathrm{~kg}$. Assume $10^{-4}$ of the core inventory leaks out of the reactor containment per day. Assume, further, 8 $1 / 2-h r$ exposure to the airborne radioactivity and a breathing rate of $3.3 \times 10^{-4} \mathrm{~m}^{3} / \mathrm{sec}$. Further, assume that as the fission products leak out of the reactor containment they occupy a volume with an average diameter $s: 5.1$ mile and one day lat.er the diameter is about 2 miles. Then the 'ingested as released' curve in Fig. 5 should be multiplied by

$$
\frac{10^{4}}{24} \times \frac{1}{2} \times \frac{1}{4} \times \frac{2}{3} \times \frac{3.3 \times 10^{-4}}{\left(0.2 \times 1.6 \times 10^{3}\right)^{2}} \times \frac{3.6 \times 10^{3}}{2}=5.0 \times 10^{-14}
$$

As a result, ingestion at 1 day aster shutdown as the fission products are released from the reactor containment gives a lifetime dose to the lings of $2.45 \times 10^{13} \times 5.0 \times 10^{-14}=1.2 \mathrm{rems}$. If the fiseion products are ingestad one day after they are released, the 'ingested one day after 
release' cirve applies and should be multiplied by $5.0 \times 10^{-i 4} \times\left(\frac{0.1}{2}\right)^{3}=$ $6.2 \times b^{-1 \theta}$. Th:s the first fission products to be released, if ingestec one day later, will give a dose to the lungs of about $6.2 \times 10^{-18} \times 2.63 \times$ $10^{13}=1.5 \times 10^{-4}$ rem.

Brample 6: Whole-Body Dose

The whole-body dose, in rens, from inhalation of all the fision products excopt the rare gases released by the reactor in Example 1 is plotted in Fig. 6. The biological half-lives of the elements are:

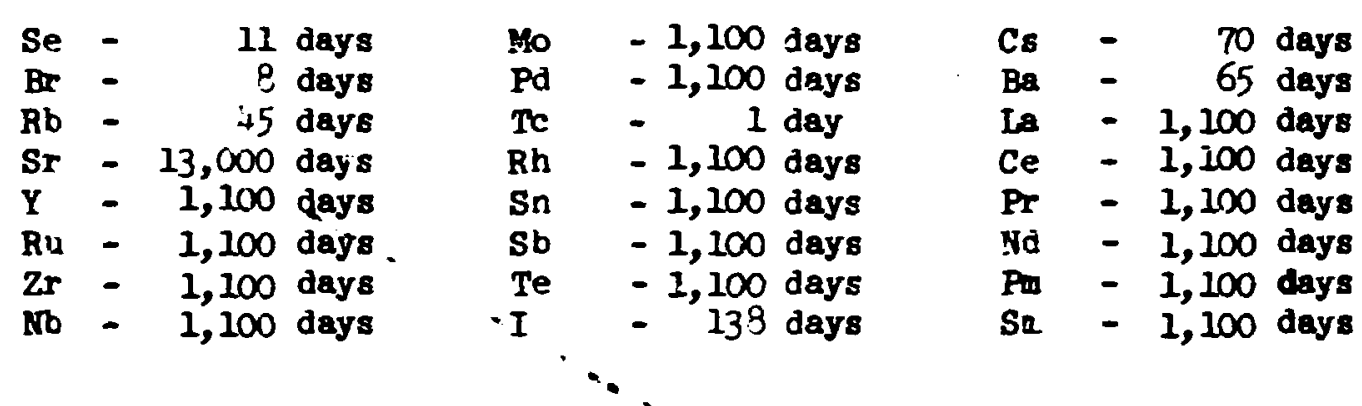

These curves also must be multiplied by the fraction of the reactor core ingested. The same general considerations to calculate the fraction of core ingested would apply as in Example 3 . Under those conditions, the whole-body dose would be $2 \times 10^{-15} \times 0.9 \times 10^{12}=2 \times 10^{-3} \mathrm{rew}$.

Example 7: Dose to a Multisection Biosystem

The lifetime dose to the bone, liver, and lungs from the acute and cronic inhalation of ${ }^{24} \mathrm{Pu}$ in the insoluble oxice form 18 plotted in Figs. 8 and 9. The inventory of ${ }^{237} \mathrm{~Np}$ in the bone and total dose rate to the lungs is also plotted in Figs. 8 and 9. The radiologlcal desay chain is similar to that used in the section entitlec "Illuatration of the Basic Method." Pigure 7 shows the decay chain, and values for the constants are given in Table 1. The notation in Table 1 is that used in Eq. (11). For Inhaled, insoluble particle." Iike PuOn, whose size uistribricion is in the 0.1 to $10 \mathrm{mu}$ range, a representation of the sections in the biological gyatex is given in Fig. 7. ihe representetion of the biological system for this particular problem can be further simpliffed by omfting short half-lived and uninvolved sections. This sioplified representation is also given in Fig. 7 and the corresponding constante in Table 1. 
rable 1. Radiological and Biological Constants"

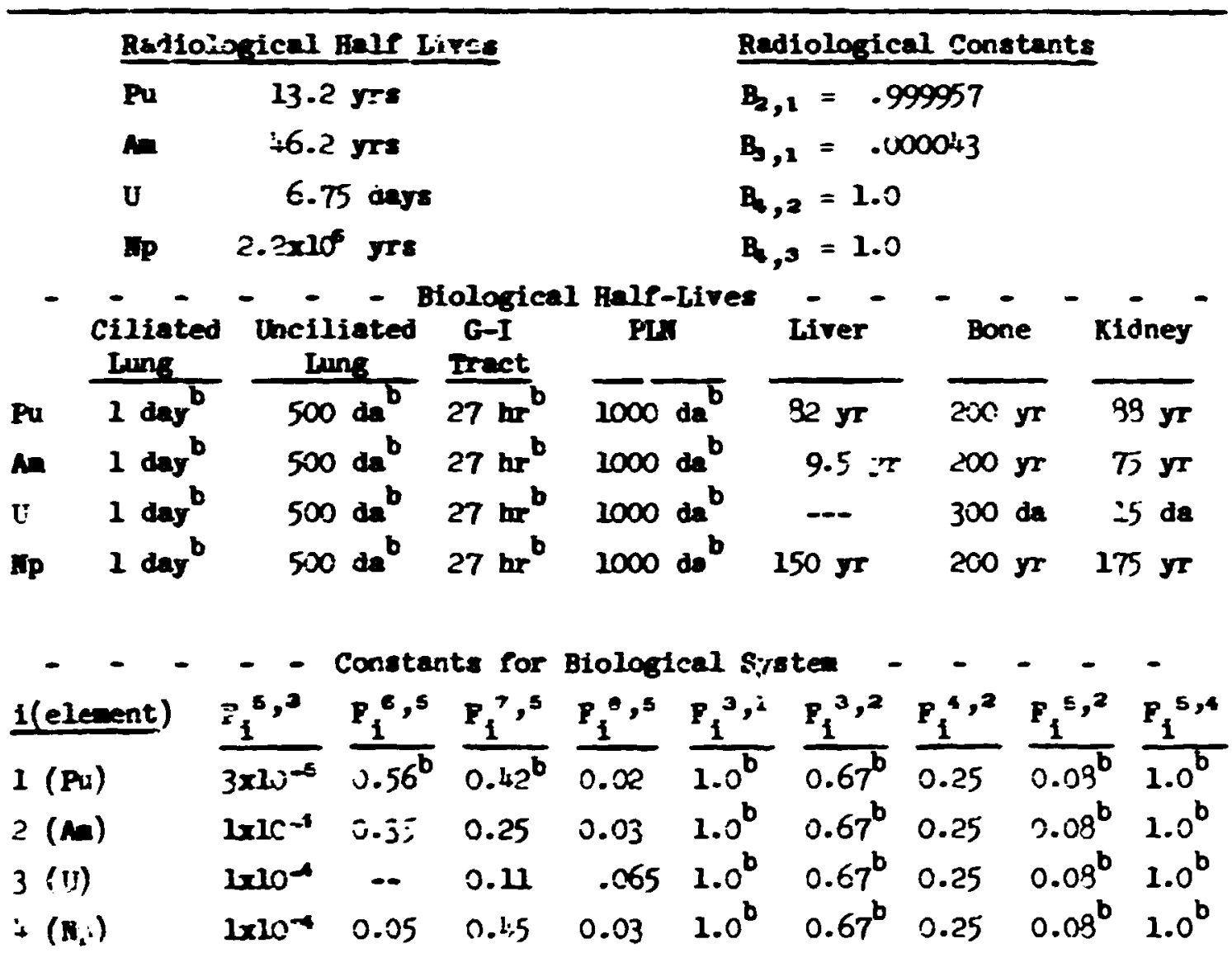

- - - Constants for simplified Biological systen - - - -

\begin{tabular}{|c|c|c|c|c|c|c|c|}
\hline i(clesent & $F_{1}^{3,2}$ & $P_{1}^{4}, 1$ & $P_{1}^{5,1}$ & $P_{1}^{1,3}$ & $P_{1}^{4,2}$ & $P_{1}^{5,2}$ & $P_{i}^{5,3}$ \\
\hline 1 (Pu) & 0.25 & $1.7 \times 10^{-5}$ & $1.2 \times 10^{-5}$ & 0.56 & 0.04 & 0.03 & 0.42 \\
\hline $2(M)$ & 0.25 & $3.5 \times 10^{-6}$ & $2.5 \times 10^{-6}$ & 0.35 & 0.12 & 0.08 & 0.25 \\
\hline $3(t)$ & 0.25 & - & $1.2 \times 10^{-5}$ & - & - & 0.04 & 0.11 \\
\hline is (kp) & 0.25 & $5.0 \times 10^{-8}$ & $4.5 \times 10^{-5}$ & 0.05 & 0.02 & 0.25 & 0.45 \\
\hline
\end{tabular}

"Ur.lear othuivise indicated, inforiation in this table is taken from "Report of Comittee II on Peraiasible Dose for Internal Fadiation, 1959"; ICRP zublication 2, Pergation, Oxford, 1959.

B. B. Pish. G. W. Kellholtz, W. S. Snyder, B. D. Swisher, "Calculatiur of Doses Due to Accidentally Released Plutonium from an IMTBR," CRTL-ISIC-7L (1972), p. 98, p. 75.077 . 
of the $\mathrm{PuO}_{2}$ inhaled, either in an acute exposure or during cronic exposure, approximately $l u$ is retained on the cillated lung surfaces and $15 \%$ on the unciliated lung surfaces. In the notation of Eq. (11), the non-zero $R_{i}^{L_{1}}$ s are $R_{1}^{1}=0.10$ k.nd $R_{1}^{2}=0.15$.

\section{CAICULATION METHOD}

Basic Decay Chain

\section{Discussion}

The system of equations,

$$
\frac{d N_{i}}{d t}=R_{i}+\sum_{j=1}^{n} B_{i, j} \lambda_{j} N_{j}, \quad i=1,2, \ldots N,
$$

is solved subject to the bourdary condition $N_{i}=A_{i}$, at $t=0$, where

$$
\begin{aligned}
N_{i}= & \text { amount of the } i-t h \text { member of the decay chain } \\
t & =\text { time } \\
A_{i}= & \text { amount of the } i-t h \text { member of the decay chain at } t=0 \\
R_{i}= & \text { constant formation rate of } N_{i} \\
\lambda_{1}= & \text { radioactive decay constant for } N_{i} \\
B_{i, j}= & \text { the fraction of } N_{j} \text { decays that produce an } i-t h \\
& \text { member of the decay chain. } B_{i, i} \equiv-1 . \\
N= & \text { total number of aembers of the decay chain. }
\end{aligned}
$$

The solutions are

$$
N_{1}=Y_{1,1}+\left(A_{i}-Y_{1,1}\right) e^{-\lambda_{1} t}+\sum_{\substack{j=2 \\ j \neq i+1}}^{N+1} Y_{i, j}\left(e^{-\lambda_{j-1} t}-e^{-\lambda_{1} t}\right)
$$

Grouping the exponential terms a.s shown in Eq. (2) permits the greatest numerical accuracy when a decay chain contains decay constanta that are very nearly equal or are greatly different. 
The $Y_{i, j}$ are coefficients evaluated by the following procedure:

Form th: matrix $\underline{\theta}$ whose elewents are $\beta_{i, j}={ }_{1, j} \lambda_{j}$. A colum vector

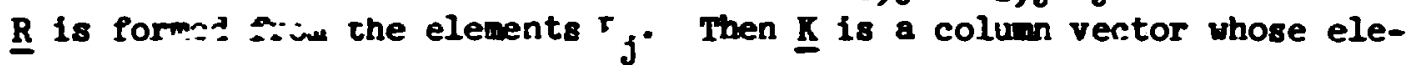
ments are $Y_{1,1}$, and

$$
\underline{\mathbf{R}}=\underline{-\underline{B}}^{-1} \underline{\mathbf{R}} \text {. }
$$

Substituting Eqs. (2) in Eqs. (1) gives

$$
-B_{1, k}\left(\dot{h}_{k}-K_{k}\right)=\lambda_{k} Y_{1, k+1}+\sum_{\substack{j=1 \\ j \neq k}}^{n}\left(B_{1, j} Y_{j, k+1}-B_{1, k} Y_{k, j+1}\right) .
$$

Arrange the $N^{2}$ number of quantities $-B_{1, k}\left(A_{k}-r_{k}\right)$ into a column vector, D. Similarly, arrarige the $Y_{i, j}$ for $i=1, N$ and $j=2, N+1$ into a colum vector, $\underline{c}$.

For efficient, rapid calculation observe that, physically, if

$B_{i, k} \neq 0$, then $B_{k, 1}$ must equel 0 . Also $Y_{1,1+i}$ is not used in Bqs. (2). Therefore, $B$ can be rearranged so that, $B_{1, j}=0$ for $j>1$. Then only the $N \cdot(N-1) / 2$ number of $Y_{1, j}{ }^{\prime}$ witk $2 \leq j \leq 1$ need be calculated. Bquations (4) can be rewritten

$-\sigma_{i, k}\left(A_{k}-k_{k}\right)=\left(\lambda_{k}-\lambda_{i}\right) Y_{1, k+1}+\sum_{j=k+1}^{i-1} \beta_{i, j} Y_{i, k+1}-\beta_{1, k} \sum_{j=1}^{k-1} Y_{k, j+1}$

$$
\begin{aligned}
& \text { for } 1=2, N \\
& \text { and } k=1, \quad 1-1 .
\end{aligned}
$$

Equations $(\hat{c})$ can te rewritten

$$
N_{1}=Y_{1,1}+\left(A_{1}-Y_{i, 1}\right) e^{-\lambda_{1} t}+\sum_{j=2}^{1} Y_{1, j}\left(e^{-\lambda_{j-1} t}-e^{-\lambda_{1} t}\right)
$$

for $1=2, \mathrm{n}$. 
The vectors, $\underline{C}$ and $\underline{D}$, car be written

$$
\begin{gathered}
C(j-1+(i-2)(i-1) / 2)=Y_{i, j} \\
D(j+(i-2)(i-1) / 2)=-B_{i, j}\left(A_{j}-K_{j}\right) .
\end{gathered}
$$

The coefficients conriecting the elements of $\underline{D}$ and $\underline{\mathrm{C}}$ can then be arranged in a matrix, E, such that

$$
\underline{D}=\underline{\mathbf{E}} \underline{\mathbf{C}}
$$

which can be rewritten

$$
\underline{C}=\underline{E}^{-1} \underline{D}
$$

\section{Illustration of the Basic Method}

For the four member decay chain shown beiow, the amount of each chain nember as a furction of time is isesired.

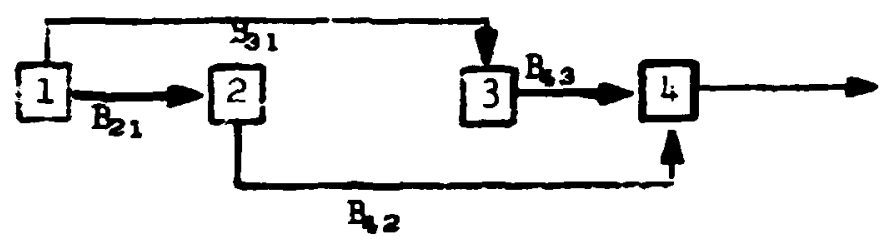

$\begin{array}{llll}A_{1} & A_{2}=0 & A_{3}=0 & A_{4}=0 \\ R_{1}=0 & R_{2} & R_{3}=0 & R_{4}=0 \\ \lambda_{1} & \lambda_{2} & \lambda_{3} & \lambda_{4} \\ B_{11}=0 & B_{32}=0 & & \end{array}$

The solut: sns for the $Y_{1,1}$ are obtained from Eq. (3).

$$
\left(\begin{array}{l}
Y_{1}, 1 \\
Y_{2,1} \\
Y_{3,1} \\
Y_{4, i}
\end{array}\right)=\left(\left.\begin{array}{cccc}
-\lambda_{1} & 0 & 0 & 0 \\
B_{21} \lambda_{1} & -\lambda_{2} & 0 & 0 \\
B_{31} \lambda_{1} & 0 & -\lambda_{3} & 0 \\
0 & B_{42} \lambda_{2} & B_{43} \lambda_{3} & -\lambda_{44}
\end{array}\right|^{-1} \times\left(\begin{array}{l}
0 \\
R_{2} \\
0 \\
0
\end{array}\right)\right.
$$


or

$$
\begin{aligned}
& Y_{1,2}=0 \\
& Y_{2,1}=R_{2} \lambda_{2} \\
& Y_{3,1}=0 \\
& Y_{4,1}=\vec{A}_{42} \cdot R_{2} / \lambda_{4} .
\end{aligned}
$$

The resaining $Y_{i, j}$ 's are evaluated from Bqs. (5) and (10).

$$
\left\{\begin{array}{l}
Y_{2,2} \\
Y_{3,2} \\
Y_{3,3} \\
Y_{4,2} \\
Y_{4,3} \\
Y_{4,4}
\end{array}\right\}=\left\{\begin{array}{llllll}
\lambda_{1}-\lambda_{2} & 0 & 0 & 0 & 0 & 0 \\
0 & \lambda_{1}-\lambda_{3} & 0 & 0 & 0 & 0 \\
0 & 0 & \lambda_{2}-\lambda_{3} & 0 & 0 & 0 \\
B_{1,2} \lambda_{2} & B_{4,3} \lambda_{2} & 0 & \lambda_{1}-\lambda_{4} & 0 & 0 \\
-B_{4,2} \lambda_{2} & 0 & B_{1,3} \lambda_{3} & 0 & \lambda_{2}-\lambda_{4} & 0 \\
0 & -B_{4,3} \lambda_{3} & -B_{4,3} \lambda_{3} & 0 & 0 & \lambda_{3}-\lambda_{4}
\end{array}\right\}^{-1} \times\left\{\begin{array}{c}
-B_{2,1} A_{1} \lambda_{1} \\
-B_{3,1} A_{1} \lambda_{1} \\
0 \\
-B_{4,2} A_{1} \lambda_{1} \\
B_{4,2} \lambda_{2} Y_{2,2} \\
0
\end{array}\right\}
$$

Preprocessing removes the zero result $Y_{3,3}$, giving

$$
\left.\left\{\begin{array}{l}
Y_{2,2} \\
Y_{3,2} \\
Y_{4,2} \\
Y_{4,3} \\
Y_{4,4}
\end{array}\right\}=\left\{\begin{array}{lllll}
\lambda_{1}-\lambda_{2} & 0 & 0 & 0 & 0 \\
0 & \lambda_{1}-\lambda_{3} & 0 & 0 & 0 \\
P_{4,2} \lambda_{2} & B_{4,3} \lambda_{3} & \lambda_{1}-\lambda_{4} & 0 & 0 \\
-B_{1,2} \lambda_{2} & 0 & 0 & \lambda_{2}-\lambda_{4} & 0 \\
0 & -B_{4,3} \lambda_{3} & 0 & 0 & \lambda_{3}-\lambda_{4}
\end{array}\right\} \times \begin{array}{c}
-B_{2,1} A_{1} \lambda_{1} \\
-B_{3,2} A_{1} \lambda_{1} \\
-B_{4,1} A_{1} \lambda_{1} \\
B_{4,2} \lambda_{2} Y_{2,1} \\
0
\end{array}\right\}
$$

Rewriting the results

$$
\begin{aligned}
Y_{2,2}= & -B_{2,1} A_{1} \lambda_{1} /\left(\lambda_{1}-\lambda_{2}\right) \\
Y_{3,2}= & -B_{3,1} A_{1} \lambda_{1} /\left(\lambda_{1}-\lambda_{3}\right) \\
Y_{4,2}= & -B_{4,1} A_{1} \lambda_{1} /\left(\lambda_{1}-\lambda_{4}\right)+B_{4,2} \lambda_{2} B_{2,1} A_{1} \lambda_{1} /\left(\lambda_{1}-\lambda_{2}\right)\left(\lambda_{1}-\lambda_{4}\right) \\
& +B_{1,3} \lambda_{3} B_{3,2} A_{1} \lambda_{1} /\left(\lambda_{1}-\lambda_{3}\right)\left(\lambda_{1}-\lambda_{4}\right) \\
Y_{4,3}= & B_{4,2} \lambda_{3} Y_{2,1} /\left(\lambda_{2}-\lambda_{4}\right)-B_{1,2} \lambda_{2} B_{2,1} A_{1} \lambda_{1} /\left(\lambda_{1}-\lambda_{2}\right)\left(\lambda_{2}-\lambda_{4}\right) \\
Y_{4,4}= & -B_{4,3} \lambda_{3} B_{3,1} A_{1} \lambda_{1} /\left(\lambda_{1}-\lambda_{3}\right)\left(\lambda_{3}-\lambda_{4}\right)
\end{aligned}
$$

Finally, the amount of each chain member is given by Eq. (2).

$$
\begin{aligned}
\mathbb{H}_{2}= & A_{1} e^{-\lambda_{1} t} \\
\mathbb{B}_{2}= & Y_{2,1}\left(1-e^{-\lambda_{2} t}\right)+Y_{2,2}\left(e^{-\lambda_{1} t}-e^{-\lambda_{2} t}\right) \\
H_{3}= & Y_{4,1}\left(1-e^{-\lambda_{4} t}\right)+Y_{4,2}\left(e^{-\lambda_{1} t}-e^{-\lambda_{4} t}\right)+Y_{4,3}\left(e^{-\lambda_{2} t}-e^{-\lambda_{4} t}\right) \\
& +Y_{4,4}\left(e^{-\lambda_{3} t}-e^{-\lambda_{4} t}\right) .
\end{aligned}
$$


Effects of a Biological system

\section{Basic Equations}

If the members of a radioactive decay chain are incorpurated into a biological system, the system, through chemical and physical processes, removes each member of the desay chain from tre system orer a period of time. In many important casto, the elimination raves can be represented with biological half-livas, $\lambda B_{i}^{M}$. In this case, Eqs. (1) can be rearitten:

$$
s_{i}^{L}=R_{i}^{L}+\sum_{j=1}^{\operatorname{NRAD}} B_{i, j} i_{i} v_{j}^{L}+\sum_{M=1}^{N B I O} F_{i}^{L, M} \lambda B_{i}^{M} N_{i}^{M}
$$

$$
\begin{aligned}
& \text { for } i=1, \text { NEAD } \\
& \text { and } L=1 \text {, NBIO, }
\end{aligned}
$$

where

$$
\begin{aligned}
& N_{i}^{L} \text { is the amc ant of the } i-t h \text { member of the decay } \\
& \text { chain that is in the i-th section of the } \\
& \text { biological system; } N_{i}^{L}=A_{i}^{L} \text { at } t=0 \text {. } \\
& B_{i, j} \text { is the fraction of the } j-\text { th members of the decay } \\
& \text { chain that decays tu procuce an } 1 \text {-th nember of } \\
& \text { the chain. } B_{1,1} \equiv-1 \text {. } \\
& F_{i} L, M \text { is the fraction of the } i-t h \text { member of the decay } \\
& \text { ch } x \text { in that is in the } M-\text { th section of the biologi- } \\
& \text { cal system that is moved via viological processea } \\
& \text { to the I-th biological section. } F_{1}^{\mathrm{L}, \mathrm{L}}=-1 \text {. } \\
& \lambda_{j} \text { is the radioactive decay constant for the } f \text {-th } \\
& \text { member of the decaj chain. } \\
& \lambda B_{i}^{M} \text { is the biological half-life of the } i \text {-th chain } \\
& \text { member in the M-th biological section. } \\
& R_{i}^{L} \text { is the constant rormation rate of the } 1 \text {-th shain } \\
& \text { member in the L-th section of the biological system. } \\
& \text { NRAD is the number of members in the radiclogical } \\
& \text { decay chaín. } \\
& \text { NBIO is the number of sections in the biologicat } \\
& \text { system. }
\end{aligned}
$$


Rewriting Eq. (11) gives

$$
\dot{\mathrm{r}}_{\mathrm{q}}=\mathrm{s}_{\mathrm{q}}+\sum_{r=1}^{\mathrm{rTOT}} ;_{\mathrm{q}, \mathrm{r}} \mathrm{T}_{\mathrm{r}} \quad \mathrm{q}=1,2, \ldots \text { NTOT }
$$

where

$$
\begin{aligned}
\text { NTOT } & =N R A D \cdot N B I O \\
T_{q} & =y_{i}^{L} \\
s_{q} & =x_{i}^{I_{i}} \\
r_{q, r} & -B_{i} \cdot j \cdot \lambda_{j} ; \text { or } F_{i}^{L, M} \cdot \lambda B_{i}^{M} \\
q & =I+(i-1) \cdot N B I O \\
r & =M+(j-1) \cdot N B I C
\end{aligned}
$$

Equations (12) are the same as Eqs. (?) and can be solved in an identical manner.

Approximation

In wany decay chains of interest all bat one menber of the winain has a shcrt biological half-life. As a result, the chain can be approximated by one nember with $A \theta$ equal to the amount of $N$ that is initially ingested, or with $R=\frac{d N}{d t}$ from $N$ at the times of ingestion for cronic ingestion. In this simplified case, the chain in the biological system has only one member

$$
\frac{d N}{d t}=-(\lambda+\lambda B) N
$$

The $d$ ise, in this case, is the integral

$$
\text { lifetime dose }=C^{L} \bar{E} \int_{\text {ingestion }}^{\text {lifetime }} \lambda N d t=\frac{C \bar{L} \bar{E}}{(\lambda+\lambda B)}\left(A \theta-N_{\text {lifetime }} \int_{\text {ingestion }}^{\text {lifetime }}\right. \text {, }
$$

where the notation is the same as in Eq. (19).

computation time will. be shortened if this approximation can be used. This approximation was used in examples 3,5 , and 6 . 
Use of Alpha, Beta, ant Gamme Ray Enerqies

\section{Alpha and Gama Ray Energies}

The average alpha, beta, and gama ray eneror rtleased per radioactive decay of the i-th decay chair. nember is

$$
\begin{aligned}
& \bar{E}_{i}=\sum_{k} F_{k, i} E_{k, i}, \\
& \text { suai over all beta } \\
& \text { rays and gamso rays }
\end{aligned}
$$

where $F_{k, i}$ is the fraction of disinteprations of the $i$-th chain member that priture, a beta ray with erurage energy or an alpha or gamma ray with energy $E_{k, i}$.

The rate of energy release by the $i$-th member of a devay chain is then equal io $\overline{\mathbf{E}}_{\mathbf{i}} \lambda_{\mathbf{i}} \boldsymbol{k}_{\mathbf{i}}$.

Input parameters for each decay chain are the $F_{k, i}$ and the beta ray endpoint eneres or alpha or gama iay ener $z y, E_{k, i}$.

Average Beta Energy

The average beta ray energy is calculated in subroutine AVBBET from

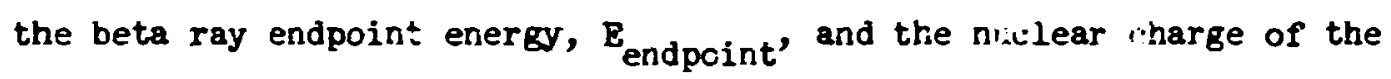
daughter, $\mathrm{z}$.

Following the method of Marinelli et al. (Rev. Mor. Phys., 19, 25 (1947))

$$
\psi_{B}=\frac{\int_{1}^{W_{0}} N(W) W d W}{\int_{1}^{W} N(W) d W}
$$

where

$$
\begin{aligned}
& W_{0}=\frac{E_{\text {endpoint }}}{M_{0} c^{2}}+1 \\
& W_{B}=\frac{E_{\text {ave }}}{M_{0} c^{2}}+1
\end{aligned}
$$

and

$$
N(W)=\frac{|M|^{2}}{T_{0}} F(Z, W)\left(w_{0}-W\right)^{2}\left(W^{2}-i\right)^{1 / 2} W
$$


An approximate expressicn for tie Couloab correction factor, $F(\mathrm{Z}, \mathrm{W})$, suggested by Hail (Fhys. Rev. 79745 , (1950)), that is accurate to better than $1 \%$ is used.

$$
\begin{aligned}
P(z, H)= & \frac{4 \pi(1+S)}{[(2 S) !]^{2}}\left(2 p_{0}\right)^{2 S-2}\left(S^{2}+\eta^{2}\right)^{s-1 / 2} \\
& \exp \left[2 \eta \arctan \frac{s}{\eta}-2 S+\frac{s}{5\left(S^{2}+\eta^{2}\right)}\right]
\end{aligned}
$$

where

$$
\begin{aligned}
& 2=\text { charge of daughter nucleus } \quad c=\text { vel. of light } \\
& s=\sqrt{1-\left(\frac{2 e^{2}}{h c} j^{2}\right.} \quad e=\text { electronic charge } \\
& P=\frac{1}{c} \sqrt{(H-1)^{2}+2 m c^{2}(W-1)} \quad \text { in }=\text { Planck constant } \\
& 0=\frac{\text { nuslear rafius }}{\frac{\mathrm{h}}{\mathrm{c}}}=1.2 \mathrm{~A}^{1 / 3} \times 10^{-3} \mathrm{cr} \quad m=\begin{array}{r}
\text { electronic } \\
\text { rest mass }
\end{array} \\
& \eta=\frac{7 e^{2}}{\left[\frac{h c^{2} p}{\left(m c^{2}+(w-1)\right.}\right]}=\frac{z e^{2}\left(m c^{2}+W-1\right)}{h c^{2} p}
\end{aligned}
$$

$A=$ nuclear mass nusier.

\section{Dose Calculationa}

Dose and dose rate to a biolngical sys::em is calculated from the ene'gy absorbed per unit weight of the systen. The dose rate from the i-th decay chain member to the L-th biological section is just

where

$$
\text { cose rate }=c^{\mathrm{L}} \overrightarrow{\mathrm{E}}_{i}^{\mathrm{L}} \lambda_{i} \mathrm{~N}_{i}^{\mathrm{L}}
$$

$\bar{E}_{j}$ is the fraction $o f$ the averagc energy released when the 1 -th chain member decays and is absorbed in the L-th biological section.

$c^{L}$ is the conversion factor for the L-th biological section that converts the results to the desired units. 
Lifetime dose is given by

$$
\text { lifetime dose }=c^{L} \bar{E}_{i}^{L} \int_{\text {ingestion time }}^{L} \lambda_{i} N_{i}^{L} \text { lifetime }
$$

Four separate cases are handled by the program.

Case I: Total Energy Absorption

'the dose or dose rate from ingested fission products is calculated assuming all the released alpha, beta, and garma ray energy is absorbed in the biological section. The product, $\vec{E}_{i}^{L} \lambda_{i} N_{i}^{L}$, has the units MeVcu-ies ror the entire reactor core or weapon. Tn convert this to an irdividual dose rate, the result must be multiplied by the fraction ingested and by $\mathrm{c}^{\mathrm{L}}$. $\mathrm{C}^{\mathrm{L}}$ for alpha rays are wultiplied by ten, the relative biological effectiveness, $R B E$, of alpha rays.

$$
\begin{gathered}
\frac{r e m}{h r}=\text { MeV-curies } \times \text { fraction of core inventory or weapor ingested } \times c^{L}(20) \\
c^{L}=3.7 \times 10^{1}=\frac{\text { disintegrations }}{\text { sec-curie }} \times 3600 \frac{\mathrm{sec}}{\mathrm{hr}} \times \frac{1}{6.2419 \times 10^{5}} \frac{\mathrm{ergs}}{\mathrm{MeV}} \\
\times \frac{1}{93} \frac{\mathrm{rad}}{\text { erg,s/gm }} \times \frac{1}{\text { gns of biological section }} \times \mathrm{RBE} \\
\mathrm{c}^{\mathrm{L}}=\frac{2.295 \times 10^{6}}{\text { gms of biological section }} \times \mathrm{RBE}
\end{gathered}
$$

Lifetime dose is calculated by integratiug over the time from ingestion to the lifetime.

\section{Case II: Gamme Ray Dose Above a Plare}

The gamma ray dose rate at one met : above a uniformly contaminated smooth plane is calculated in units of ( $\mathrm{em} / \mathrm{hr}) \cdot \mathrm{ft}^{2}$.

For each gainma ray energy, an RBE of one is assumed and the following calculation is made:

$$
\begin{aligned}
& \frac{\text { rem. } \mathrm{ft}^{2}}{\mathrm{hr}}=2.741 \times 10^{3} \times\left.\left.\right|_{\frac{\sigma_{\text {absorption }}}{\rho_{\text {air }}}} ^{\frac{\mathrm{cm}^{2}}{\mathrm{~g}^{\mathrm{m}}}}\right|_{\mathrm{air}} E_{\mathrm{MeV}} \\
& x \frac{1}{2}\left[E_{1}\left(\omega_{0} H\right)+\frac{b}{\omega_{0}} e^{-\mu H}\right]
\end{aligned}
$$


where

$$
\begin{aligned}
& \mathrm{E}_{\mathrm{NeV}} \text { is the gamase ray energy } \\
& E_{1}(x)=\int_{x}^{\infty} \frac{e^{-z}}{z} d z \\
& \frac{b}{s_{0}}=\left(\frac{\sigma_{\text {scattering }}}{i_{\text {atsorption }}}\right)_{\text {air }} \\
& \text { No = total attenustion, } \mathrm{cm}^{-3} \text {, in air } \\
& o_{\text {air }}=\text { air density, } \frac{g^{m}}{c^{3}} \\
& \mathrm{H}=1 \text { weter. } \\
& \frac{1}{2}\left[E_{1}\left(\mu_{0} H\right)+\frac{b}{\mu_{0}} e^{-\mu_{0} H}\right]=\int_{x=H}^{x=\infty} e^{x-x}(1+b x) 2 \pi x d x \frac{1}{4 \pi x^{2}} \\
& e^{\gamma_{\alpha} x}=\text { attenuation } \\
& 1+b x=\text { buildup factor } \\
& 2 \pi x d x=\text { contarinated area } \\
& \frac{1}{4 \pi x^{2}}=\text { soiid angle contribution } \\
& 2.741 \times 10^{3}=3.7 \times 10^{\circ 0} \frac{\mathrm{dis}}{\mathrm{sec}-\mathrm{curie}} \times \frac{1}{6.2419 \times 10^{\mathrm{s}}} \frac{\mathrm{ergs}}{\mathrm{MeV}} \frac{1}{33.9} \frac{\mathrm{ren}}{\mathrm{ergs} / \mathrm{gm}} \\
& \times 3600 \frac{\mathrm{sec}}{\mathrm{hr}} \times 1.0765 \times 10^{-3} \frac{\mathrm{ft}}{\mathrm{ctr}^{2}} \text {. }
\end{aligned}
$$

To convert the results to $\frac{\text { rem-mil }}{h r}$, divide by $2.793 \times 10^{7} 1^{2} / \mathrm{mi}^{2}$. To obtain $\mathrm{rem} / \mathrm{hr}$ from the (rem/ $\left.+^{*}\right) \cdot \mathrm{ft} \mathrm{t}^{2}$,

$$
\frac{r e m}{h r}=\frac{r e m \cdot f t^{2}}{h r} \times \frac{1}{f^{2} t^{2} \text { contaninated }} \times \begin{aligned}
& \text { fractic.1 of the core or weapon } \\
& \text { sprad out on plane }
\end{aligned}
$$

\section{Case III: Dose from Ingestion and Inhalation}

The dose rate is calculated from the alpha, beta, and gama ray energies, if all the beta ray energy and a fraction of the gama ray energy is absorbed in biological section of specified weight. The gamm 
ray energy fraction is calculated assuming absorption in a sphere of water with the sase weight as the biological section. For each grmm ray energy, the sollowing quantity is evalua:zd.

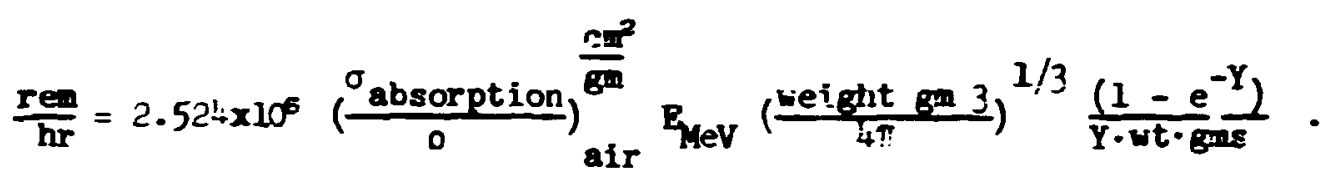

where

$$
\begin{aligned}
& \text { EMt = gawad ray energy in MeV } \\
& \text { Weigi:t gms = weight of biological section in gms } \\
& Y=1.1 \times\left(\frac{\text { total atten. }}{D}\right)_{\text {air }} \times\left(\frac{3 \text { weight gass }}{4 \pi}\right)^{1,3} \\
& 1-e^{-Y}=\text { approxiante fraction of energy absoibed. }
\end{aligned}
$$

These equations use the approximate relationship

$$
\left(\left.\frac{\mu}{0}\right|_{\text {weter }} ^{c m^{2} / \mathrm{gm}^{\mathrm{m}}}=1.1 \times\left[\left.\frac{\mathrm{t}}{\mathrm{c}}\right|_{\text {air }} ^{\mathrm{cm} / \mathrm{gm}}\right.\right.
$$

Case IV: Opti onal Input

Any decay-rate-related quantity that can be included with input information can be incorporated into the calculations. This quantity is muitiplied by. curies for each member of the decay chair. An example input quantity is the average MeV released per disintegration. Another example is the (1sotopic weight/mole) $x$ the number of disintegrations! secondicurie divided by the isotopic isintegration constant and the number of atows per mole. The result of the final calculation will te grams of each isotope va time.

Continuous Release of Pission Products

A calculation option is permitted that considers the fissicn products continuously released from the nuclear reactor containment after a core meltdown. Any biological half-life can be applied after release. This option makes it possible to calculate a downind dose frcm a 
continuous release of radfoactive aterial even though the release rate and wind speed vary. A wore detailed discussion of the use of this option is discussed elsewhere. ${ }^{1}$

'R. O. Chsst.er, Dose ard Deposition from a Nuclear Reactor Core Melt Jown, CRNL-4944, (1974). 
APPEEDIX A

MOI-STAMDARD USE OF THE CODB, YIEIDS 


\section{AFPB.DIX $A$ \\ WON-STMDAD USE OF THE CODB, YIBIDS \\ Reactor Rerueling Schedule Change}

In the min progran, lines numered 1030, 1040,1050, 1300, 1310, 1320, and 1360 deternine tha refueling schedile. $T 1, T 2$, and $T 3$ defined fr. lices 1030. 1040, and 1050 are the tixes elmpser in secunds before shutdorn that each section was refueled. The inventcry it shutdown for each sertion is calculated in lines 1300, 1310, and 1320. For example. iine $132 x$ is

$$
\text { Call sorma ( } T, 1, V, Y, A \text {, EChan, 2) - }
$$

The result of this calculation is the inventory in a reactor that has been optrating $T$ seconds is stored in array $A(K, 3)$. The $K$ values depend on the decay chain but 3 is 1 plus the last argument in the call statecent cni $A$ is the fifth argunent.

Line 13 in adds the relative rractions of fission products produced by each of the core sections. In this particular core, each section produces ine-third of the fission product.s.

\section{Buildup of Fission Products During Operation}

If the same refueling schodule is mintained and $T$ is the elapsed time before reactor shutuun, replace the first argument in lines 1300 , 1210 , and 1320 with

$$
\begin{aligned}
& T 1-T+T 3^{*} G, \\
& T 2-T+T 3^{*} G, \text { and } \\
& T 3-T+T 3^{*} G, \text { respectively. }
\end{aligned}
$$

Where $G$ is the skallest integer, including 0 , that keeps all three arguments greater than zero. Output statements and an iterative procedure must be inserted. Por example,

$\begin{array}{ll}\text { GO TO a } & 1290 \\ 10 \text { DO Ilo IBLDUP }=1, \mathrm{NIT} & 1291 \\ \mathrm{~T}=\text { TIME (IBLDUP) } & 1292 \\ G=\text { AINT ( (T-T1) } / \mathrm{T3}+1 .) & 1 \hat{\varepsilon} 93 \\ \text { IF (T1.GT.T) G }=0 & 1294\end{array}$




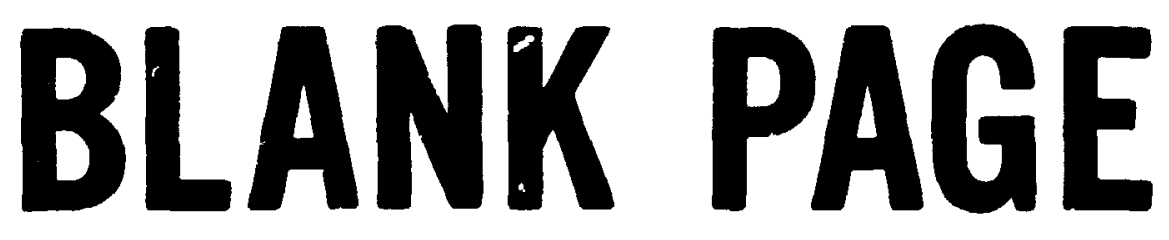


CALL SOLMA (TI - T + T3*G, 1, V, Y, A, HCHATR, 0)1300

CALL SOLICA (T2 - T + T3*G, 1, V, T, A, KHAIR, 1)1310

ChLl selica (T3 - T + B*G, 1, V, Y, A, MCHATn, 2) 1320

etc.

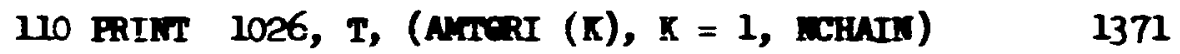

1026 Perant (9 E 14.4)

Modifications of Beta and Gare Ray Bner zy Calculations

Functioris of beta and garm calculations are perforsed in subroutine cospca. The averaze beta ray energy is calculated from the endpoint energy in line 940

$$
16 \operatorname{EG}(\mathrm{K}, \mathrm{I})=\operatorname{AVESBT}(\operatorname{BO}(K, I), \mathrm{ZD})
$$

where

$K$ indicates the $k$-th beta ray,

I indicates the $i-t h$ member of th- decay chain,

$\mathrm{ZD}$ is the atonic charge of $t$ le beta decay daugnter, and the endpoirt energy in MeV, $\mathrm{EG}(\mathrm{K}, \mathrm{Z})$ is coriverted to the average energy by the function AVBBEr.

Processing of the gawn energy is done in line 920 or line 930 by subroutines ABSN or SRCHAR. A detailed discussion of the use of these routiiles is given in the section entitled "Dose Calcuiations." The average energy releaged per decay chain member disintegration tive $c^{\mathrm{L}}$ in Eq. (9) is stored in array $\mathrm{SBB}(\mathrm{K}), \mathrm{K}=1$, MCHIN and calculated in lines 1050 through 1140 .

If an average energy or other quantity per decay thain member disintegration is read in with the decay chnin tata, it is stored in array $A B B(K), K=1$, MCHAIN. Further processing statements should be inserted after line 740 and before line 750 .

Calculation of energy-activity products is done in subroutine soLm, lines $410,420,430,450,460$, and 430 . Modifications can be inserted as needed. 


\section{Use of the Atonic Weight}

The atomic veight, IA, and atomic numbers, IZ(I), for each decay chain are stored in the Cexwa labeled MARZ. A check of atomic number is ade before extensive calculations are perforwed. The check starts in lire 1120 of the min routine. As a result, IZZEST is set equal to $I$ or $O$ if the current decay shain dces or does not contain elener.ts of interest. A check on atomis weight night also be done in conjunction with the atosic number check and IZZEST correspondingly alterer.

\section{Firsionable Material ott.er than ${ }^{235} \mathrm{U}$}

The only nubers in the decay chain data cards that would have to te changed are the fission yields in percert. It way te necessary to aid a few additional decay chain sperifications if their total fissicn yeld is non-negifible.

\section{Dscay Chains for Induced Activity}

Induced activity information must be obtained from other sources. In sowe caces, this additional information car be added to the calculations fC: a complete list of a chemicai epecies. Fo- example, in ar: operating reactor core, stable ${ }^{133} \mathrm{Cs}$ captures a neitror, to form ${ }^{134} \mathrm{Cs}^{*}$ and ${ }^{134} \mathrm{Cs}$. If the amount of ${ }^{134} \mathrm{Cs}$ is known at some tine after shutdown, the amounts of ${ }^{134} \mathrm{Cs}^{*}$ and ${ }^{134} \mathrm{Cs}$ at shutdown can be estimated and the ${ }^{134} \mathrm{Cs}$ contribution to dose or energy relater salculations can be made. The decay chain is specified

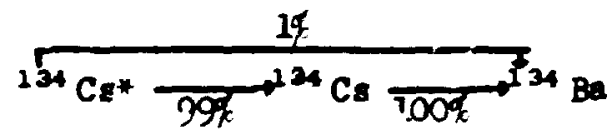

$$
\begin{aligned}
& 3.2 \mathrm{hr} \quad 2.3 \mathrm{yr} \text { stable } \\
& \text { B } 0.15 \text { 1\% } 30.5570 \% \\
& r .010 \quad r 0.605 \\
& \gamma 0.137 \quad \gamma \quad 0.797
\end{aligned}
$$

with ficticious fission yields to produce the observed quantities at shutdown. 
APPEDDIX B

IRPUT CARDS 


\section{APPETDIX E \\ INPUT CARDE \\ Inpl:t Card Sequerce}

One card:

Contents: Gperating level in therrel megawatts and the vord REACTR, or Fissior. yielt ir megatons and the wor? WEAPON

Variable nemes: THETHR, REACWP

Format:

EIO. $4,1 X, 124$

Examples :

$$
\begin{aligned}
& \text { 34:0. REACAYR } \\
& \text { 1. WEAPOS }
\end{aligned}
$$

Cne card:

Contents:

Changes for the parameters IMUL ${ }_{T}$, IGALA, IRPT, LTFD

Variable names:

(RDIIST'I), IRD( $(I), I=1,4$ )

Format:

$4\left(1 A^{4}, 3 X, I 1\right)$

Examples :

STD

LIFD $\$ S=2$ I $C A M A=3$

Parameter values:

STD

IMULD $=1$ or 2

IMUI $\phi=1, I$ GAMA $=1, I R P T=1$, LIFD $\$ S=0$

IGAMA: $=0,1,3$, or 4

single or cuntinuo's release of îssion products

Curies, MeV-curies, rems or rem/hr to a biological section, or rem/hr. $\mathrm{ft}^{2}$ one meter

IRPT $=3$ or 1 above a coritaminated pleine

LIFD $\$ s=0,1,2$ or 3

Minimal or detailed printed -utput

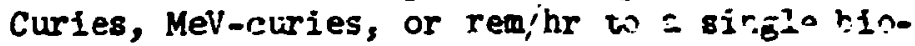
logjcal section; Lifetime dose to a single biological section: dose rate in a multisection biosystem, rea/hr; cose in a multi$\varepsilon \equiv$ ction biosj'sien, rems

One card:

Contents: $\quad \because e i g h t$ of a single biosection in grams: This card is read only when IGANA $=3$ and IIFD $\$ S=0$ or 1 .

Variable name: GS

Format: $\quad$ ElO.4

Examples: $\quad 70000$.

1000. 
One card:

Contents: $\quad$ Specification of chroric or acute exposure of a multisection bissyicen to fissior products

Variable name: CRAC

Format: $\quad \mathrm{IA}_{4}$

Examples: $\quad$ CRdNIC

ACUTE

One or mare cards:

Contents :

A list of chenical species whose results are to be summed: The list of atomic numbers is preceder? by the number of the list

Variable names: NIIIST, (IZIIST(I),I=1, NIIIST)

Fornat: $\quad 26 \mathrm{I} 3$

Finanies: $\quad 153$

One st wire cards:

Contents:

Btological half-life in days of each chenical species in order as specified in the prevtous card. A zero is interpreted as an infinite biolo, jical halt-life.

Variacle names: (TZLIST(I), $I=1$, NILIST)

Furmat: $\quad 9,320.4$

Examples:

ijo.

i1. 45. 13000. 14000.65.

Four or more vards:

These cards describe the ratiolopical decay chains and multisection biological system and are ciscussed in dete.il in Appendix C.

One card:

Contents: $\quad$ Case title

Variable namea: ( $\operatorname{TITLE}(I), I=1,18$ )

Format: $\quad$ 18A4

Examples: IODINE DOBE TO ADULT THYROTD,R,REAC,TOR CORE MELT

$R-F T * 2 / H R$ AT 1 METER ABOVE SMOOTH YLANE, 1 MT 
One card:

Contents: Case separatcr=ST $\phi$ for last case, otherwise anything

Variable name: TITLE(1)

Forwat: $\quad \mathrm{IA}_{4}^{4}$

Examples: $\quad$ ST中P

MER 
Inpor CAnd

\section{manple 1}

34:. nescron

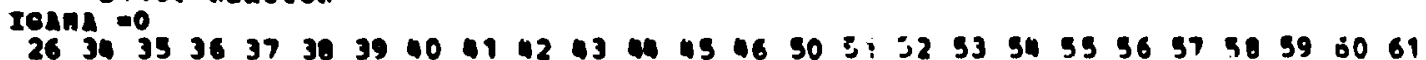
62

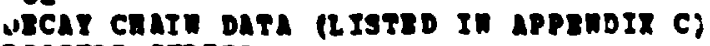
nsseron cosiss

nons

$\begin{array}{ll}\text { IxAMpLE! } & \text { Conte } 2\end{array}$

renpa $=0$

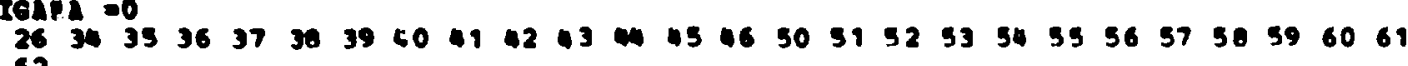

62

decay caIy data (RISTRd In Appendix C)

nenton coniss

3708

\section{RXAHPLE 2}

3440. nencron

Conve 1

580
26 62

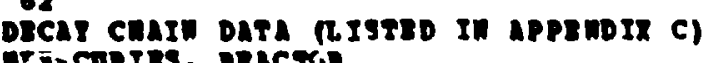

ati-conies. MeACxis

nors

\section{ExAMPLE 2}

3440. nencros

STD

- $3940 \quad 19 \$ 203 \quad 4 \quad 4562$

DECI C CUII DATI RISTID I" APPEDDIR C

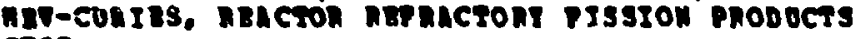

srop

3460. nneton

\section{EXATPLE 3}

IOAn -3LIPDOS=1

20.

139.

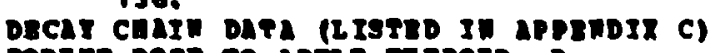

sodine dose to adoze thrnoro. A

sros
ERPLANATION

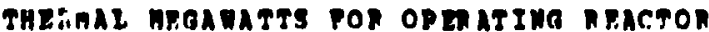

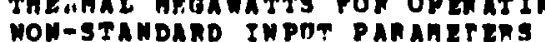

monic mongr hronic nonezhs op piss

CAsE TITLE

ENDS BXARnLE

nzGATOK 3 PTSSION TiELD POR WEAPON MON-STANDARD INPIT HARAMETERS

ATONIC NOADERS OP PISSION ProdoCTS OSPD

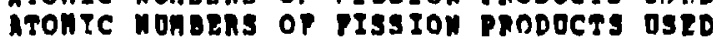

CASI TETLF

EMDS EXAMPLE

THERHAL HEOA UATTS POA OPERATIMS REACTOR STAMDARD INPOT PARAMETERS REOOESTED

STED ATOHIC MOHeERs OP PISSTOM PRODUCTS OSED

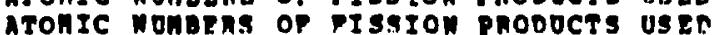

CASz TITL

ENDS EXAMPLE

THERHAL HEOAMATTS POR OP ERATINO REATTOR STANDARD IHPOT PARAHETERS RROOERTPR aronIC MOMaEAs OP ISSION PhODOCTS OSRD

Case TITL

ENDS EXAMPLE

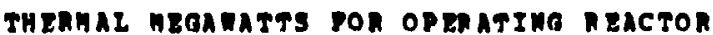
THEAMAL nEoA WATTS POR OP EAATI

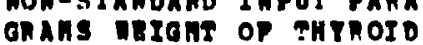

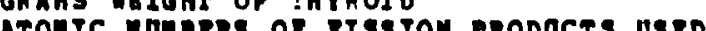
BroLOOTCAL MALP-ITPE. DATS

CAsE TITL

ENDS EXAMPLE 
1. vranon

2030 35 $37303940 \div 1424340450650515253 \quad 5556 \quad 57585960 \quad 6162$

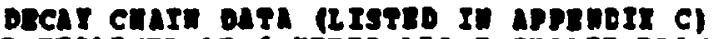

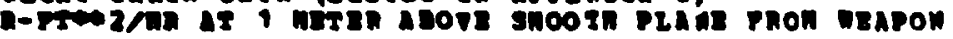

nons

\section{$\operatorname{crnnpr}$ \\ $\operatorname{con} 12$}

1. Mann

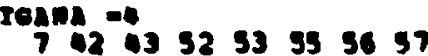

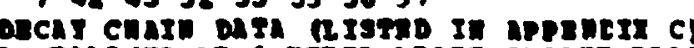

$n=\sqrt{2}$

Ser.

\section{Mxanpes 3}

3400. mencton ALL CORTES

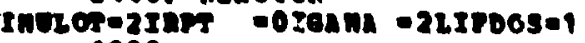

1006.

252900

500.

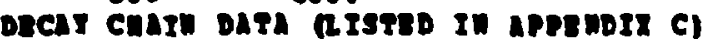

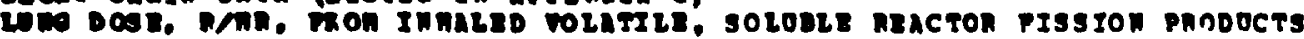
sros

\section{axinpzs:}

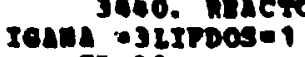

70090.

- 3500 o1 575059606162

60.162

100

1100.

1100.

1100.

1100.

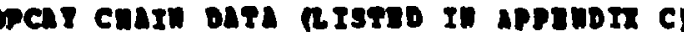

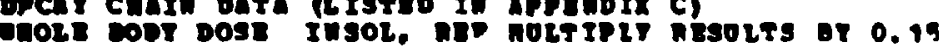

3440. nencron

Tane $-317 y$ coser

70000 .

74240 is 4690 s1 32

400 as of 90 si

$1100.1100 . \quad 1100$.

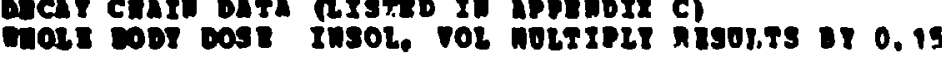
none

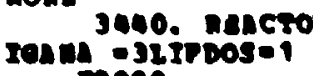

7000.

2335

132.

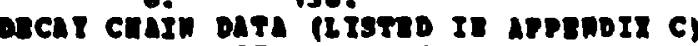

moze cods bose mizoesns

non

3040. ancros

reank -32 rpooser
nEGATONS PISSION TIELO POR EEATON

HOH-SPANOARO INPOT PARAMETERS

ATOHIC MOABRAS OP PISSION PRODOCTS U.SED

CASE TITLE

INDS EXAHPLE

nEOATONS PISSION YIELD POR UEAPON

mon-staypand inpor pananzteng

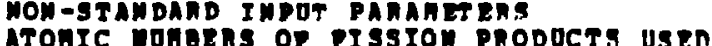

CAsR TITLE

EMDS ExaMPLE

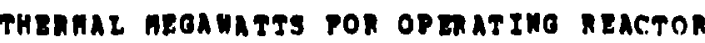
MON-STAMDARD INPAN PARAMERERS

oRAMS DEJoht oD zonos

Aronic monerRs or pission prodncts o.ge BIOLOGICAL MALP-IITES, DATS

CAsI TITLE

ENOS ExAMPLE

THERHAL MEOA WATTS POR OPERATIMG MEACTOR

MON-STANDAHD INPOT PARAM Ex EAS

QNAMS UEIOHF OP HNOLE BODP 1100. BIOLOGICAL MALP-LITRS, DATS

chse TITr

THEAGML GEOA WATTS POR OPERATING MEACMOR MON-3TANDARD INPOT PAMANTEERS

MOMTANDAMD INPOT PAMAKI.

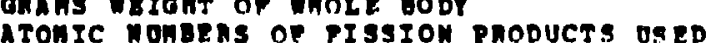
1100. BIOLOQICAL HALP-LIVES, DATS

CAsz TITLE
RnOS SOBCAsE

zhDS SOBCASE

MON-STANDARD INPOT PARAMET RA.

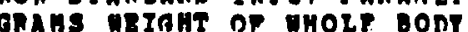

ATOHIC MOHERAs OP PISSION PHODUCTS USED

DIOZOQICAL HALP-LIVRS, DATS

CAge TITLE

ENDS SOBCASE

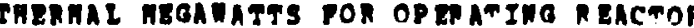

MON-STAMDARD INPDT PARAMETERS 
7000.

74249 as 4650,5152

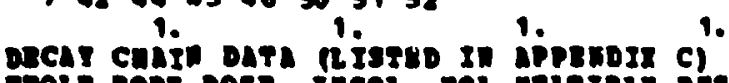

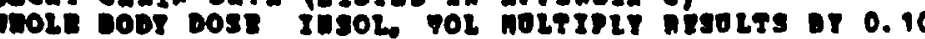
nose

3400. ARACro

reand asir

. 3940 a1 575099606162

$$
1 .
$$

1.

ง.

1.

1.

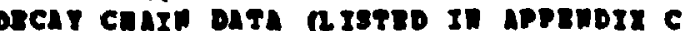

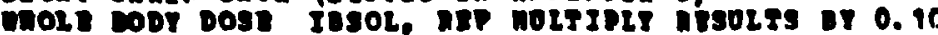

3040. macron

Iears -31sposes

70000 .

- 30 37 30 a 9596

$1.38+0$

1. 20.

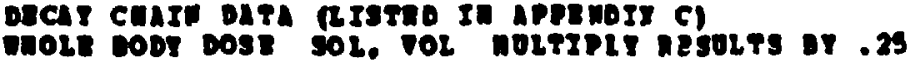

stop

IxAnpL: 7

$\cos 831,2,3,0$

\section{Danon}

$$
\text { actis }
$$

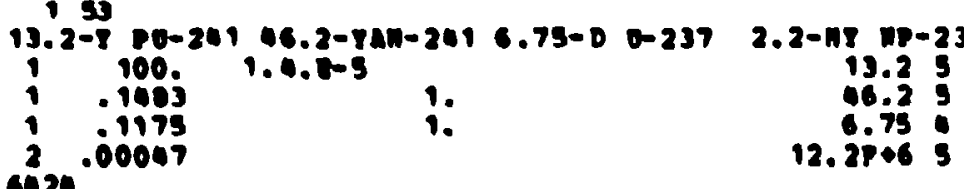

San 1000. 1000. 700. 1700. 7000.

$20890-018$

1.

1.

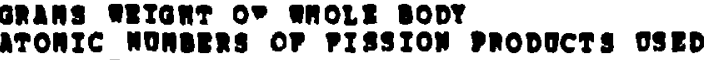
. Bjozocical mazp-livis, dars

Case ITLE

chos sobcis:

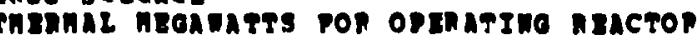
MON-STAMDARD INP OY PARAHErsas

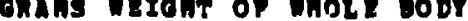

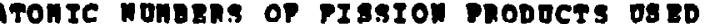

1. oroloctcal maLP-LITES, DATS

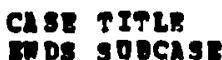

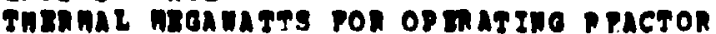

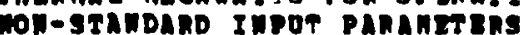

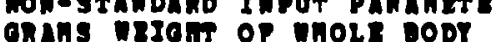

ironge noine op

dozoojcal hizp-LTtes, Dats

CAsE TITLE

BHDS ithMPL:

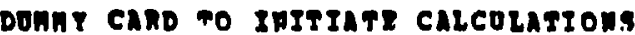

MON-3raMDARA IMPOT PARAMETERS

TTPI OP Br.0L OGICAL Exposons

DOAnY CARD

TrTze pon MADIOLOBICAL DECAT CHAJ

Dreat ChaIN deschiotion

90959293201

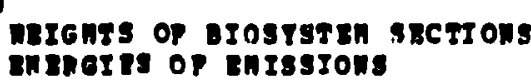

$10.8-34.910$

100.000

2 6. 5.076

95. .208

53. 0.787

1.10

14. 3.433

29. 0.767 3. 0.87

oncis. ione

D21 0.87 2IVE

$.23^{2.10-51.5-5} .04^{.03}$

1000.

อ2.

200.

$.25^{0.8-93.8-5} \cdot 12 \quad 09$

1.

1000.

0.5

200. 5

1.

$.29 \quad \begin{array}{r}1.8-3 \\ .04\end{array}$

1000.

gons

TITLS por otosteren

rosysten descrimson po

madioloorcal chain wanter.

DIOSTSTEH DESCRIPTION POR

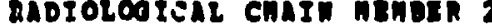

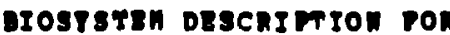

haorozocrcaz chasn nzmera 3 

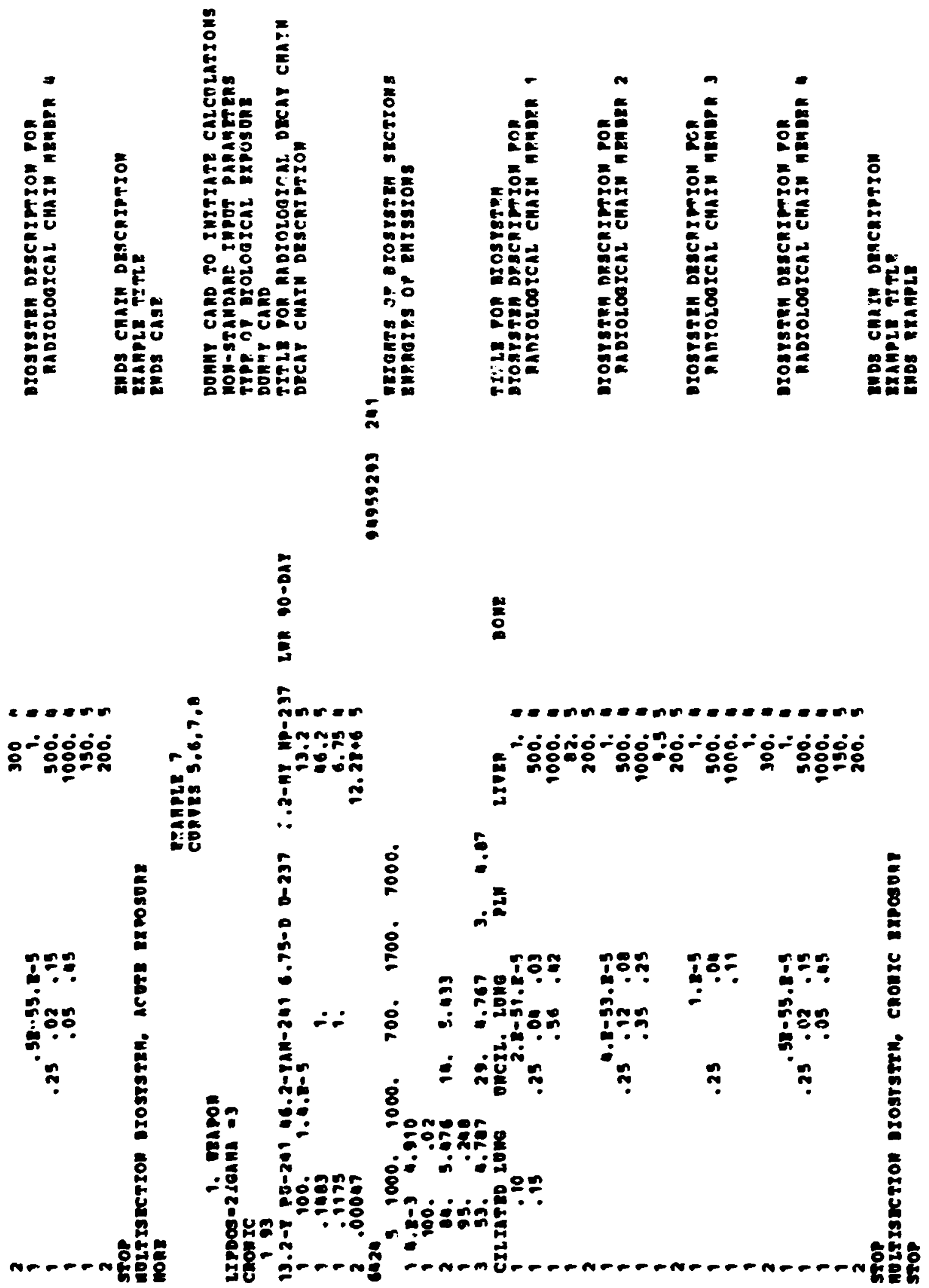
APFEDIX C

DEENIS OP DECAY CHATH DATA 


\section{APPEIDIX C}

DETAIIS OF DECAY CHAIN DATA

Standard Decay Chains for ${ }^{235}$ U Fission

The input cards for the decay shain with atomic weight 39 are used as an example. A complete listing of the decay chain Jata follows this section. A pictorial description of the atomic weight 39 chain is given beiow. 


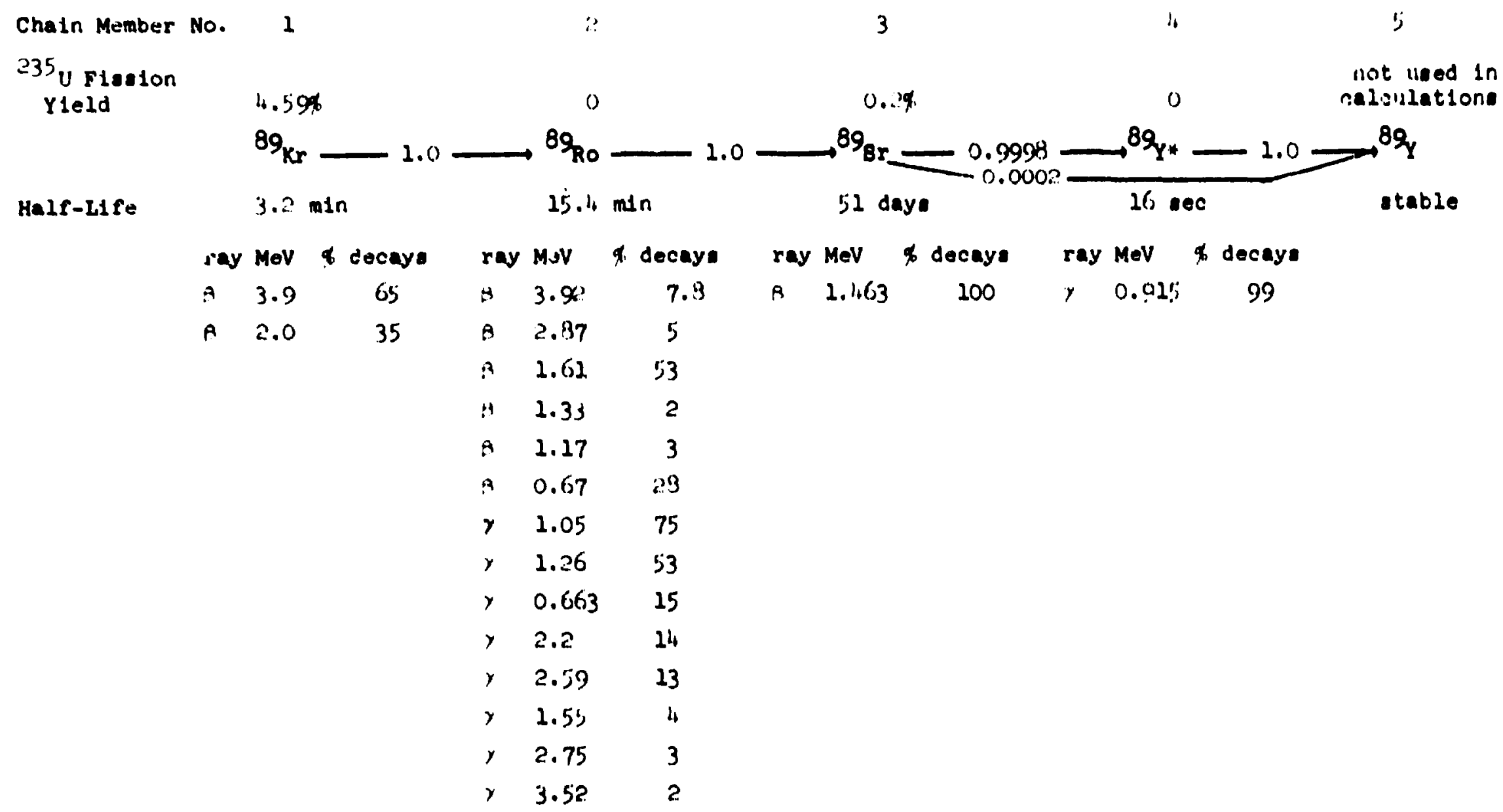

say MeV tecays

ray MuV decay

A $3.9 \quad 65$

- 3. $\%$

7.3

ray MeV \& decaye

B $1.1,63$

100

ray MeV

A $2.0 \quad 35$

ค $2.37 \quad 5$

3 $1.62 \quad 53$

$41.33 \quad 2$

A 1.173

a $0.67 \quad 23$

$\gamma \quad 1.05 \quad 75$

$y \quad 1.26 \quad 53$

$y \quad 0.66315$

$y 2.2 \quad 24$

$r .59 \quad 13$
$x \quad 13$

$>1.534$

$y \quad 2.753$

$\times 3.522$ 
Th: Input rarte for this chain are a: sollowa:

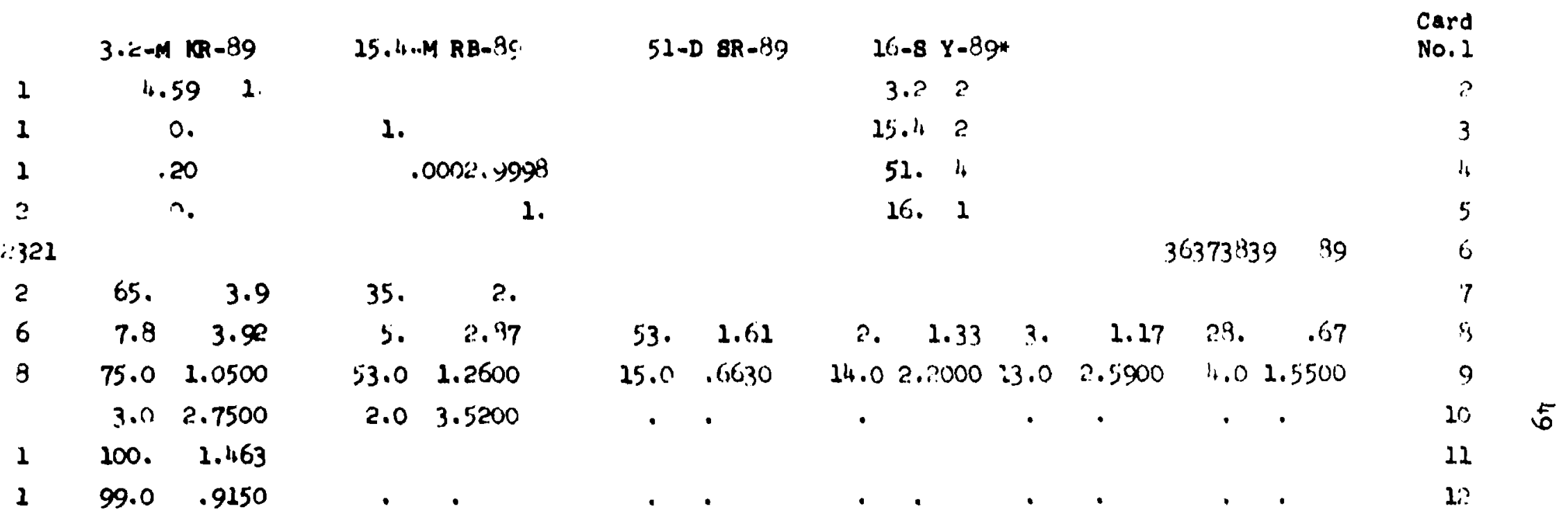

Card Number 1 -D Decay Chatn Title -- Format 18Al,

$\frac{3.2-\mu K R-59}{\text { deacription of }} \begin{aligned} & \text { first momber of } \\ & \text { decay chain }\end{aligned}$

To align output headinge keep the description of each member of the decay chain lese than 1 j chacucters. 
Sarde Nuber 2, 3, 4, 5 .. Decay Chain Deta11, -. Formax I2, $78.3,6$ 5.2, E10.3, I2

Each car 1 refore to one nomber of the decay chaln. Im 1 refere to the firat member, Im 2 refere to the second menter, etc.

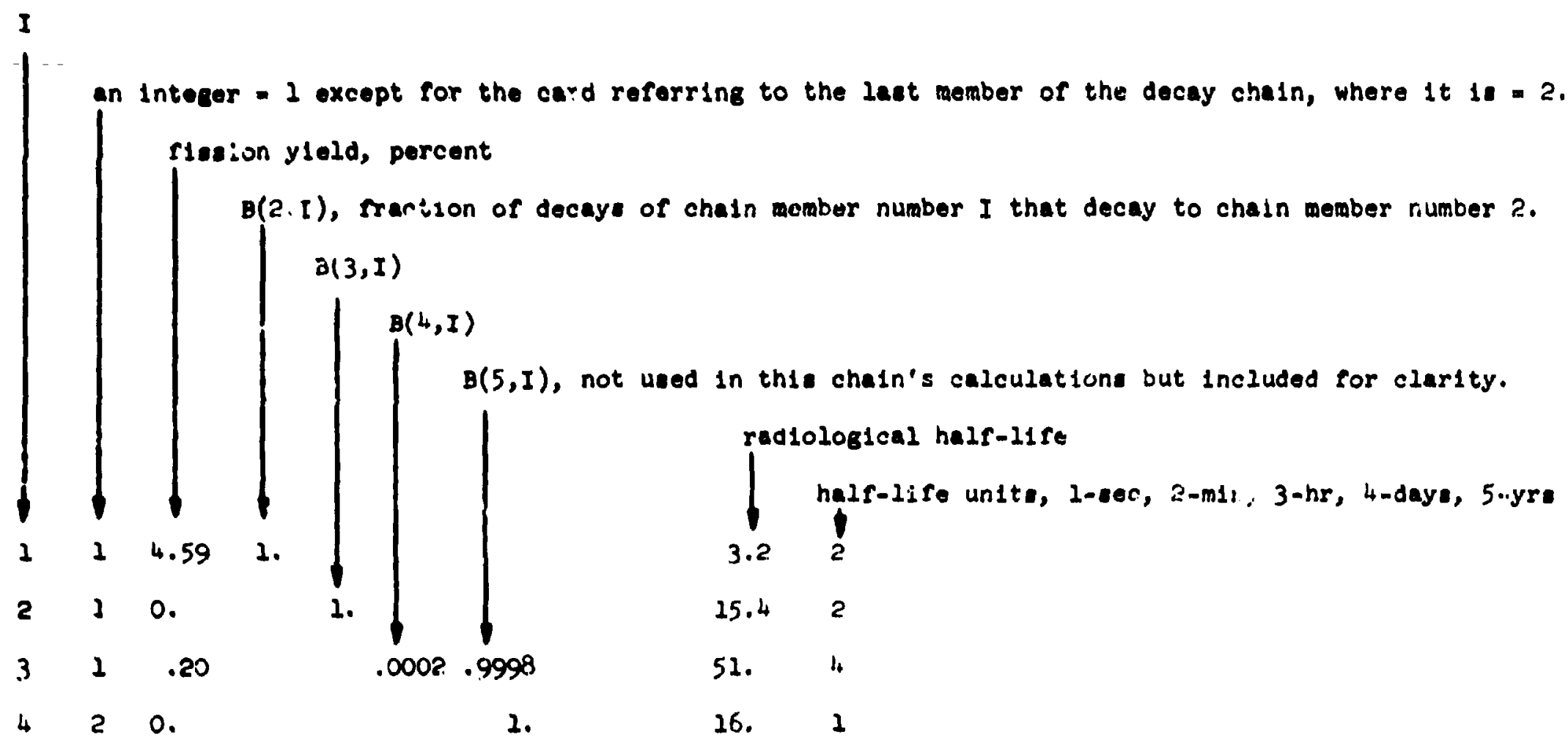




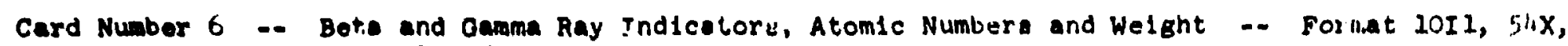
I2, $2 x, 5 I 2, I 3$

an integer indicating whether beta or camma rays are emitted when the firat member of the chaln decaya.

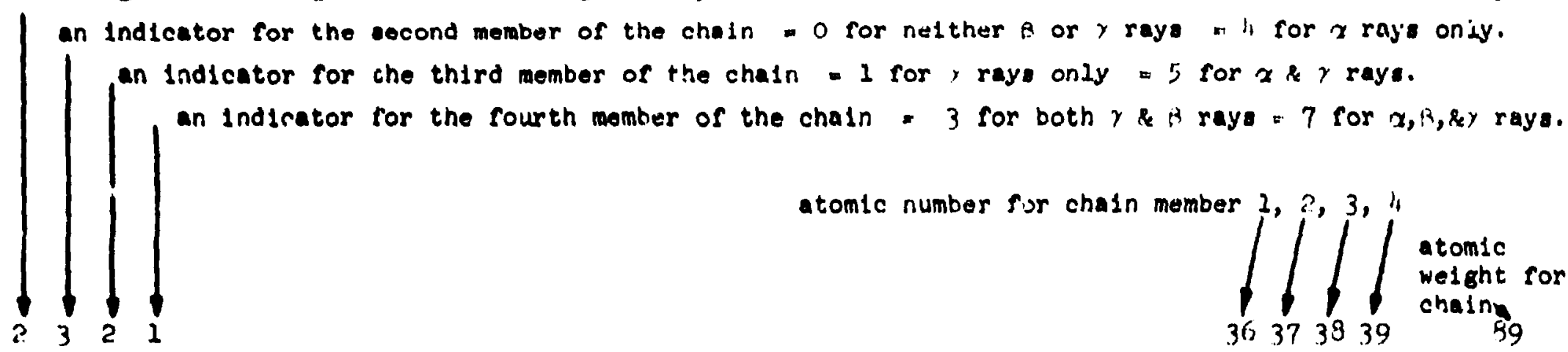

Carde Number $7,9,9,10,11,1 ;$.. Alylia, beia, and gamma ray descriptione .- Format (12, 6(\$6.1, 27.11)/ $(283.1,87.1,5(\mathrm{Ex}, 1, \mathrm{E} 7.4)$ )

the number of beta laye enitted by the rirat mimber of the decay chain

1 percent of desays emittine the rirst beta ray

L enerey of ine rielet bete ray, MeV

$\int \begin{aligned} & \text { percent of jesayy omstting the escond beta ray } \\ & \text { per ine rlaet bete ray, MeV }\end{aligned}$

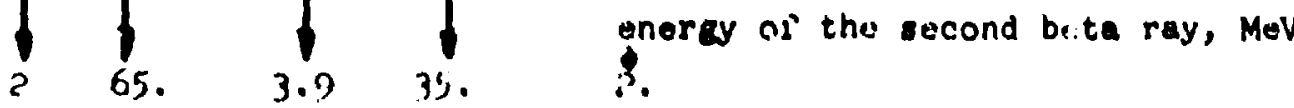

$\begin{array}{llllllllllll}7.9 & 3.9 & 5 . & 2.97 & 53 . & 1.132 & \because & 2.33 & 3 . & 1.17 & 04 . & .67\end{array}$

$\begin{array}{llllllllllll}75.0 & 1.0500 & 53.0 & 2.2000 & 15.0 & .6630 & 11.0 & 2.2000 & 13.0 & 0.5000 & 4.0 & 1.5500\end{array}$

$3.0 \quad 2.7500$

100. 1.1663

the number of gamma rays emitted by the courth mesmber of the chain.

[the numbre of beta raye enltted by the thlrd member of the chain.

L the number of gamma rays emitted by the oucond member of the chali.

- thi. number of beta rays imitted by the oucond me:mber of the chain. 
Multisection Siossten Data

When a antisection bicaysten is to be used in the calculations, the bicasten specification wust be ande vith each dece / chain. output is Frinted for eacy decas chain before proceeding to the aext chain. The card order is as follows:

Cards 1 through 6: Radiological decay chafn description as discused in previou secting in this Appendix.

Card 7:

Contents: Iuber ana weight of the biosysten sections.

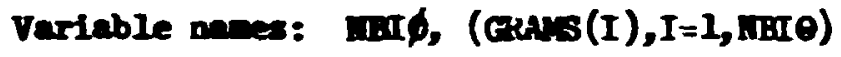

Powet: $\quad 15,677.4$

Baples: 21000.1000.

5 1000. 1000. 700. 1700. 7000.

Card3 8 through 13: Alpha, beta, and om ray energies as deccribed in cards 7 through 12 of the previous section in this Appendix.

Card 14:

Contents: The title for the biological output

Vartable nanes: (TITLB(I),I=1,18)

Formet: 1844

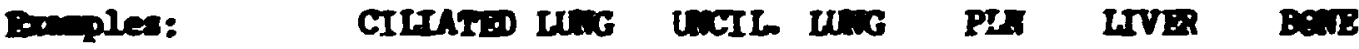

Two or nore cards:

Contents:

Blolodical section description for the first neber of the radiological recay chain. These cards hove the sane farmat as cards 2 through 5 of the previous section in this Appendix. The values of the constante are taken Tron Plg. 7 . 


\begin{tabular}{|c|c|c|c|c|c|c|}
\hline Brample: & $\begin{array}{l}1 \\
1 \\
1 \\
1 \\
2\end{array}$ & $\begin{array}{l}.10 \\
.15\end{array}$ & $.25^{2}$ & $\begin{array}{l}\text { E-51. } \\
.04 \\
.5^{\prime}\end{array}$ & $\begin{array}{l}E-5 \\
.03 \\
.42\end{array}$ & $\begin{array}{r}1 .:- \\
500 . \\
100 . \\
92 . \\
200 .\end{array}$ \\
\hline
\end{tabular}

Two or more cards:

Contents:

Bxample:

Contents:

Two or more cards:

Two or more cards:
Biological section description for the second member of the radiological jecay chain. These carcs have the same format as cards 2 thro'igh 5 of the previous section in this Appendix. The values of the constints are taken from Fig. 7 .

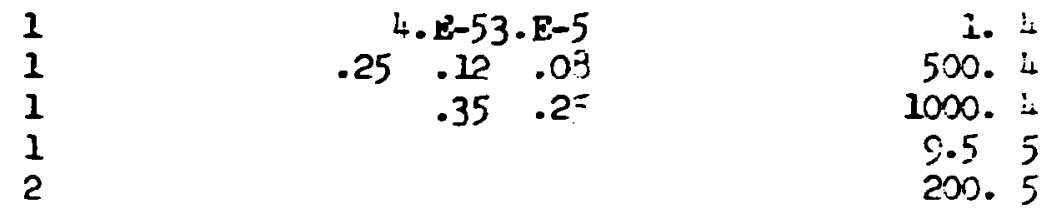

Banple:

Contents:

Exalple:

Last card:

Contenta:

Pormt:
Biological section description for the third nember of the radiological decay shain. These cards have the same format as cards 2 through 5 of the previous section in this Appendix. Tt: values of the constants are taken from Fig.?.

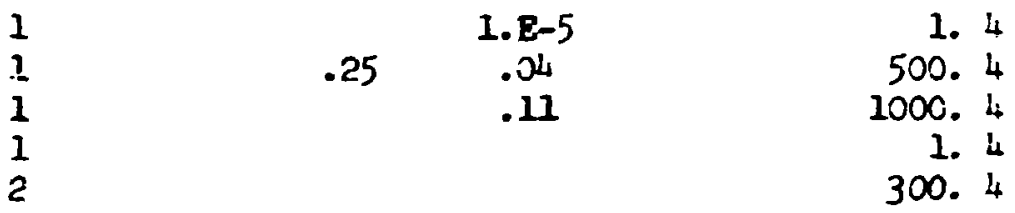

Biological section description for the fourth member of the radiological decay chain. These cards have the same formet as cards 2 througt 5 of the previous section in this Appendix. The values of the constants are taken Trom Pig. 7 .
1

1

1

1

2
$.5 B-55 \cdot B-5$
$.25 \quad .02 \quad .15$
$.05 \quad .45$

1. 4 50.). 4 1000.4 150. 5 200. 5 
u-235 decay imain data

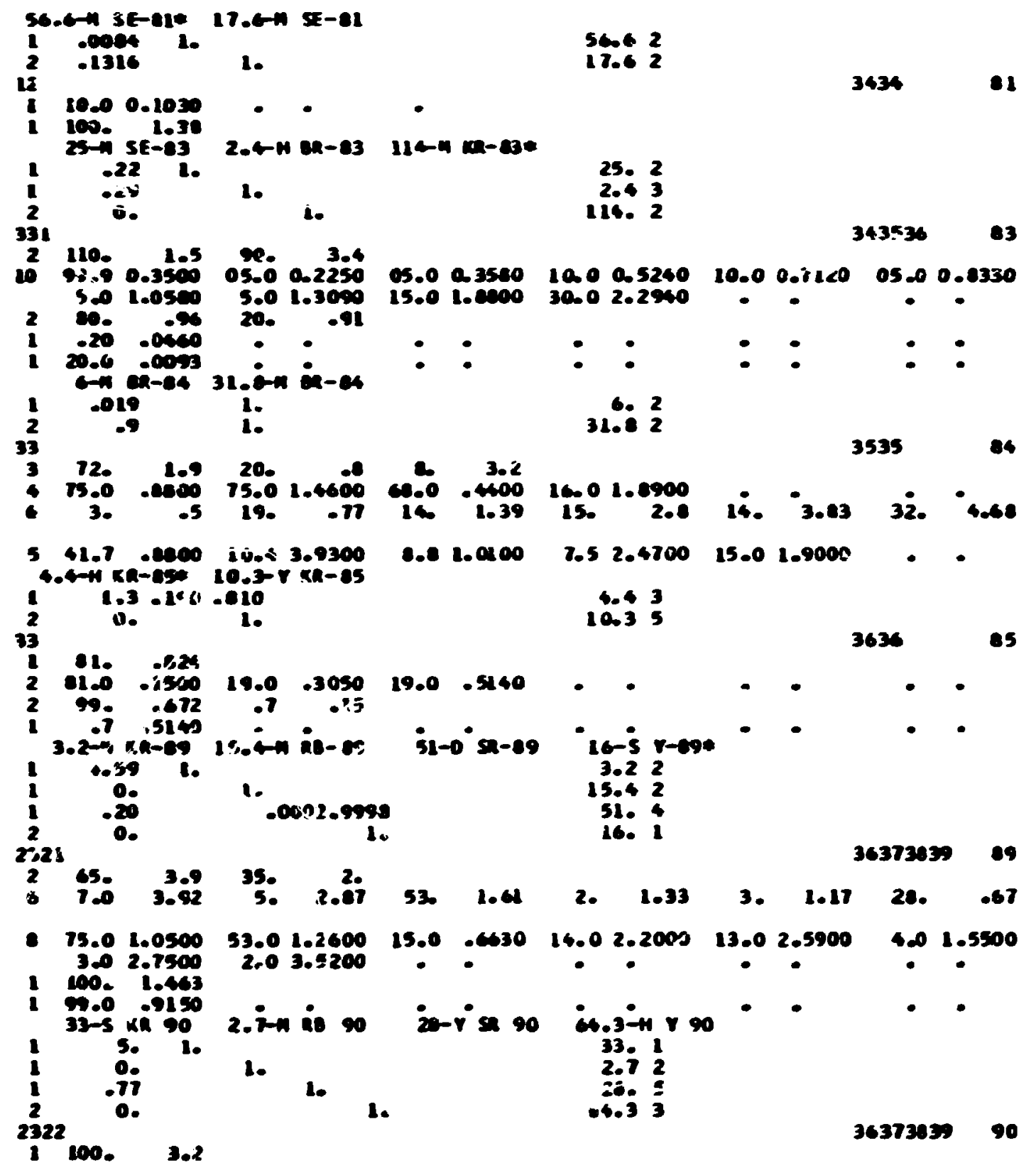




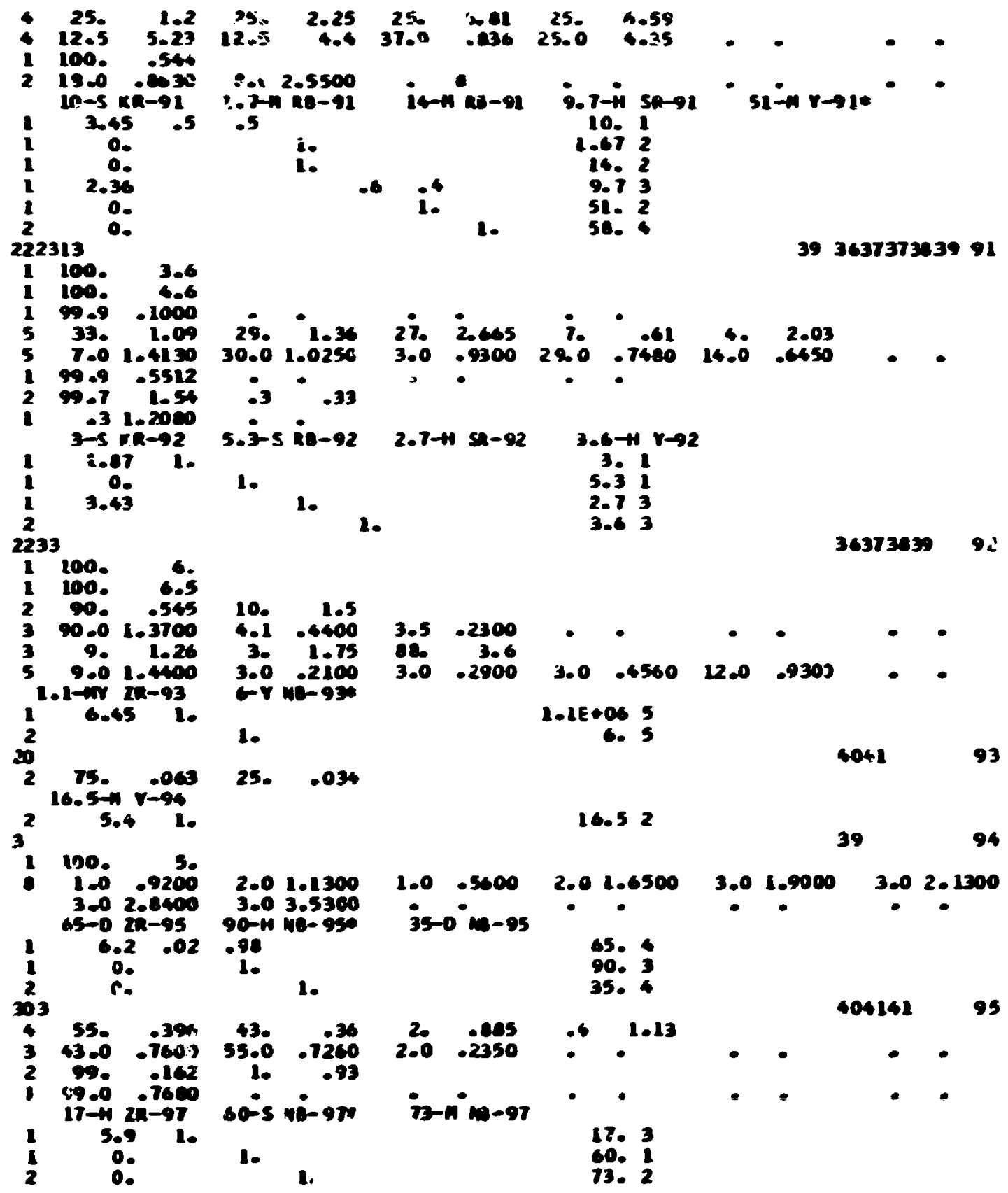




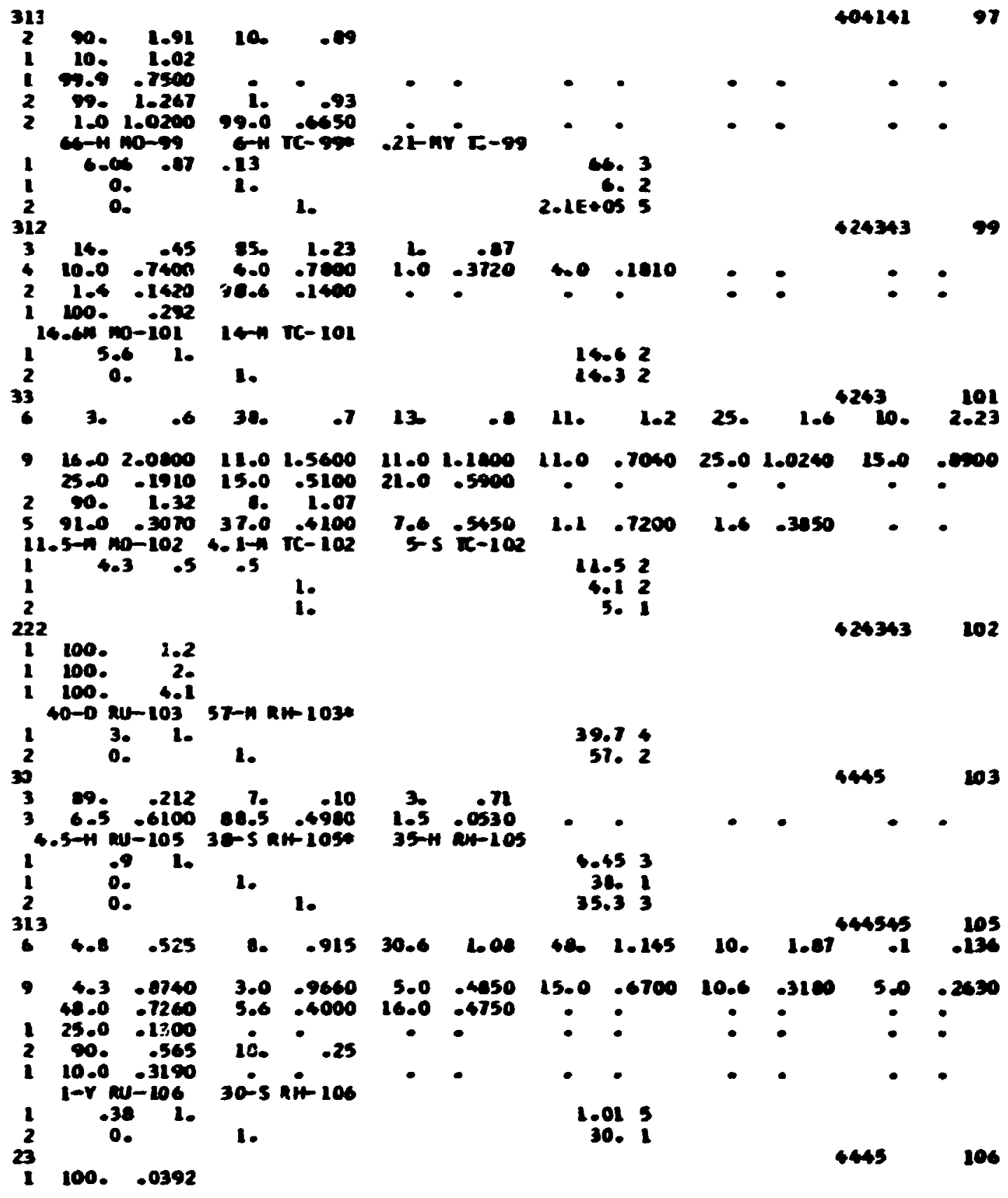




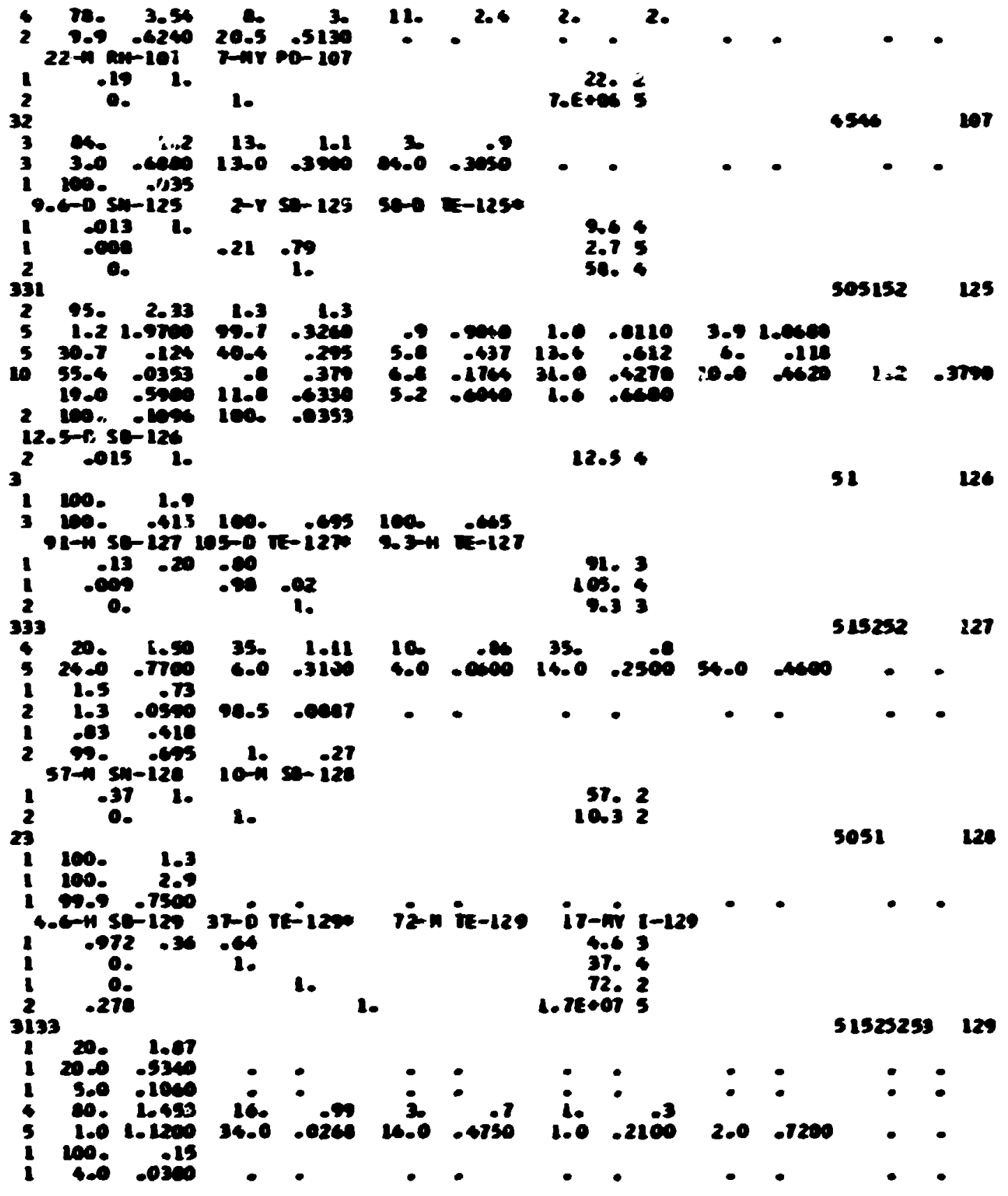




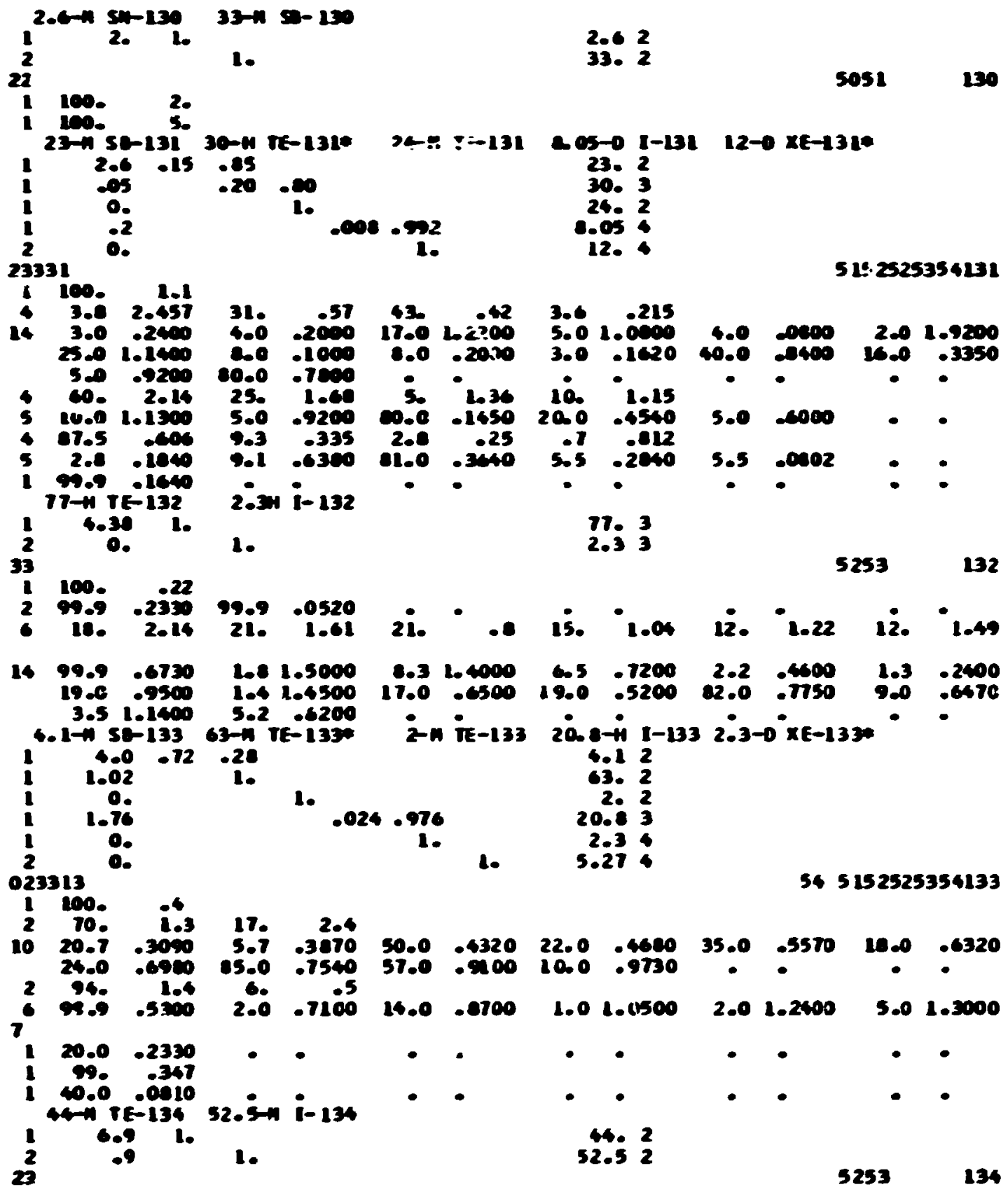




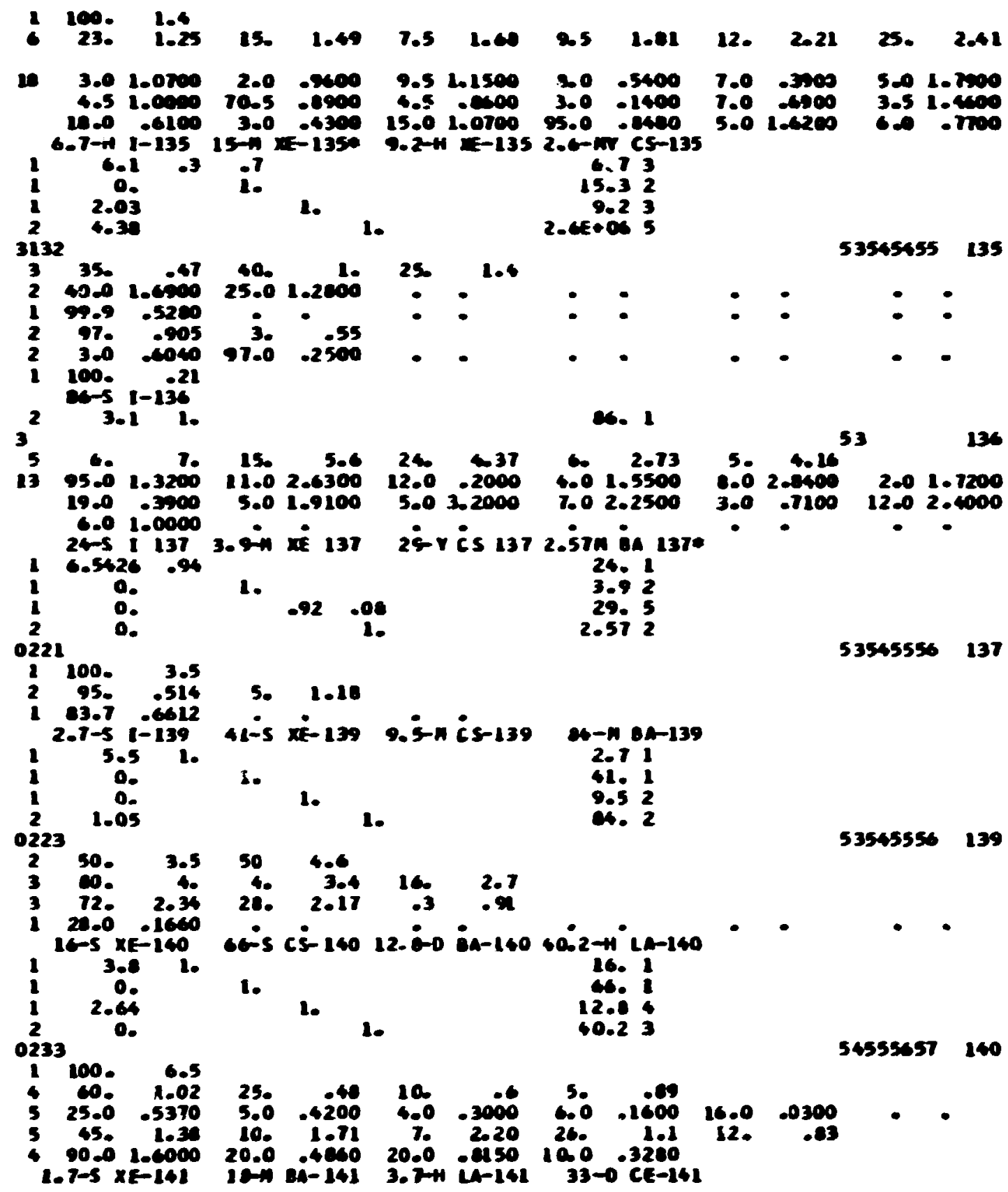




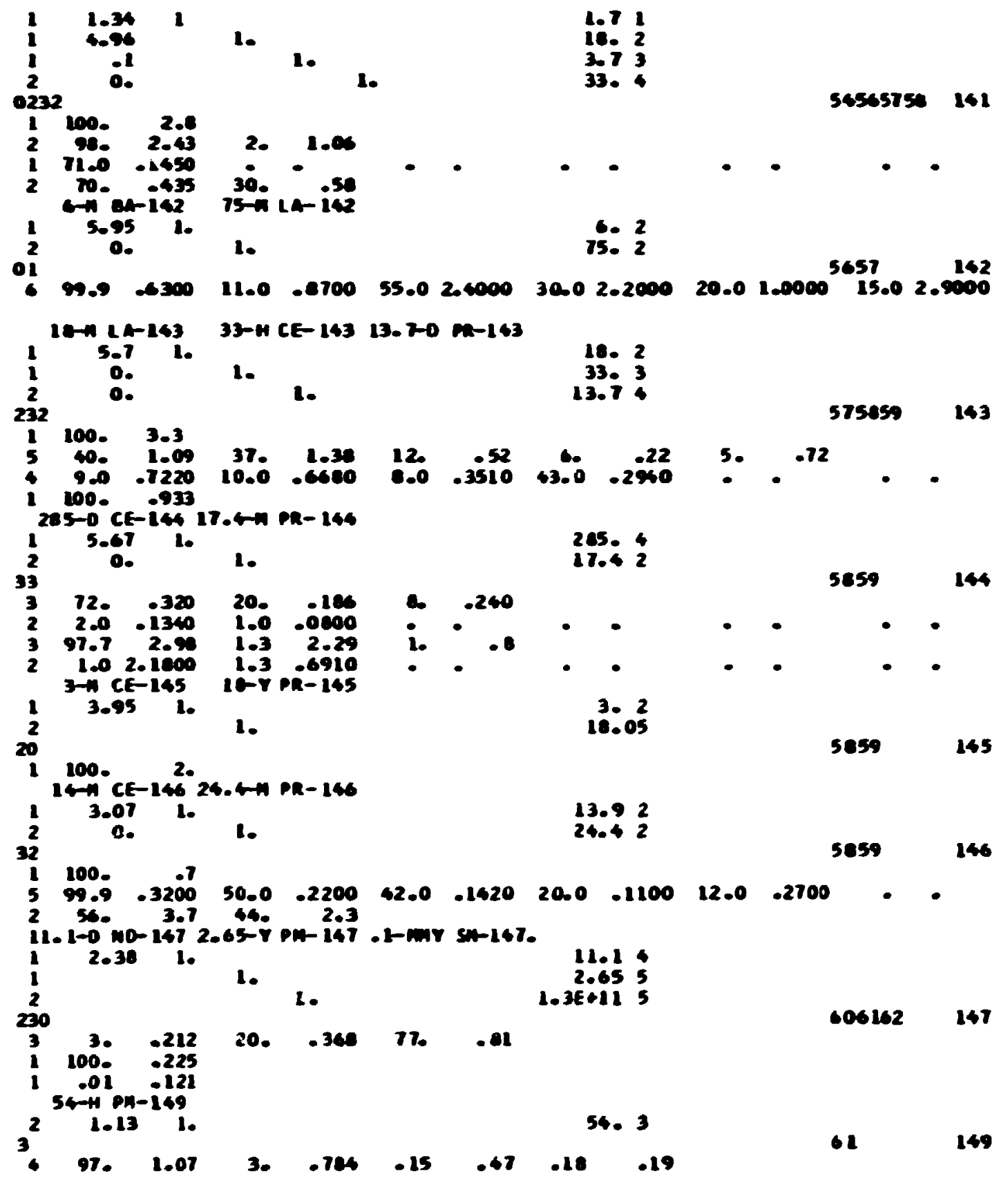




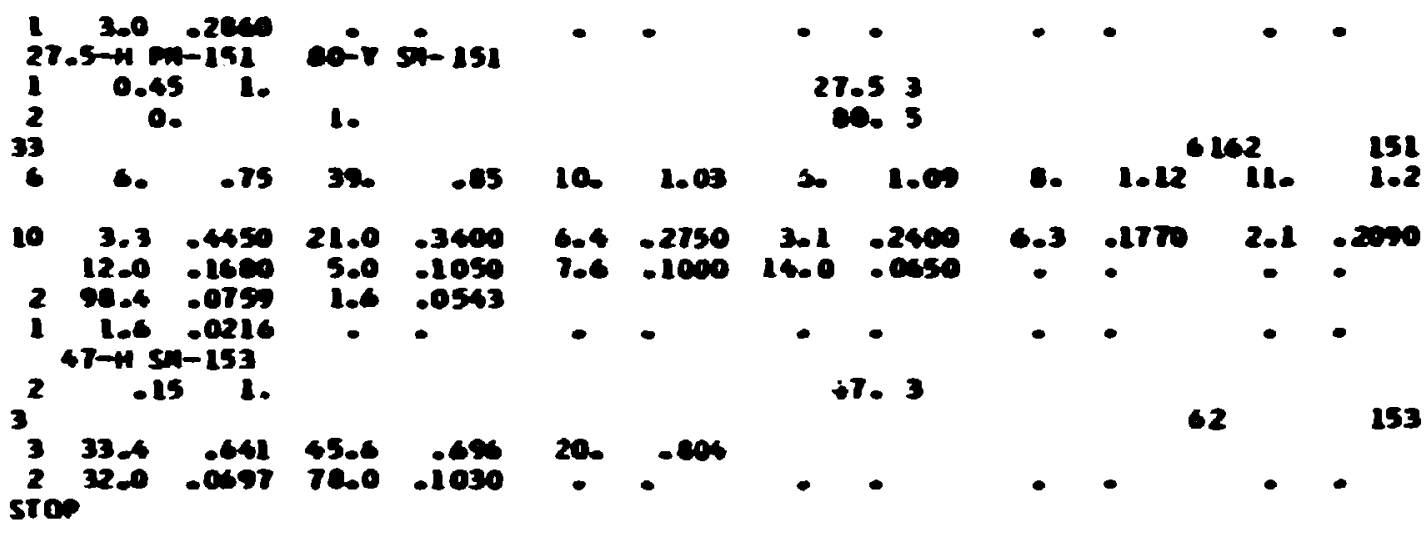


APPEIDIX D

COYPLESE IISTING OF YIEIDS CODE
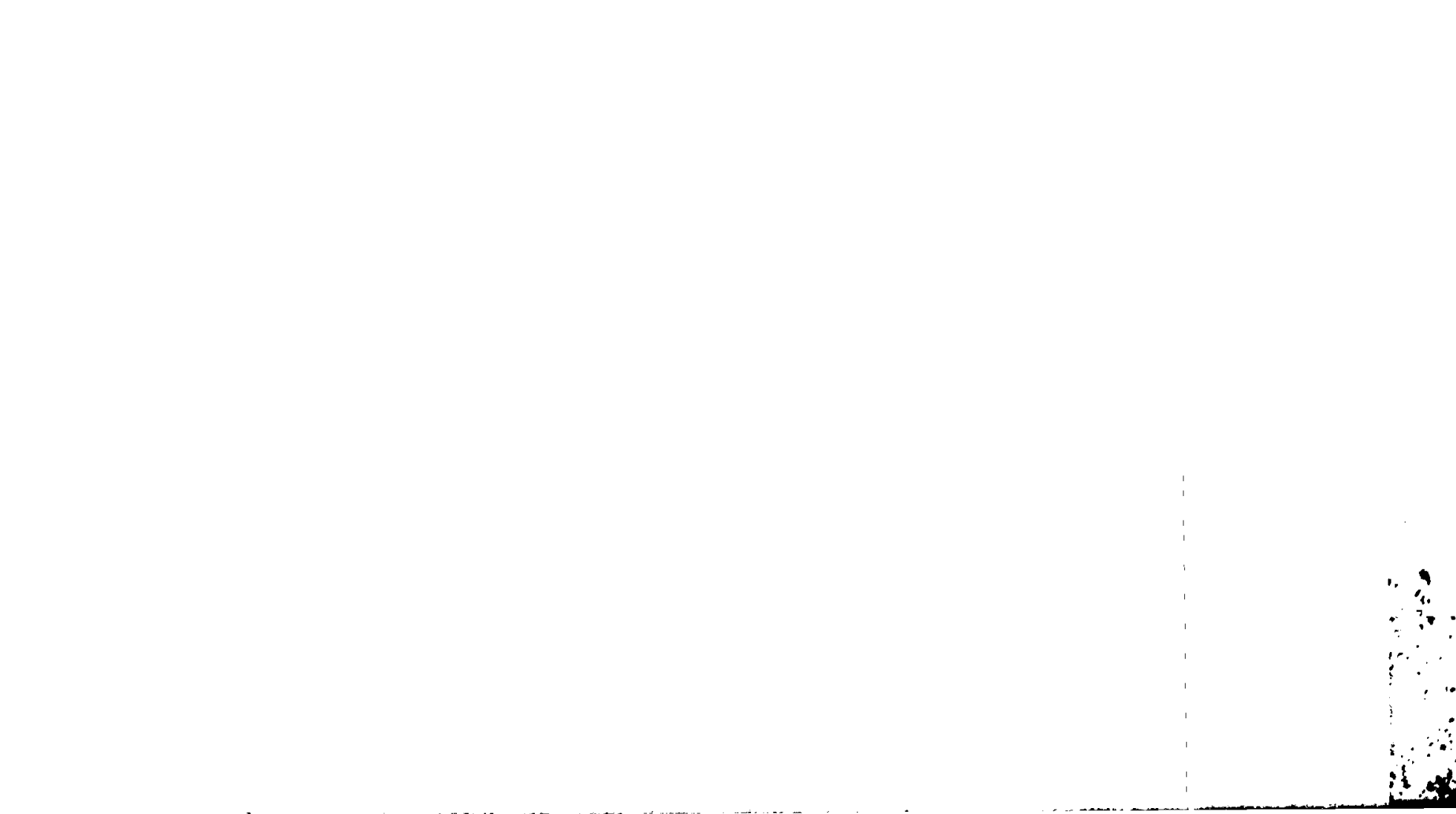
comon CAmaze u(s). In

coman inct IVIN ACTIT 6.1009

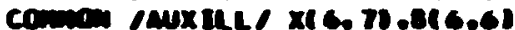

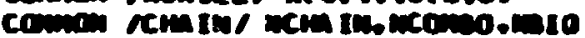

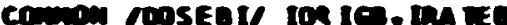

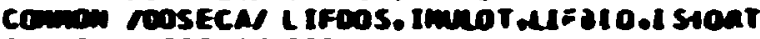

comain REEES WO EEE

crmom GEXTRA WIT. IDINCM

comom censugte gis.cunst 6

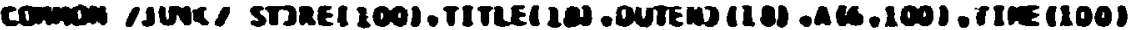

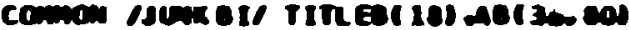

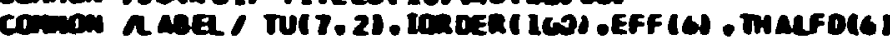

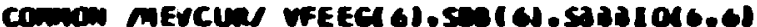

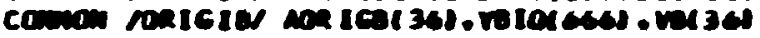

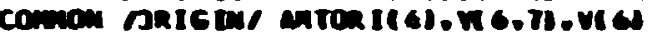

Conch Mates/ al s). ITICI ios

comon melost/ reoni $3 \times 1$

comor MEEATI IRPT

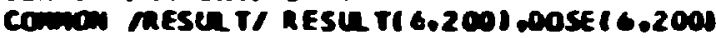

COMNOW MPERMI MAH.ERI 201 ARMCF TI 201

comou ISE Ex/ IGATA. IREAC ol TAMm, I WEAP

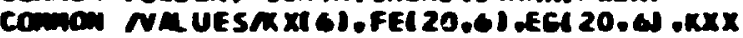

comon rstene/ rste.

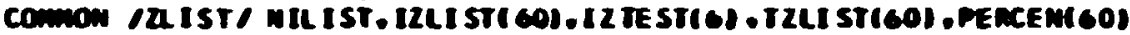

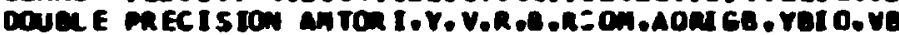

I=I

ReTun

Exo

andor 10

Anow 20

Alcons 30

Areas ac

Atow 50

aroos 60

alood 70

aroos 20

Aloor 50

AIO0 100

AIO0 110

LIDO 120

Arod 130

Alog 140

AI00 150

Amo 100

AIBo 170

A100 180

A100 190

a100 200

A100 210

A100 220

A100 230

AroD 240

AIDO 250

AlOD 250

A100 270

$A 100280$

A100 290

onocan riegrs

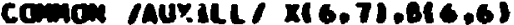

Coman IAANDZ/ I216). IA

Conmon saCtivis aCt IV 6,1001

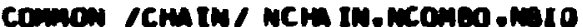

common roOsEeI/ ton ICS. IRA TEB

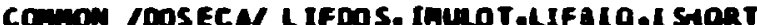

COMnON JEEESTO/ EEE

Comion TEXTRA NIT. IPUNCN

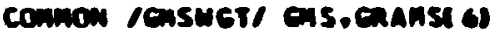

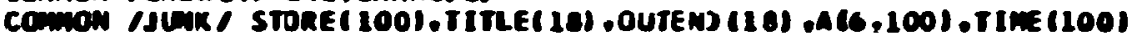

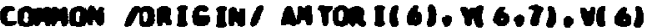

Comos matest Ris). ITICI 108

Comow MEPEAT BRP'

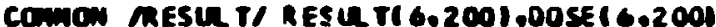

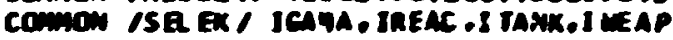

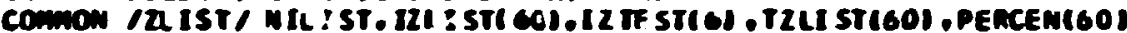

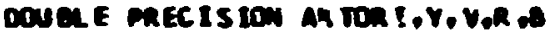

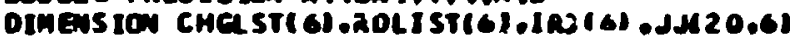

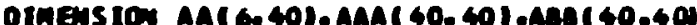

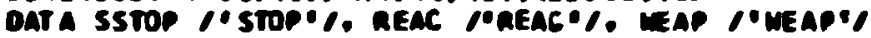

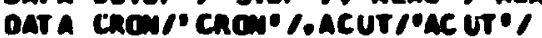




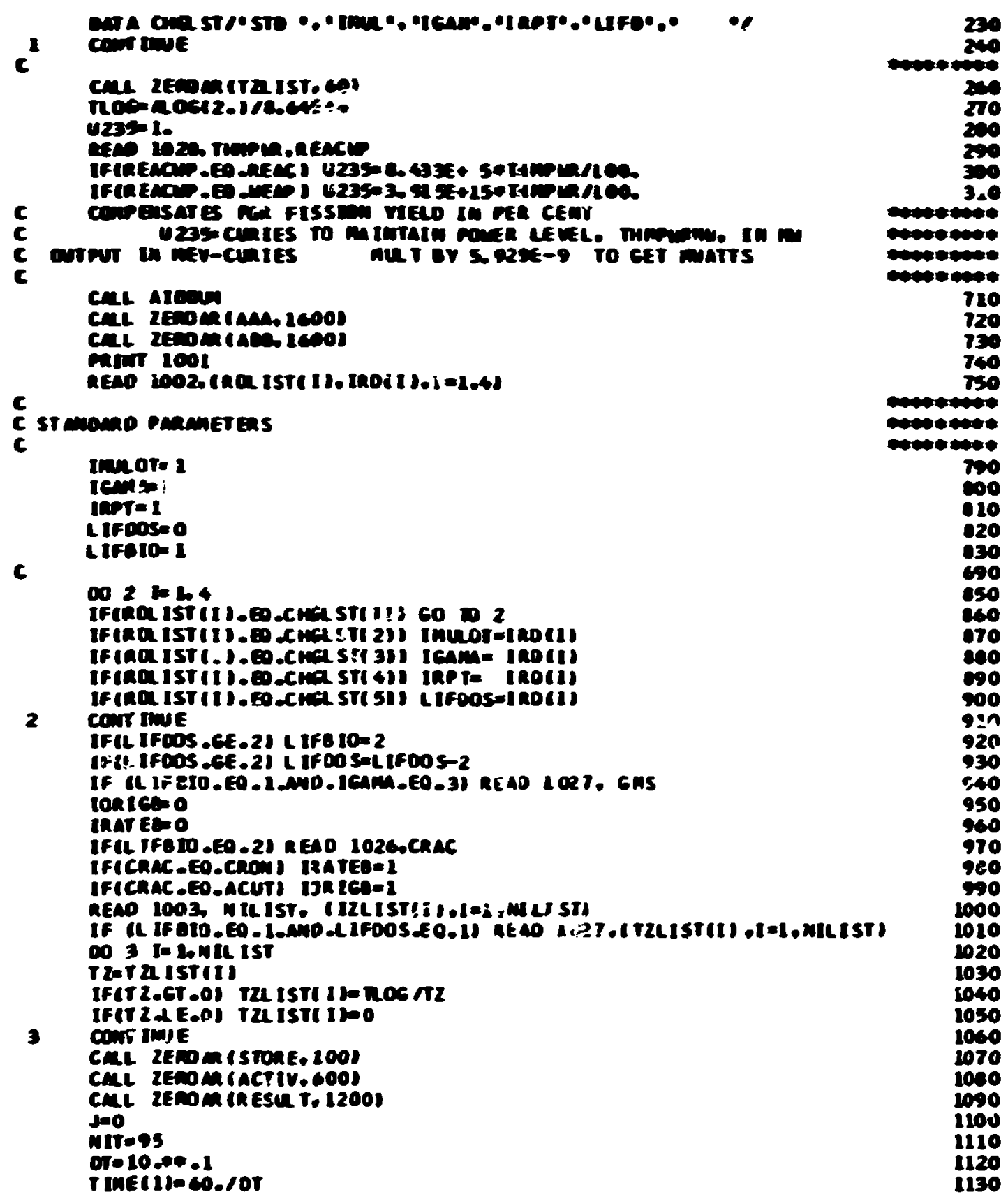


aIt Iment +1

Co betr I

116

IIs0

- Tmetiociet matime

IIs Inucione

:

T=3.153ect?

T3estot

TIAT33.

T22.0.18

5 construe

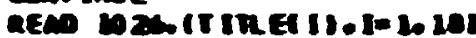

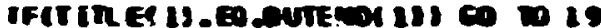

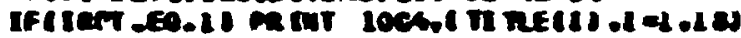

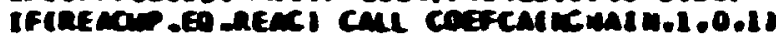

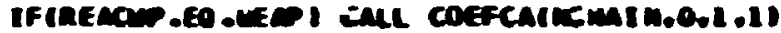

CML ZEDOMIIRTEST - 61

$122 E 5 T=0$

or $: x=2$ ncua

of 7 Lavil ist

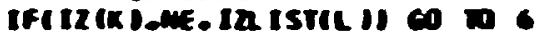

IITESIK IRL

IRZEST=1

co 00

- cont Ime

Com IDUE

cont tuve

IFIIZZEST -EO - O AMD. InP T LO - 10 MUMT 1005

IFIRILEST - EO.OLNOALIFOOS_EO. 11 SO TO 5

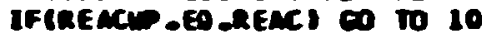

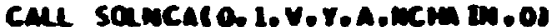

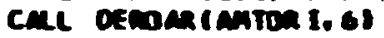

co 9 re 1. ncm en

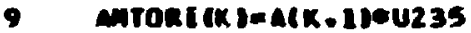

co 1012

10 Call solncalt1.1.8. 7.A.tCmim.08

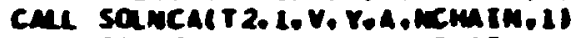

CML soLvCAIT3,1,V, Y,A.MEMIM, 20

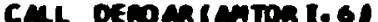

$j=j+2$

DO $11 \mathrm{~K}=1$. MCHATH

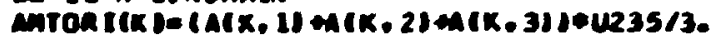

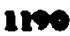

120

1210

$12 \times$

1250

1260

1250

1260

170

120

1200

1300

1310

1320

1320

1340

1350

1300

1370

1300

1340

1600

1410

1420

1430

2440

1450

1400

1470

1600

1400

IS00

1510

1520

1530

1540

1550

1500

1570

CMI COEFCAINCM IH, 0.2.08

IFITITEI II.EOLOUTENDIII c0 TO 19

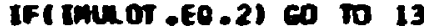

CALL soluAnI 1. 11

co to 5

13 cont Imue

0016 IT $=3.39$

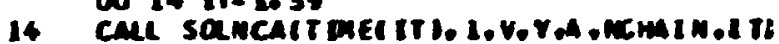

1590

1000

1610

1620

1630

140

$0015 \mathrm{~K}=\mathrm{L}$. NCHATH

AACK, If = INTOR ICR)

015 IT: 2,40

15 MAIK. IT FAIR. IT)

D 18 IT 1040

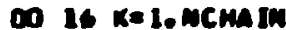

1670

1680

1400 


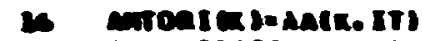

1700

chl coffenincmin.0.200 1710

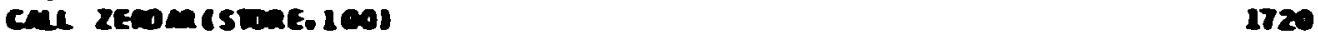

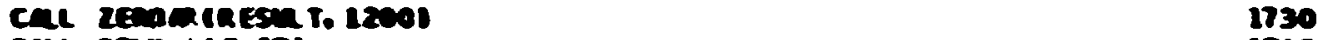

chl sonimis. ITI 1760

$0172=11.40 \quad 1750$

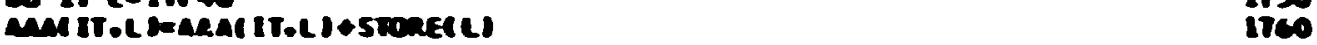

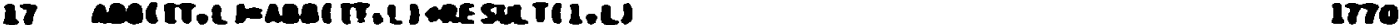

10 Cot ine 1700

$00 \mathrm{~s} 5 \mathrm{irs}$

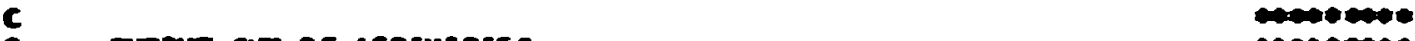

c ortert sn of activities

15 cost tive 1030

If

$0020 \mathrm{~L}=1.001050$

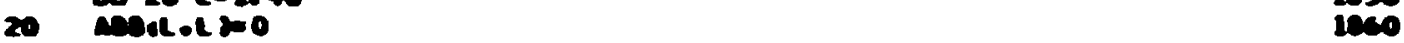

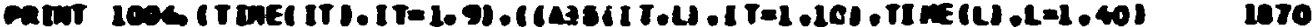

$0021 \mathrm{n=2.4} \quad 1000$

IT 21007

IT4 IT $2-1$

IT 12 IT 20

$T 3=\pi-1$

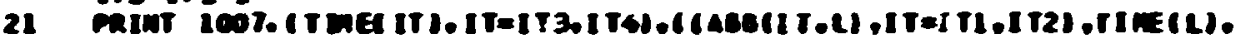
$r=1.401$

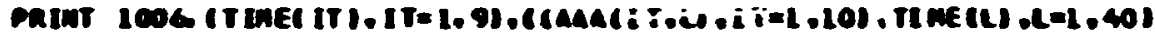
$0022 n=2.4$

IT $2=1000$

IT 4 IT 2-1

ITI IT $2-9$

IT 3 IT 1-1

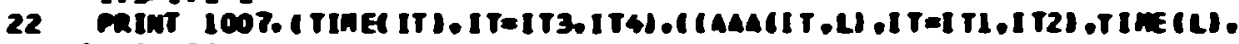
$\mu=1.0101$

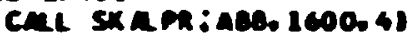

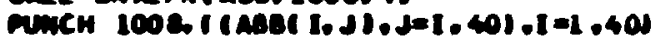

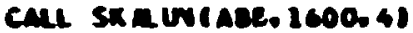

CALl singriam, 1600, 41

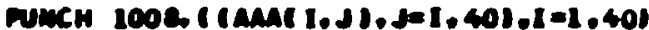

cme sx nut AaA. 1600. 41

23 CONT INUE

0024 I= 2. IILIST

IFITZLISTELINE.01 RLISTII=TLE/TZLISTEI 2090

24 COMT TMUE

IF (InULOT.EO-21 Cro 27

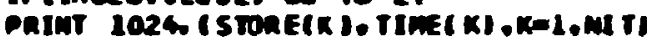

100

1000

1910

1920

1930

1931

1960

1950

12e0

1970

1900

1990

2000

2001

2010

2020

2030

2040

2050

2060

2070

2110

2120

2130

Do $26 x=1.411$

IFISTONE(K) DUE.01 CO TO 25

RESI T $(1, K)=0$

2140

2150

CO TO 26

25 cont inve

26 cont IMUE

27 REAO 1026.1TITE(1), I=1.103

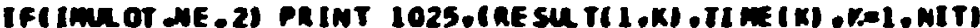

2160

2170

2180

2190

2200

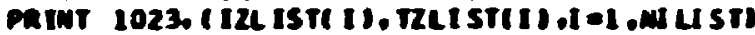

2210

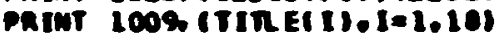

2220

IF IInUL OT .EO. II PA INT 1010

2230 


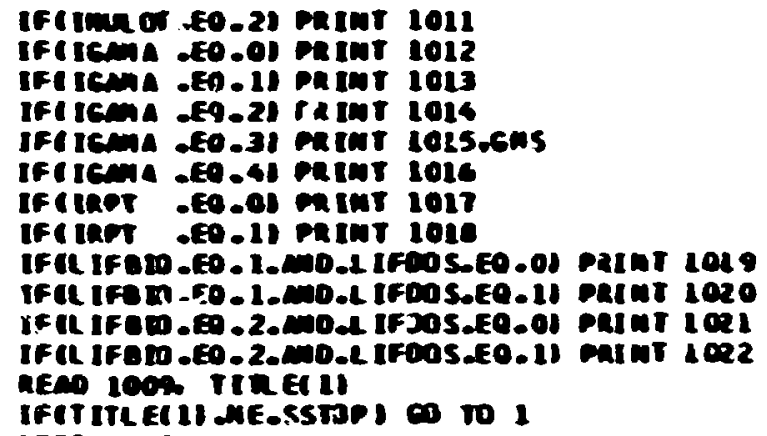

2600

2470

2480

2490

2500

2510

2520

2530

2531

2540

2550

2560

2570

2580

2590

2600

2601

2610

2311

2620

2621

2622

2630

2631

2632

2633

2640

2050

2650

2570 


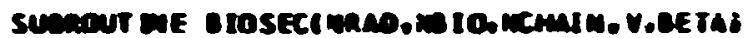

$\operatorname{agns} 10$

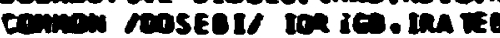

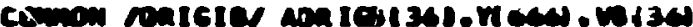

comper metoste rounl sol

olmension vi10. CETA110

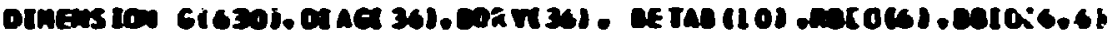

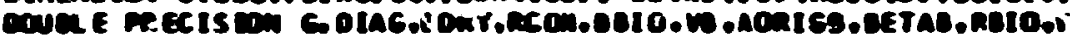

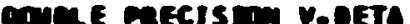

outa maICo, 0/. Dhatea/ll

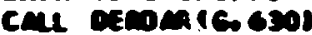

cent oencinom. 3si

cal areom (nerob)

coll atomimie. 341

co 5 te loma

in $1-1$

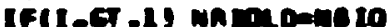

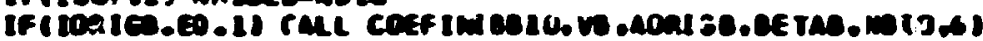

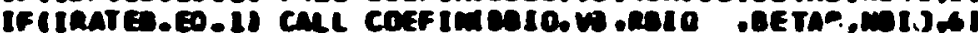

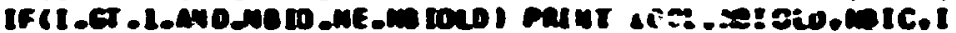

$\cos 20$

erose 30

Drose 40

stose 50

ams e

oros E 70

CLos E 0

CIOS E 0

eros 200

eros 110

CIIS 120

eras 130

IIOS 140

eicos 100

0105140

eros 170

cros: iso

190

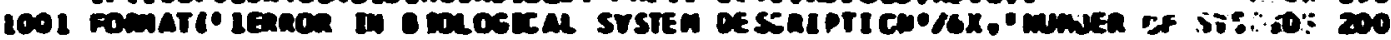

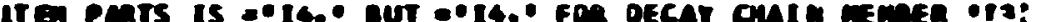
raco ilewero

inotis is $11-21 / 2$

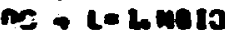

Re Inoon

$x \cos x+(x-1) 12$

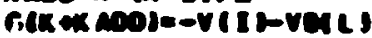

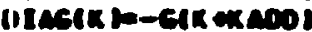

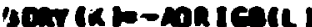

ecen (Kis-nglore :

$4=1-1$

LACLLL $\bullet(L-2) 12$

IFILEE.L I 00 TS 2

OC $1 \mathrm{mat} 2$

jenticioo

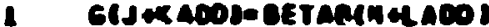

2 IFIt.EO.1, of is

$\infty 3+211$

wets-1mein

conex AoDle oetral delacons

constinge

com Inve

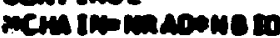

or te bmema

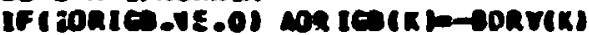

- rein bopinates

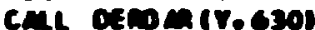

Do 7 blomemarin

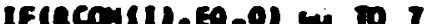

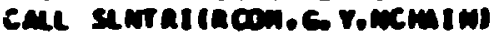

coto

7 contine

- cont iseconresiori 28

010 gezoncms

It: I-1

-ios .210

aros 220

$\cos 2200$

orus 240

eros 250

ctos 200

eros 210

$\operatorname{ctas} 200$

ctos 220

$\cos 390$

olcs 310

elos 320

0205330

cics 340

clos 359

cras 30

ces 370

cros 300

cios 30

eris co

extos 410

cros 420

$\cos 430$

iras 400

eros 450

encs 40

cios 470

elos ape

atas 4h

ens 500

cios 510

onas 52

D 530

sios 54 


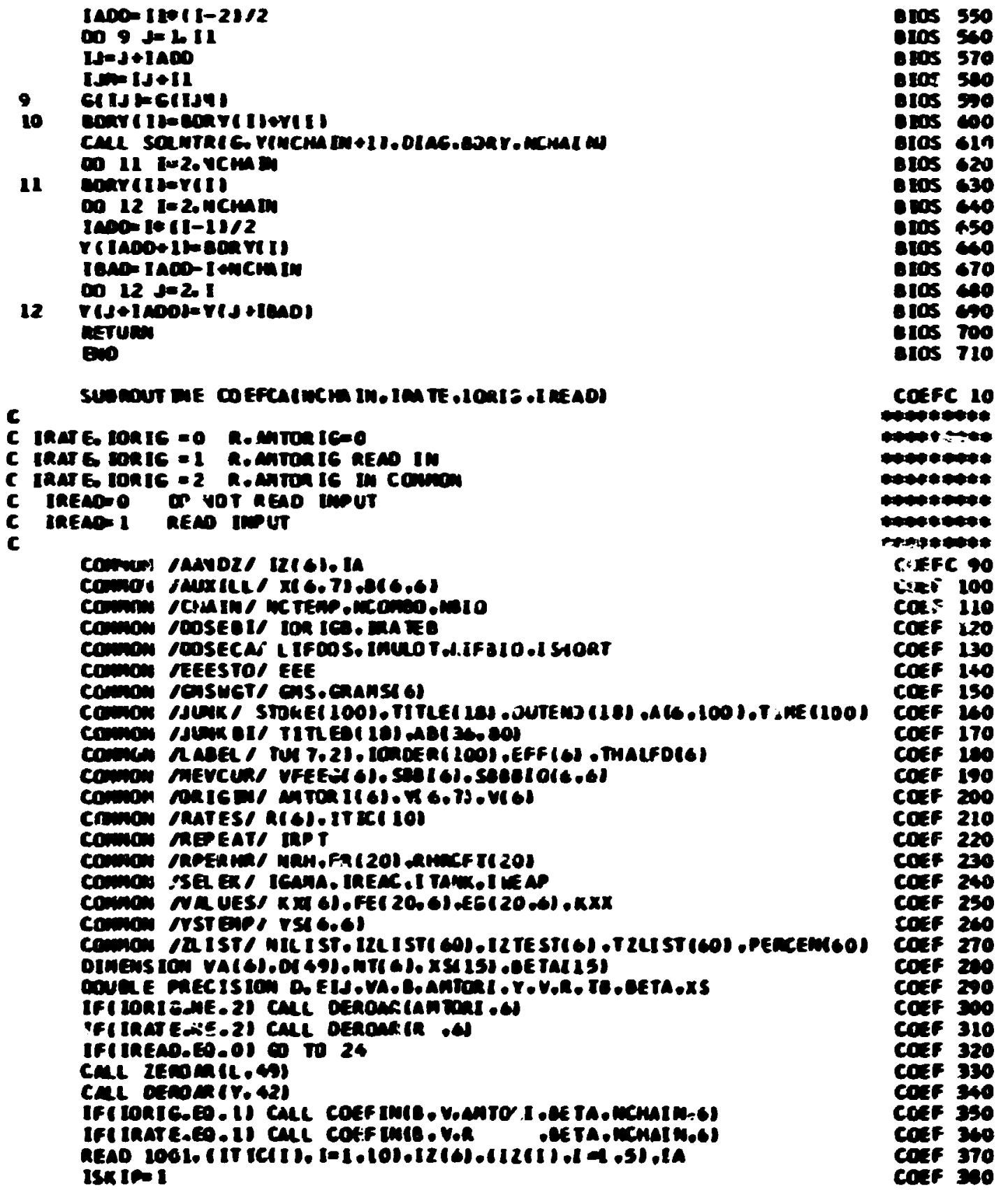




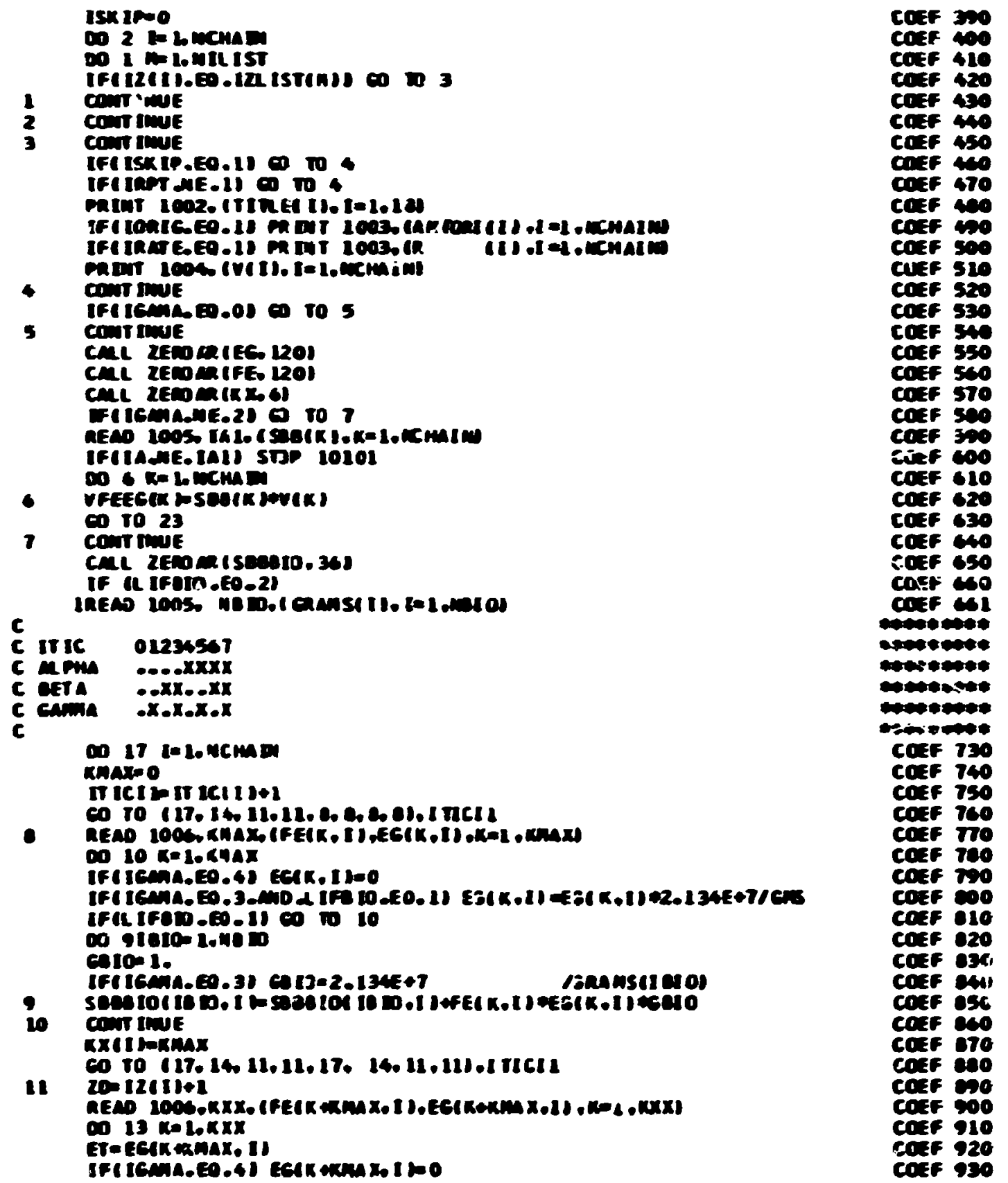




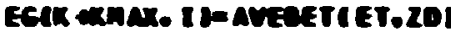

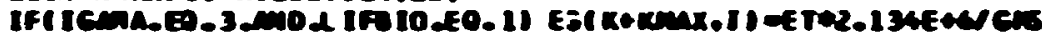

IFIL IFED-E.-11 C 1013

012101.610

corion. 1.

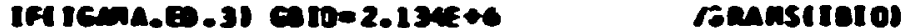

$\mathbf{2 2}$

13

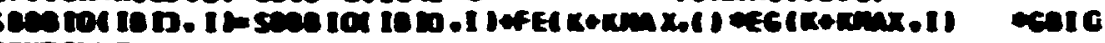
Conit IINe

CII textresnar

$\operatorname{anax}=\cos (1)$

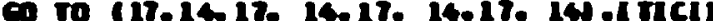

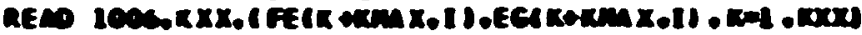

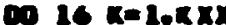

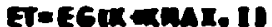

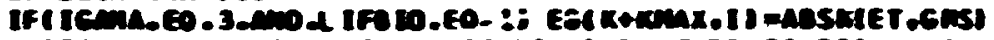

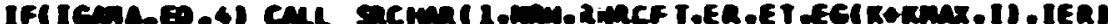

IFA IFOD . E. II Co wo 16

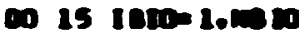

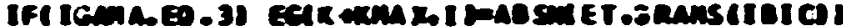

15

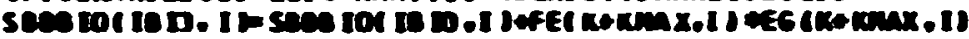

contr DUE

cxet rexxexnax

chareaxiti

17 ConT True

axixekx 110

co 10 Is Loncmin

$16 \quad \mathrm{xxpanaretkx(1),0 \times x)}$

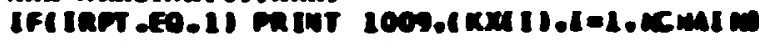

IFIIRT te.11 Mint 1013

in 19 lobkxx

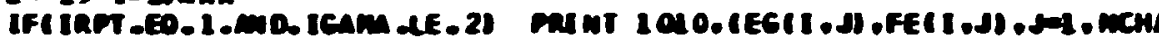
1 IIII

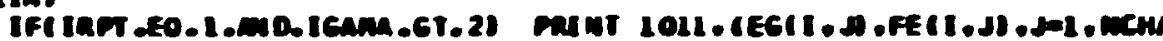
$11 \mathrm{I}$

19 cont inve

or 22 re loncuntu

sea

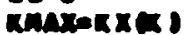

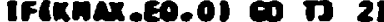

D $20 \mathrm{nh}=1 \mathrm{kmax}$

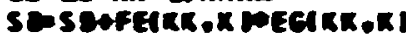

secuk te sevioo.

VFEEGIK I SE VIK $1 / 100$.

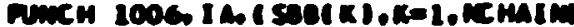

CONT INUE

IFI IAPT dUE. II CO TO 24

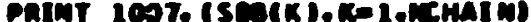

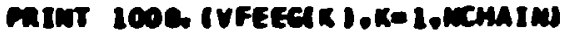

CRIsT 1012

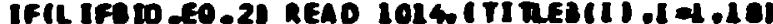

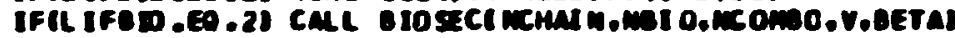

26

comtrinue

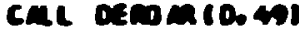

call ocenarir.42)

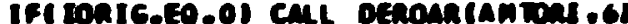

IFImate. 00 .01 To 20
COEF Sal

COFF 95

coter 20

cotero 970

care 20

coif sen

cos 100

ces 2010

cos 2020

cos nas

col mas

co 1080

cos

cos 1079

cos

cos

cot 1100

cor 1110

cos 1120

cos 1130

cos 1140

cos 1150

cos ino

cos 1170

cos 1180

cos 180

cos 200

cor 212

at 1220

cos 1230

co. 1248

coe 1250

coe 1251

$\cos 1260$

$\cos 1270$

$\cos 1200$

coc 1290

$\cos 1300$

cos 1310

cos 1320

cos 1330

$\cos 1340$

poratinace

$\cos 1360$

cos 1370

COE 1300

cos 1250

COE 1400

cos 1410

$\cos 1420$

$\cos 1430$

cos 1460

cos 1450

$\cos 1450$

cos 1470 
0025 I=1. псмит

$1000=1 \%(1-1) 12$

on 25 Je1. I

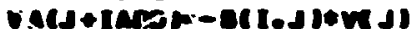

0026 je lovenatim

IfIR ill.ME. Ol 0 I0 27

26

cont the

co 102

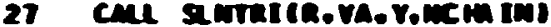

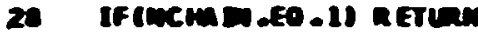

of 29 de1. incure

29 ods mis.1t-arionilds

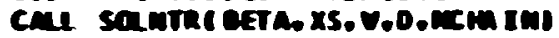

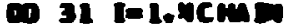

IFIL-EO.11 e0 wo 31

1E- I-1

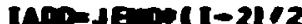

co 39 J LodENo

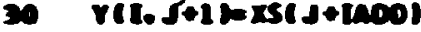

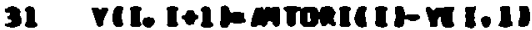

CTTUn:

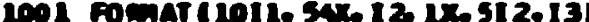

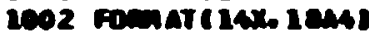

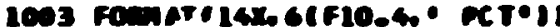

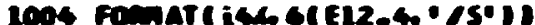

ICOS Fomati I5, GF 7.4)

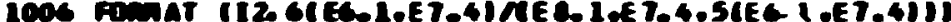

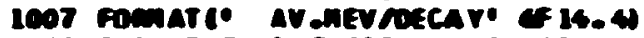

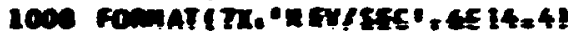

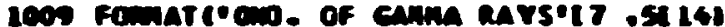

1010 Fomat I 1650 C1F7.40F7.118

1012 Fomat (145, 12F7.11

1012 Fomat $(2 \mathrm{k})$

1013 fomatc16x.

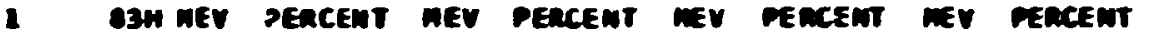
2EV PECET

1014 Fomatciens

end neV Pencent

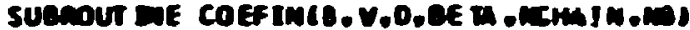

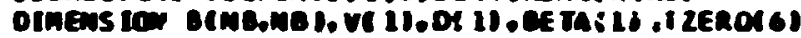

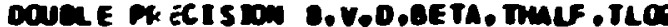

TLOC acos 12.001

CMI $x \in 0$ Miv. 61

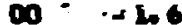

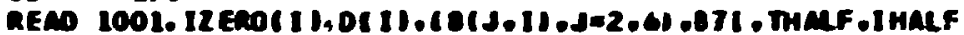
NCuAIK =

Co To (C,2,3,4,5). ImLF

2 THMFETMEF 60.00

CO TO 6

3 THM F-Tun F* 2600.00

CO TO

- THM FeTMLFA 06400.00

Co 10

5 THMF=THAF 3.1536707

Co To
CoE 1400

cos 1490

coc 1500

COE 1510

$\cos 1520$

cot 1530

$\cos 1540$

CoE 1550

$\cos 1500$

cos 1570

cos isao

COE 1500

cot 1600

Cos 1510

cos 1620

cos 1030

cos 1000

cos 1050

cos 1400

cos 1570

cot weo

coe 1 coso

cos 1700

cos 1710

cos 1720

cos 1730

Co. 1760

cor 1750

cat 1700

COE 1770

coc 1700

CoE $17 x$

CoE 1000

coe isin

coe 1121

COE 1012

cos 1220

CoE 1030

COEFI 10

coefI 20

cosfl 30

cokfl 4

coffl 150

COEFI 60

cotf 170

COEFI 100

COEFI 90

cotf 100

COEF 110

COEF 120

cozf 130

cosf 140

corf 150

COFF 160

cosf 170 


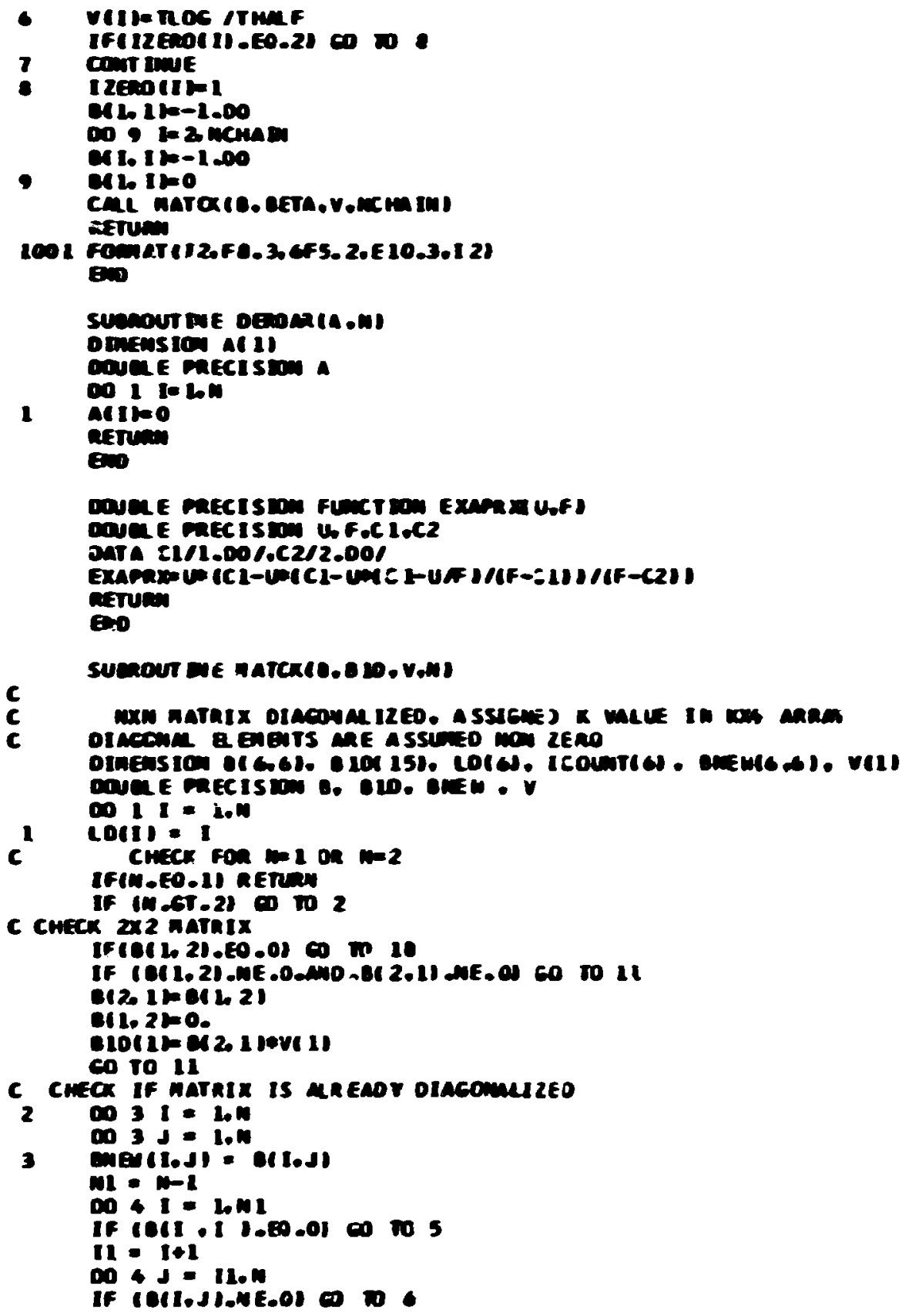

CoEF 100

cose 190

cosf 200

COEF 210

COEF 220

cosf 230

cosf 240

coef 250

CoEF 200

coEf 270

COEF 200

cote 200

canon 10

ocian 20

cenon 30

cecion 4

cenoa so

cenos 0

cenos 70

10
20
30
6
50
6

nerca 10

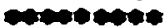

- coverene

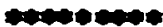

arca 10

ince 50

merce 40

NITCK 70

nomerente

mercx 90

nerc 100

arecente

$\operatorname{mic} 120$

arde 130

Are 140

Anc 150

nare 160

$\operatorname{mic} 170$

-inote

mate 190

nats 200

ante 210

nerc 220

metc 230

nare 260

mate 230

mire 200

nive 270 


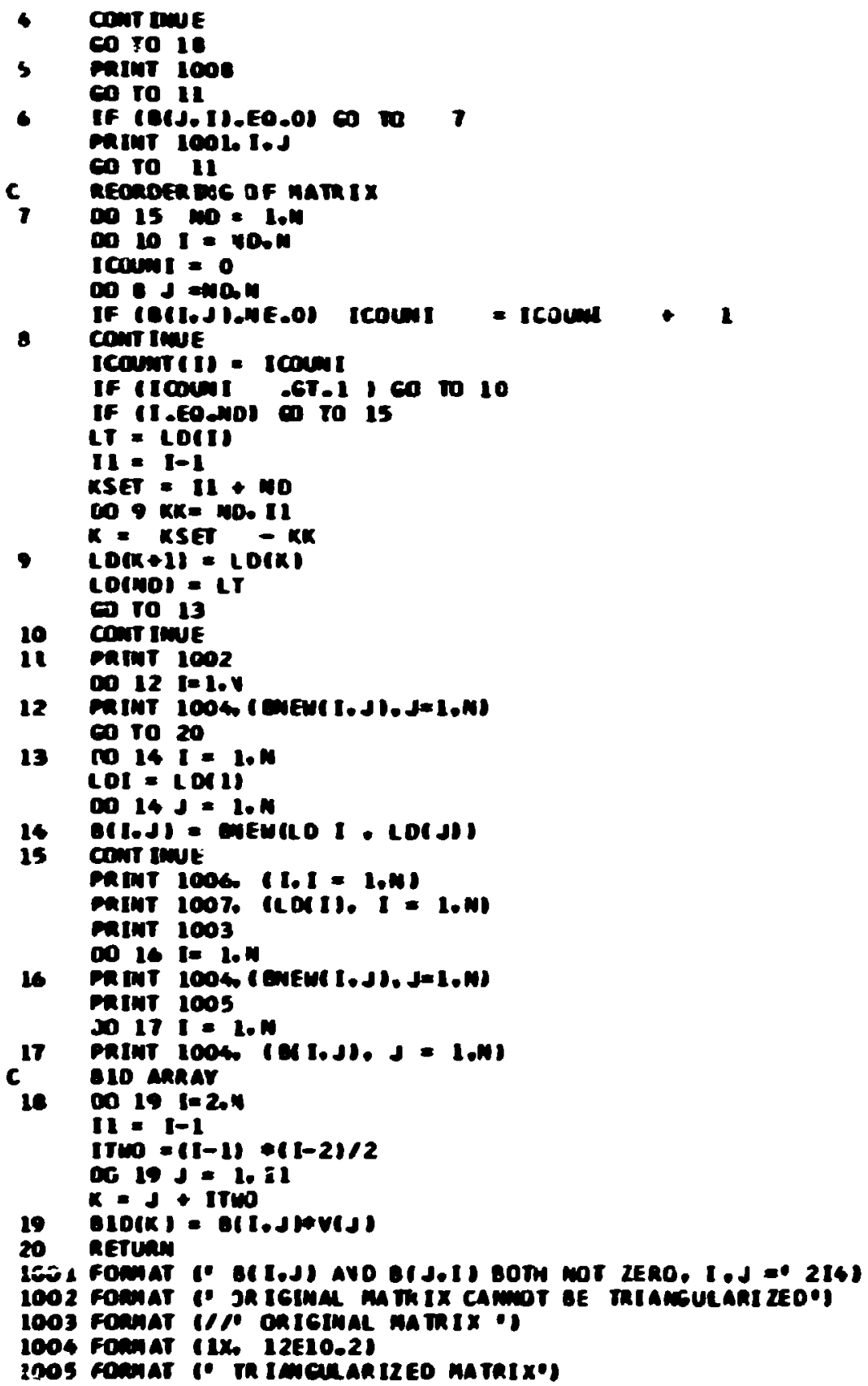

marc 200

Mre 290 MTC 300 MC 310 Marc 320 nexc 330 MuC 340 - materea nerc 300 matc 370 $\operatorname{nec} 390$ Murc 390 Aatc 400 $\operatorname{mic} 410$ merc 420 matc 430 $\operatorname{mat} C 40$ $\operatorname{mat} 450$ $\operatorname{mat} c$ narc 470 $\operatorname{matc}$ weo arte 400 nate 500 me 510 $\operatorname{marc} 520$ anc 530 Mirc 540 Merc 550 mire seo जarc 570 Mrac 580 marc 590 matc 600 marc 610 marc 620 anc 63 ? Mre 40 Mitc $\$ 50$ matc 680 matc 670 matc 600 mirc 690 mirc 700

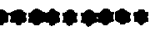
mere 720 matc 730 marc 760 nerc 750 nare 760 me 770 matc 780 marc 790 matc 600 जar C 810 narc 820 mate 530 


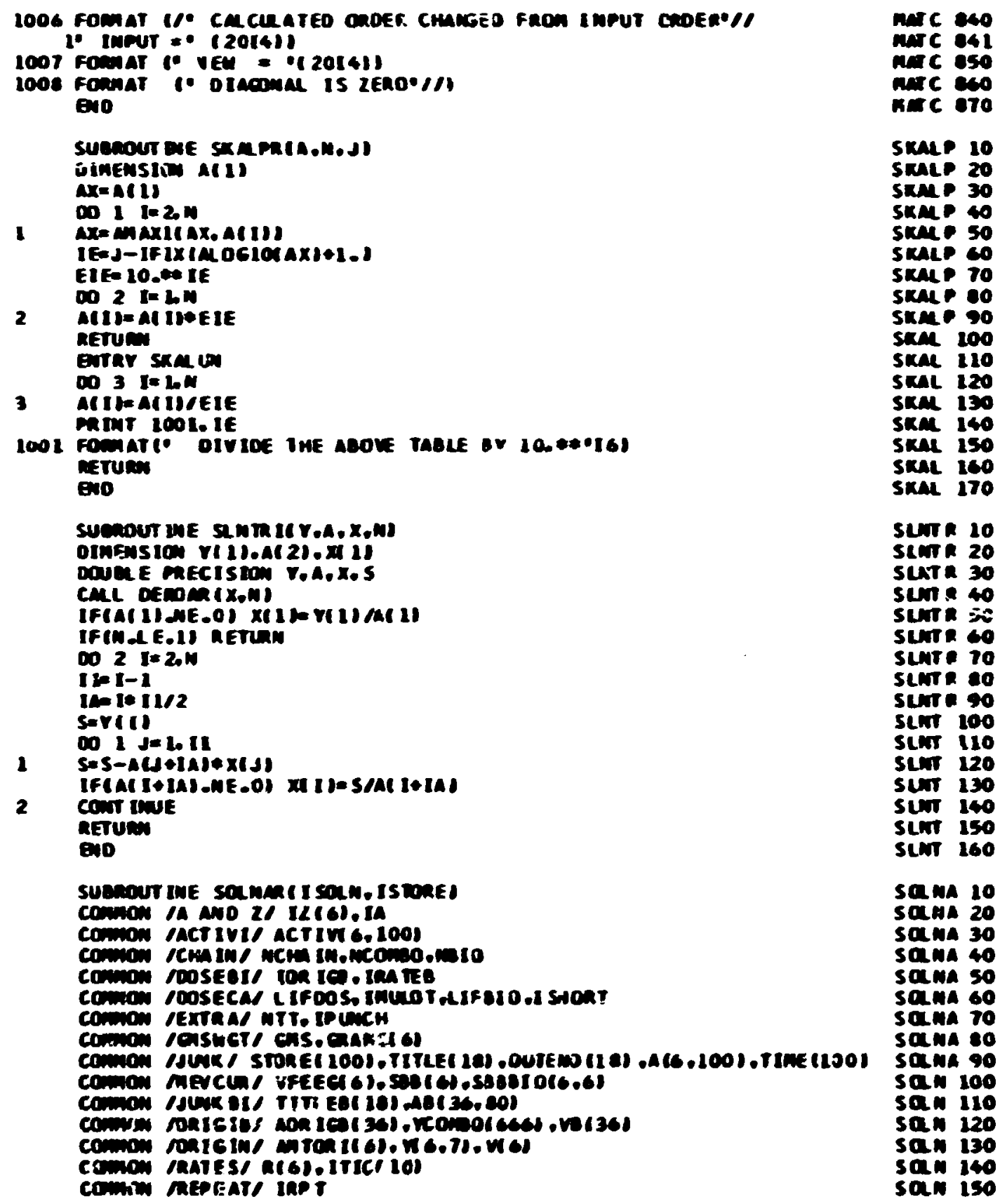




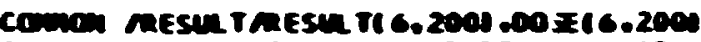

$\operatorname{sen} 100$

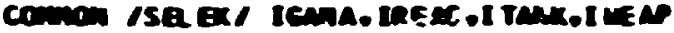

$\operatorname{sen} 170$

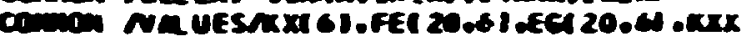

$\operatorname{san} 100$

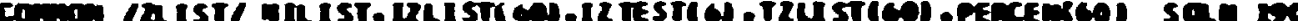

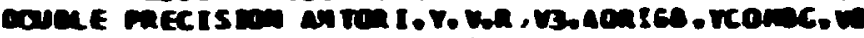

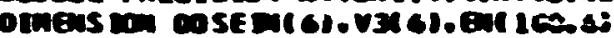

aITants

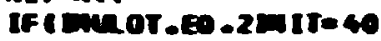

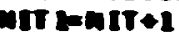

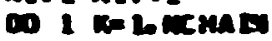

v3ets $=v a(x)$

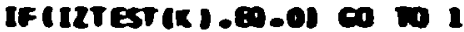

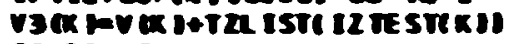

com InUe

$c=1.250025$

ins 34-278333

1

If itum or _Ee-21 neistuat

Isonterentos

If Ischinete-s) IsOLLEI

04 Itrangit

TEREITET THEC IT:

$c$

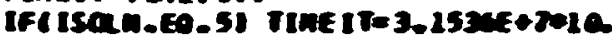

IFAL IFOOS DE- 11 es 03

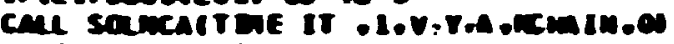

$\operatorname{sen} 20$

$\operatorname{sen} 210$

$\sin 220$

$\operatorname{sen} 20$

$\operatorname{sen} 20$

$\sin 260$

$\operatorname{sen} 260$

sean 270

$\operatorname{sen} 200$

$\operatorname{sen} 200$

san 30

sen 310

$\operatorname{sen} 320$

$\sin 330$

$\sin 360$

$\sin 3=0$

san 30

$\operatorname{san} 370$

senerese

$\operatorname{sen} 30$

$\operatorname{sen}$-an

कo 2 re Lema

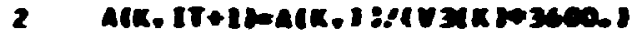

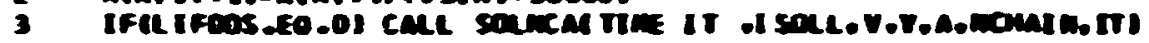

$\operatorname{san} 410$

$\operatorname{san} 420$ Do 4 te 1. mene

$\operatorname{san} 430$

MCT $N(k, I T+1) A(k, I T+1)$

sen

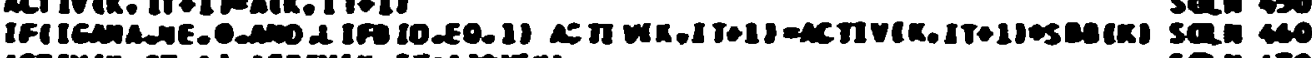

4

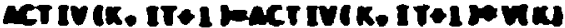

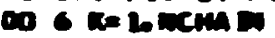

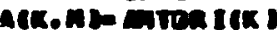

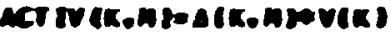

Ifilema-ge.01 of to 5

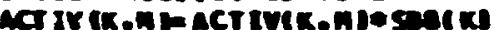

5 cont bue

- comtrinus

007 a bisum

stone (n)

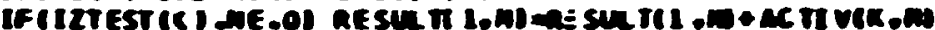

007 ITAmoIt

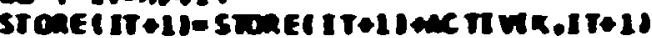

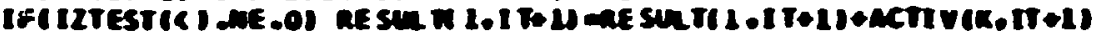

$\operatorname{sen} 470$

$\operatorname{san} 40$

$\sin 40$

san 300

san 510

$\operatorname{san} 520$

$\operatorname{sen} 530$

san sea

$\operatorname{san} 5$ so

sen sea

$\operatorname{sen}=\pi$

$\operatorname{sen} \sec$

sain 500

$\operatorname{san}$

$\operatorname{san} 610$

$\operatorname{san} 620$

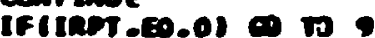

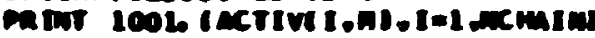

Do santit

Leje)

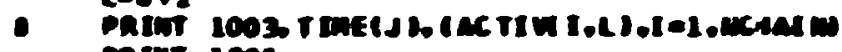

caint 1002

comis Inve

IFIL IF in ane 21 netren

TSonsode3.153et +7

$\operatorname{sen} 630$

$\sin 100$

$\sin 650$

san ces

$\operatorname{san} 670$

san

san

san $\pi$

cell zeminian zoos

san 780 


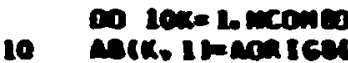

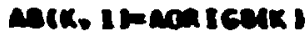

0012 ITe do 20

TIMEITET LNE( IT)

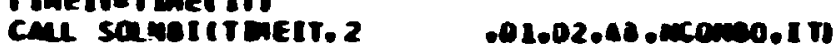

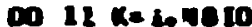

Do 11 KR= 2oncmin

te trik-1 1 anseto a

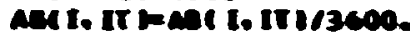

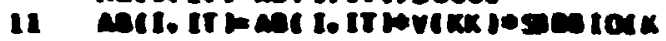

- ins evers

12 Contrue

00 is $x=1$. nсman

KSe $8 \mathrm{x}-1$ wheto

IIEr $5+1$

rars 5 wow

mint look

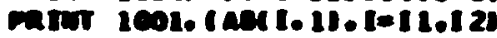

D iste 200

a ITa ACt IVIK. ITS

Ite IT: 1

13 mint 1003 tince It

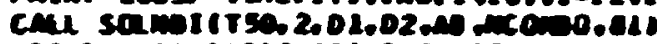

16 mant icosicact 1. C21.1011.121

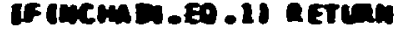

mint 100 s

$001017=2.00$

LEIT+1

as 15 is inero

or 15 kezoncurm

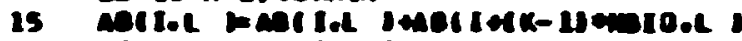

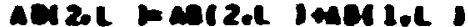

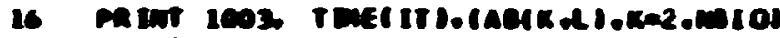
Armen

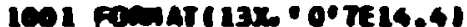

1002 romatim $/ 1$ in:

1003 gomaterso.48

190 eanatio 16. SEe 1 iensi

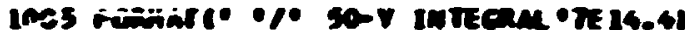

sem

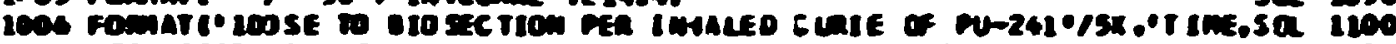

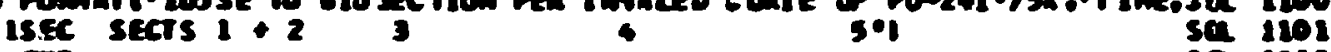

Ex sa isie

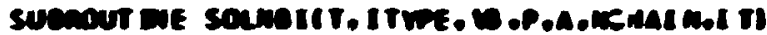

$\sin 10$

$c$
$c$
$c$
$c$
$c$
$c$
$c$
$c$
$c$

IrTPE $=1$ nets

ITVEe $=2$ it

and ox

IrTee $=3$

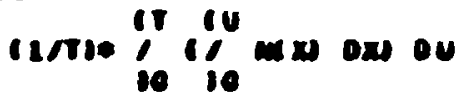

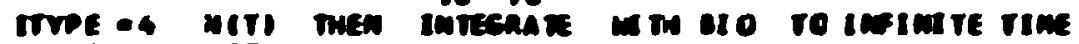

YCK. IS WUST - 0

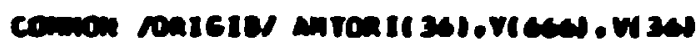

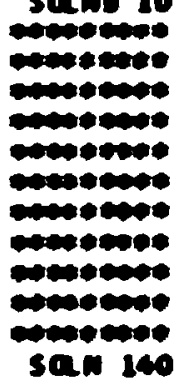




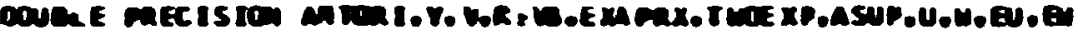

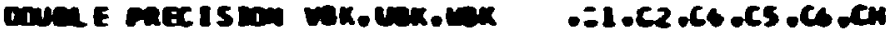

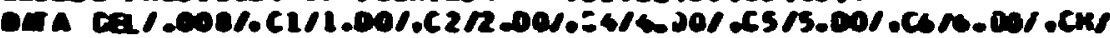
1. sooe

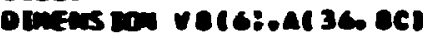

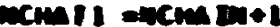

0131 re 1. ncmen

x cosene $(k-1) 12$

a ber anoel

Gevarget

Iftu-cain 1. 15

$1 \quad 210$ 12034.2\%,ITTEE

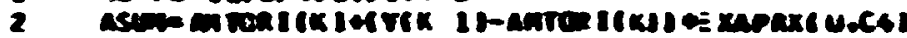

0105

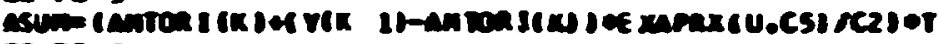

0705

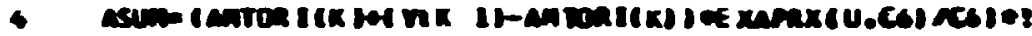

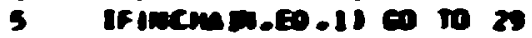

00 is lo.2.

Sielex ene

IFIY EK II.EO.01 CD 10 is

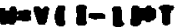

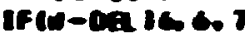

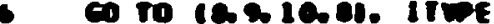

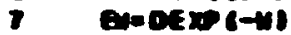

$07011612,13,111$. ITHe

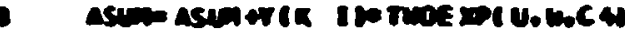

CO TO 14

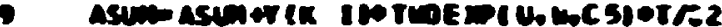

00 T0 14

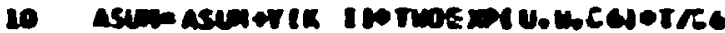

CB To 16

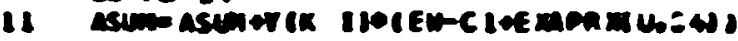

Co 1014

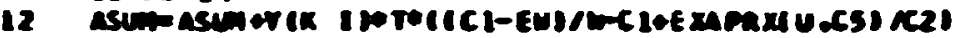

001014

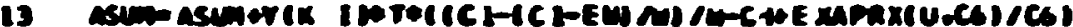

14 controne

co 7029

$15 \operatorname{ancese}(-4)$

$60501 \% 17.16,16 \%, 10 \mathrm{rr}$

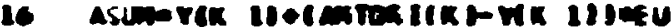

Co 1018

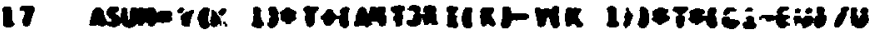

CO 1019

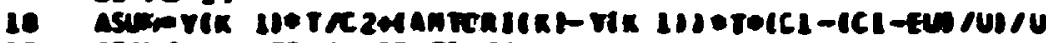

19 Iftecmit.60.18 Co 29

$020 \mathrm{gez}, \mathrm{K}$

KI. $140 \mathrm{cos}$

Eivia Is.E0.01 ces to 20

weve I-16it

IFIN-ta 120, 20,21

20 co To $122,23 \cdot 24,221$. ITw

21 evosin $(-4)$

Co 10125.20 .27 .251 . I Twe

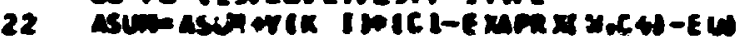

$\operatorname{san} 150$

$\operatorname{sen} 160$

sat 170

$\operatorname{sen} 172$

sati 100

so.n 150

$\operatorname{sen} 200$

$\sin 210$

$\sin 220$

san 230

$\operatorname{san} 200$

san 20

$\sin 20$

san 270

san 20:

san 200

san 30

san 310

sall 320

$\operatorname{san} 330$

san 340

san 30

sen 30

san 370

san 300

san 300

sen 400

san 410

san 420

sain 430

$\sin 100$

$\operatorname{sen} 450$

$\operatorname{sen} 10$

sain 470

san 4

$\operatorname{sen} 400$

san seo

san 510

san 520

=an 530

sin 500

san

san seo

sall 370

say sed

san $5 x 0$

san

san 110

$\operatorname{san} 020$

sal 420

sain 40

s2n 650

san

sen 670

san 400

$\operatorname{san} 400$ 
001020

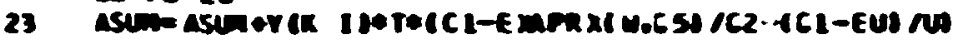

$\operatorname{sen} 100$ CB 1020

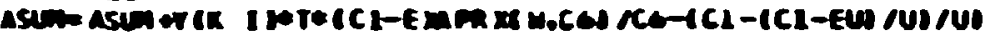
Co To 20

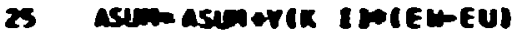
CO TO 20

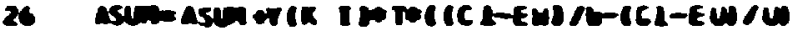
CO 1020

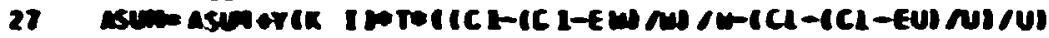

20 cont InUE

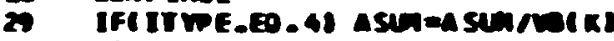

$30 \Delta\left(k_{0} \mathrm{IT}+\mathrm{R}\right.$ Rasem

IfIAsu_et.01 ed w 31

$A\left(K_{2}, I T+1\right)=0$

Matur ICOL.R. T.ASIn. WRI

31 cont rinue neturn

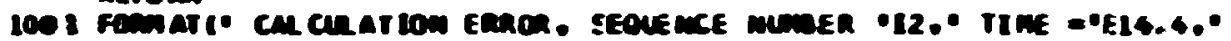
IEsul: = E14.40" oecar consinnt $=" \equiv 14.41$ ENo

$\operatorname{san} 710$

$\operatorname{sen} 720$

$\operatorname{san} 730$

$\sin 700$

$\operatorname{sen} 750$

$\sin 760$

$\operatorname{sen} 770$

$\operatorname{san} 700$

$\sin \pi$

$\operatorname{san} 60$

$\sin 010$

$\sin 22^{\circ}$

san 830

san 840

san 050

san 10

$\operatorname{san} 070$

soin eas

$\operatorname{sen} 00$

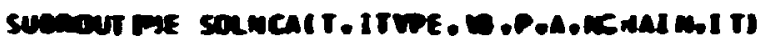

$\operatorname{sen} 10$

ITVFE - 1 NETI

ITHE $=2$

I T

10

mxs ox

it 10

ITree $: 3$

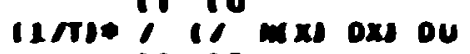

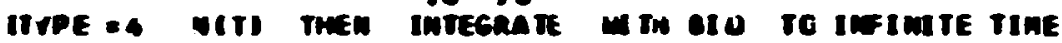

TAR. 11 vUST 0

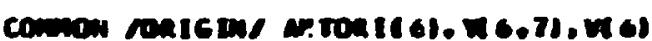

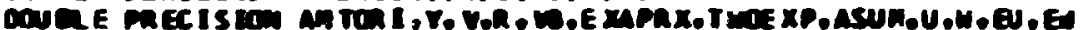

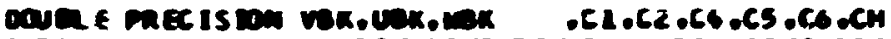

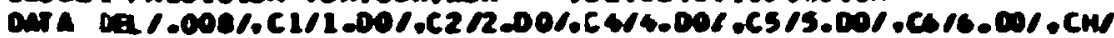
1.500\%

our a daf .016

Dimens in velob.A1 C. 1008

mener 1 ancun enel

Do $30 \mathrm{k}=1, \mathrm{ncm}$ (n)

Goven sat

IF IU-DQ:21.15

1 TO $12,3,4021$. ITTPE

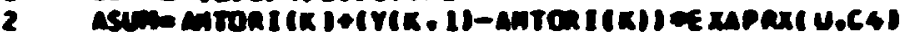

CO 105

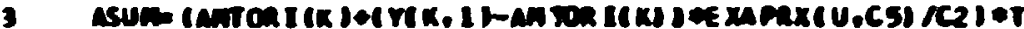

00 TO 5

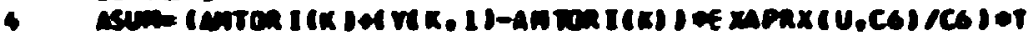

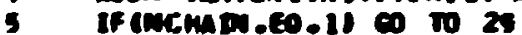

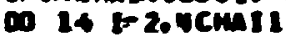

IFII $50 x+11007014$

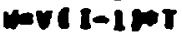

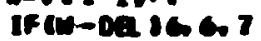

scomes

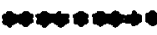

cheretes

covereper

-aparate

chereter

-arater

ratertertore

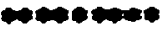

comperte.

rperereter

san 140

$\operatorname{san} 150$

san 160

san 170

sats 171

sam 100

san 190

san 200

sen 210

$\operatorname{sen} 220$

san 230

$\operatorname{son} 240$

son 250

san 260

soln 270

san 200

$\operatorname{san} 290$

san 300

san 310

san 320

san 330

san 300 


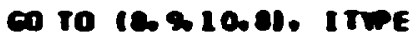

$\operatorname{san} 350$ enecexpi-ni

00 TO 11. 12.13, 111. ITUE

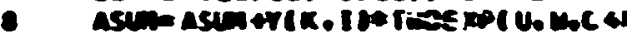

CO 1014

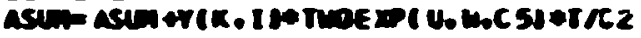

01014

10

11

12

13

14

15

is

17

10

19

21

22

23

24

25

20

27

2

2.

30

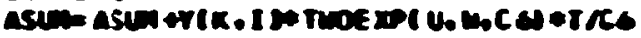

01014

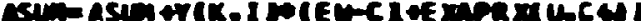

$\rightarrow 1014$

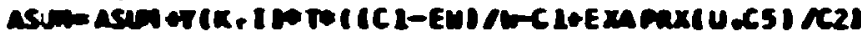

00 TC 14

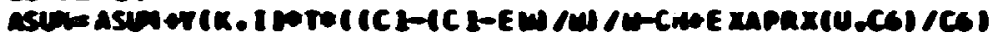

cons rine

57029

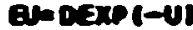

$\Rightarrow$ T0 110 17. 10 101.8TUE

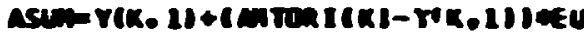

$0 \mathrm{TO} 19$

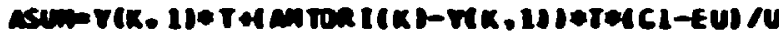

$\rightarrow \mathrm{TO} 19$

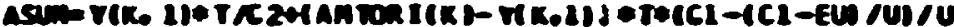

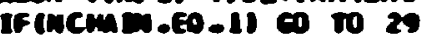

10 20 le 2ncmis

IfI $-60 \mathrm{~d}+1100 \mathrm{~W} 20$

Heve $1-1 \% 5$

IFIU-0. $120,20,21$

$070122,23 \cdot 24,220$. ITUE

QPe 0en $(-1)$

$\rightarrow T 0125,26,27.250$. ITWE

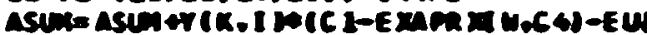

$\rightarrow 1020$

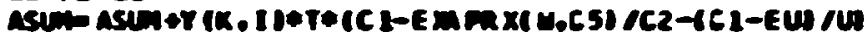

co 1020

ASUm ASU

01020

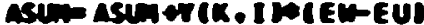

07020

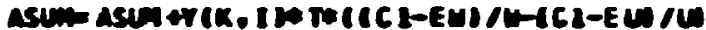

co 1020

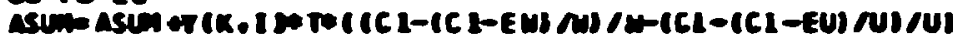

ant rine

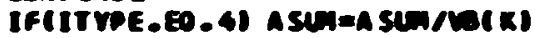

iflasund T.01 call Earo

ACR. IT+2Rasu

aciun

ENO

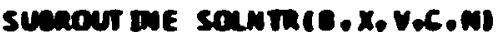

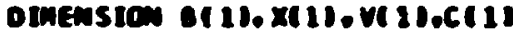

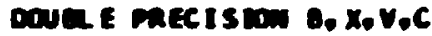

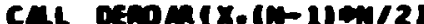

015 Ienn

$15=1$

$12=1-2$

Sold 320

som 370

son $39 a$

$\sin 320$

$\operatorname{san} 400$

$\sin 410$

$\operatorname{sen} 420$

sin 430

soln 40

$\sin 450$

soln wo

$\operatorname{sen} 470$

sine seo

$\sin 400$

sat soo

son 510

$\sin 520$

son 520

$\sin \operatorname{sen}$

san 550

san seo

san 570

san 50

sal seo

sam 100

san 610

san 120

san 630

san 40

$\operatorname{san} 050$

san 10

san 670

san wo

san 190

san wo

son 710

san 720

soln 730

san 740

San 750

san 700

son 70

san 700

$\operatorname{san} 790$

san 00

san 010

san 020

$\operatorname{san} 10$

samt 20

saw 30

sam 40

saiv 50

sam 6

sant 70 
D $5 k=1011$

san 100

$x=x-1$

$1 K=K+1400$

KST ART $=K 2+(K-2) / 2$

sumect $x)$

IF(R LE.I) OD Do 2

LIarstant +1

Lexstcat th

Do 1 Lallol?

sumsunexil a

sumed ax resen

IfEI $C X+1)$ OIO

$\infty 03 \mathrm{~L}, 12$

$1 M 10=j *(J-1) / 2$

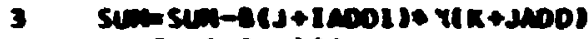

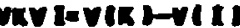

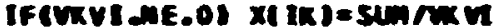

5 comtinue

arrus:

ENo

$\operatorname{san} 110$

san 120

$\operatorname{san} 130$

$\operatorname{san} 140$

$\operatorname{san} 150$

san 160

$\operatorname{san} 120$

sam 100

$\operatorname{san} 190$

soln 200

san 210

$\operatorname{san} 220$

$\operatorname{san} 230$

$\operatorname{san} 240$

$\sin 250$

$\operatorname{san} 260$

sin 270

$\sin 200$

$\operatorname{sen} 290$

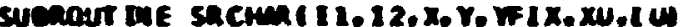

secus 10 Othension x(2), 121

$121=12-1$

ne 11

IFII217. 7.1

IFIIII, 7,2

IF(T)111-7(12)13, 7, 10

Oo $1=11.121$

IFITFIX-YIIIIS. She

Ite 1

$1=121$

IF(TFIX AE.TII2)! Co TOS

$I=12$

CO 50

IFIYII I LE.0I 60 To

IFITIIt) $\alpha E .01 \mathrm{CO}$ TO

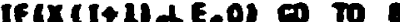

virixil IaE.0i on to:

ifirfix dE.01 00 mo

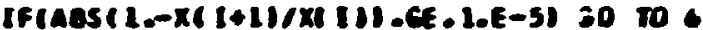

IFII LE-III 00 T0

I. $t-i$

Iue 1

co ros

XUEVINT IU, $x, y, y F[x)$

Retuan

xuevent (IU, $x_{0} v_{0}$ we Ix)

astuan

IUE I

xus $x+11$

60107

30

Do 11 IEIL 121

IfIVFIx-VIIB B1, 9.5

sucun 20

sucus 30

secins 40

secma so

suche 40

secma 70

SACHA 80

semena 90

Sech 100

SNM 120

SNCH 120

SICH 130

STCH 140

SnCH 150

sinen 160

SECH 170

SNCH 100

SNCH 190

SRCH 200

Sick 210

SRCH 220

SIICM 230

SNCH 240

snch 260

sech 260

SNCH 270

SNCH 260

SNCH 200

SACH 300

SNCH 310

SRCH 320

SNCH 330 
Bro

$\sec 300$

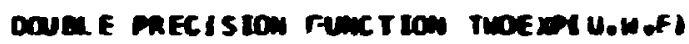

SACH 390

Deuere mecis Iow u, f. W.Cl.C2

Dat a C1/1.00/.C2/2.001

Jimeu

UNGUVithen

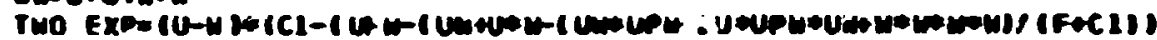

MFU IF-CLUIRF-C2UI

AETUAK

ED

Punct ION VINTCI.V.F.FIATS

otwension Villofili

YISE CII:

VINT=VI

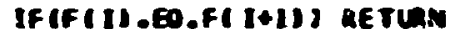

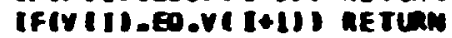

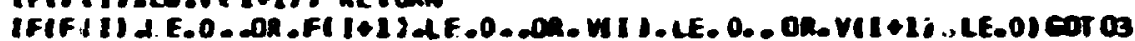
VO=VII+11N!

FFE FINT IFIII

FO= FII $11 / F I$ II)

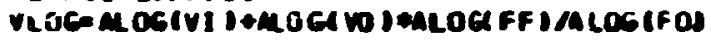

IFIVI OG.6T.174.) noc-174.

$V$ IfT $=$ EXP(INOG)

2 RETuRM

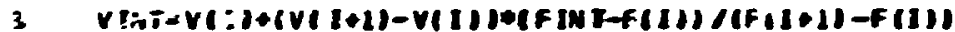

RFTURN

ENO

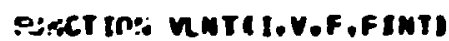

DHAE'SIOS VIIB.f(I)

VIFIEFIII

IFIFIII.EO.FI I+1) RETIRH

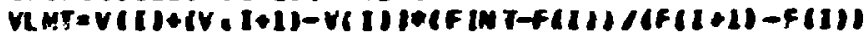

Reruan

END

SUEROUT TIE 2 EPSAR (A, N)

DIMENSIGA AC 11

$001-20 \mathrm{~V}$

1

Al1 $9=0$

RETURA

END

acos 0 atra

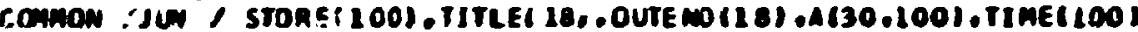
nata eEer...

oata ojtenc, stopo 
Punct dow anenecoensi

c Eemin enencioner

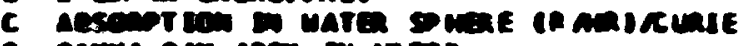

c cenma nin ans in ented

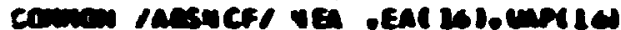

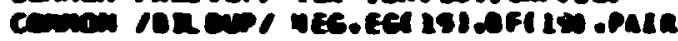

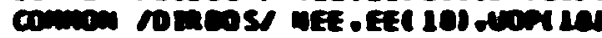

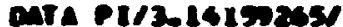

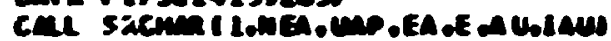

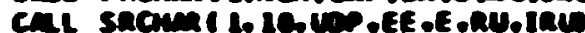

cul sncun 1 1. 186 GF . EGoE. Sti I Sin

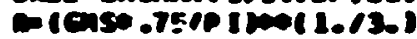

Tolime 1. 1

ES=ExP(-Y)

Fo ko-T/2.

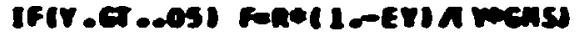

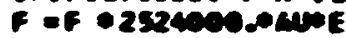

ans

ctrun

ans

ancora

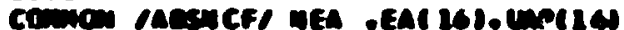

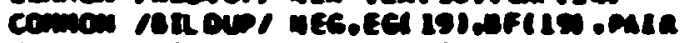

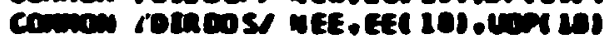

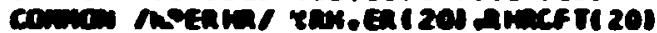

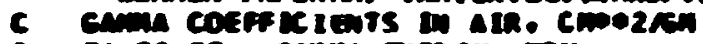

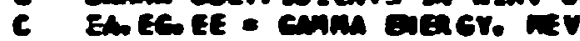

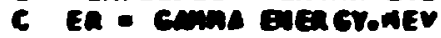

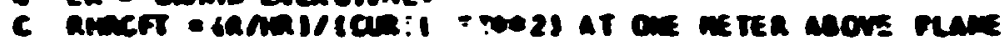

uos - rota artem

vas = rota areineris:

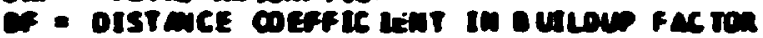

park - air cinsitr. enace

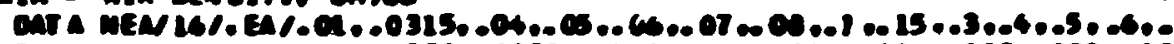

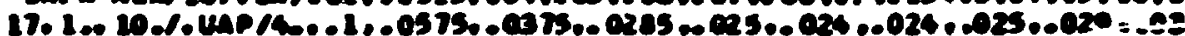

$20.036 .0295,0240.027 .001521$

ori palpoerase

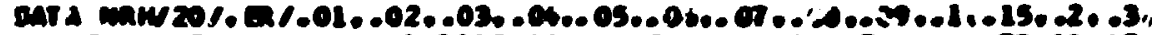

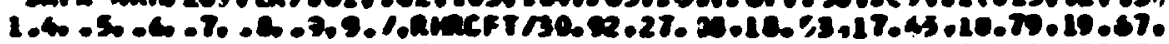

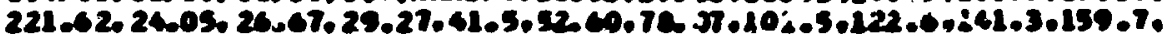

$3175.06101 .5,2000,1$

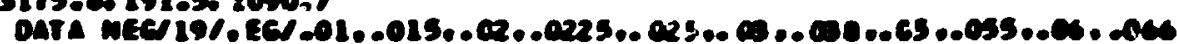

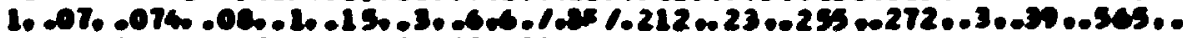

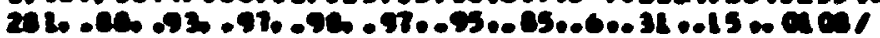

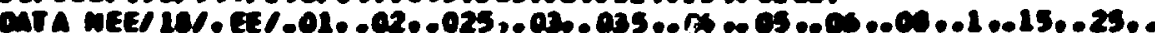

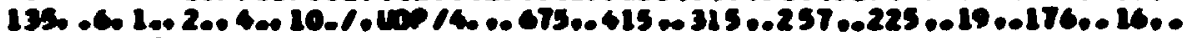

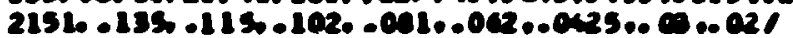

and

Amet 200 areosteges

c

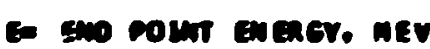

c marean cmes of cicisite 136 o 42

$\cos 10$

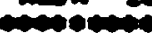

(1)

ran

arsm 5

An

ans 7

arin

Ans

a

A 110

arin 20

Arin 230

ansin 140

19. 1

As

A 1 in

A 1 10

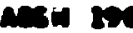

An 200

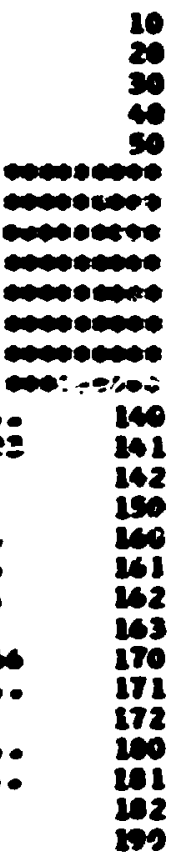

MEOE is

nomerese -

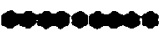




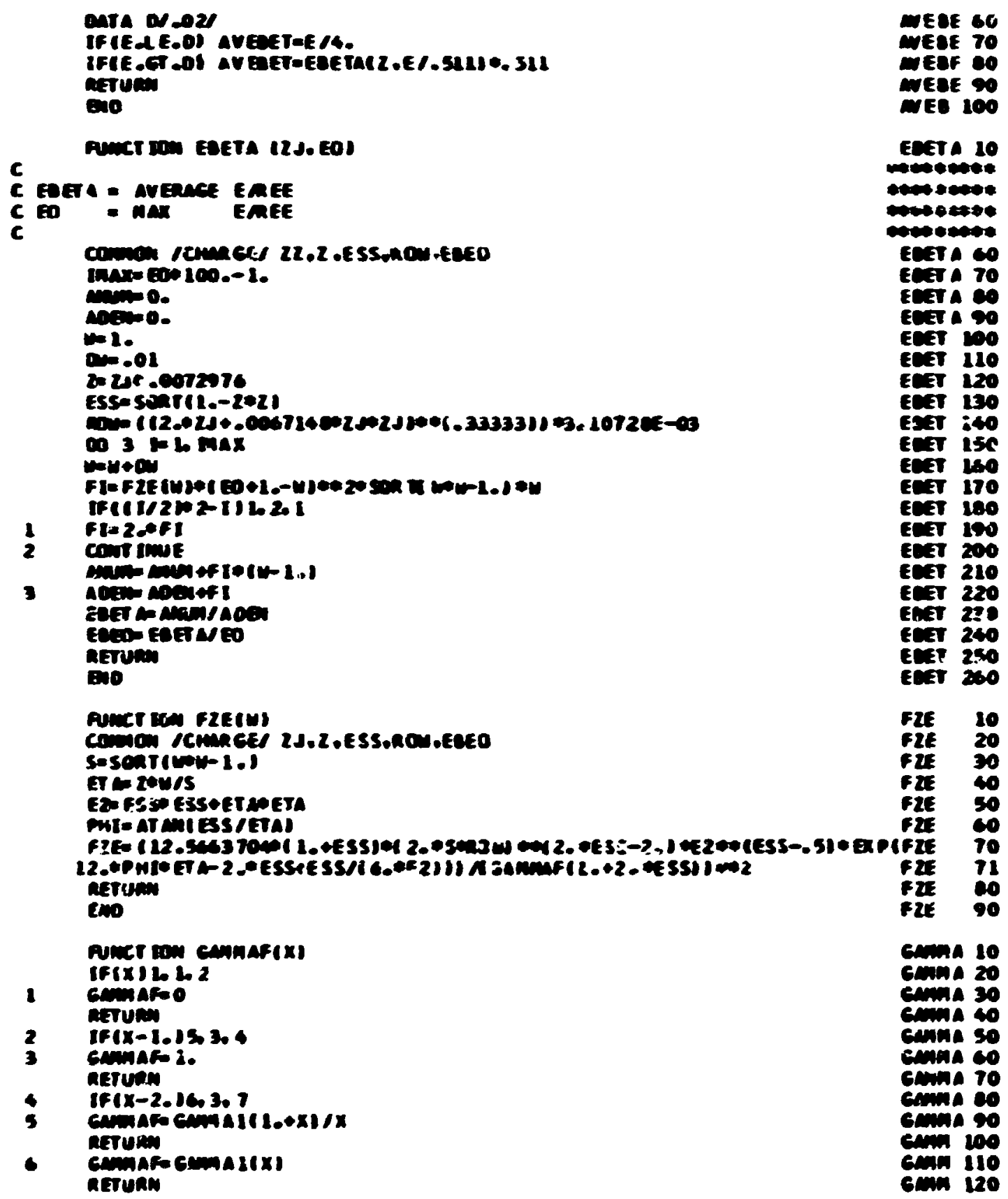

Fit 90

MESE 60 MEOE 70 MEaF 0 WEEE 90 MEO 100

ERET 10

menterese contrenes -becter necespara

ECTT 0

Ecci 70

ctrt a 0

Eck 120

Eect 100

EccT 110

ELT 120

ECT 130

Fलग

ECT ise

ENT 180

ECT 170

EeTT 190

EcT 100

EarT 200

ECTT 210

ECTT 220

Enim 228

CकT 240

ecet 250

EexT 200

FIE 10

F2E 20

Fus 30

FTE 40

fat 50

fat 70

crma 10 Grana 20 ennin 30 Enma 40 comese 50 crmina crima 70 camis oo crmin 50 enmin 100 crmin 110 cmin 120 


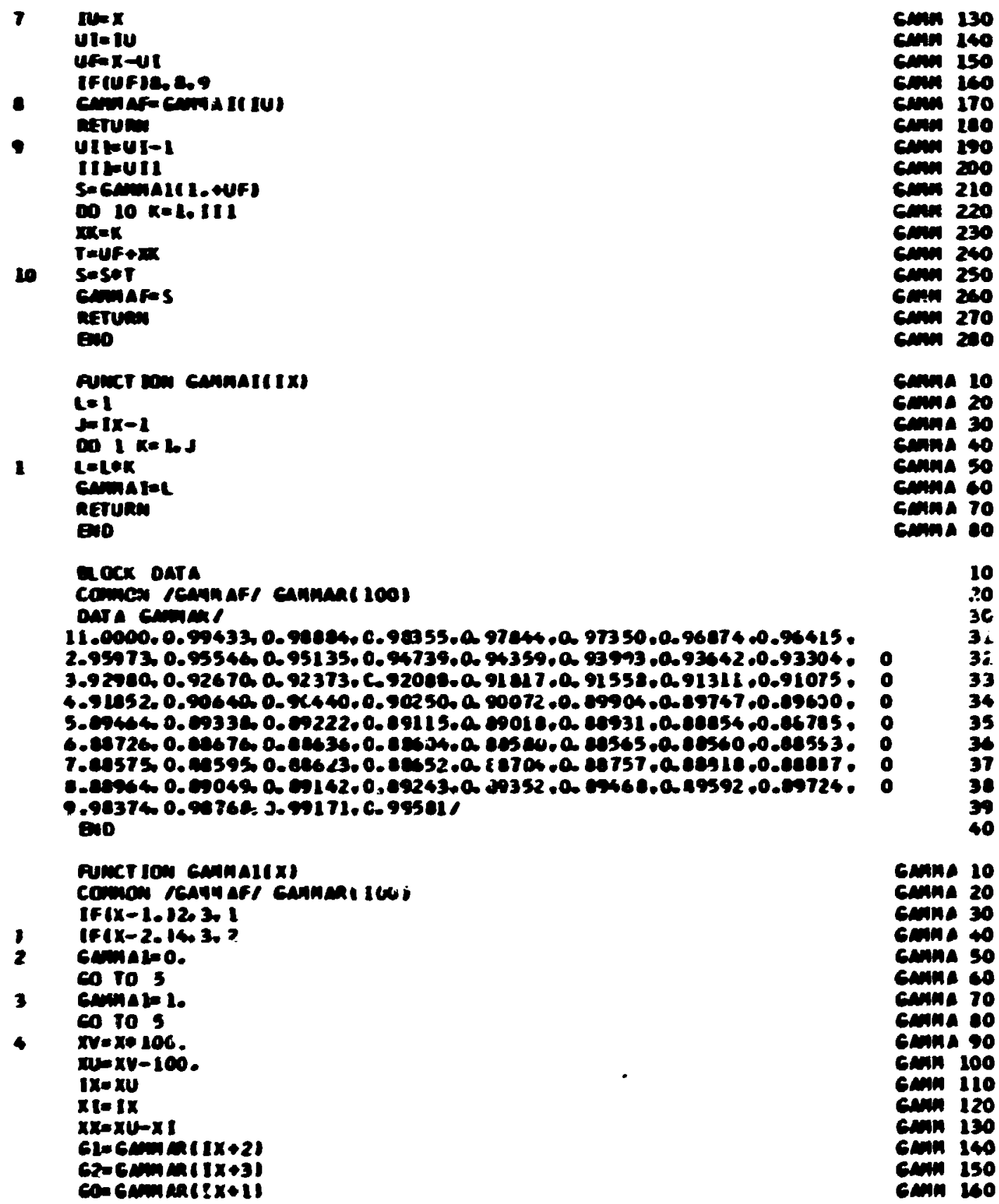




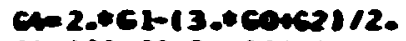

$\operatorname{com} 170$ CSiconc2-2.

cam 100

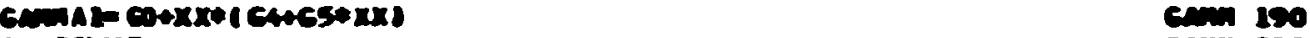

METUM.

$\operatorname{com} 210$

80

cand 220

eock ana

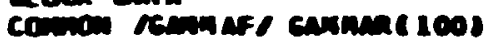

mita canco

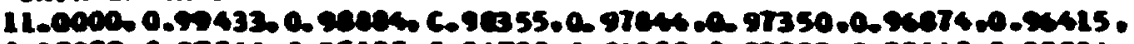

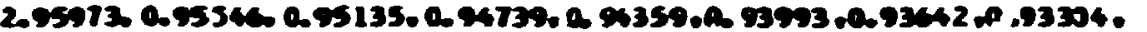

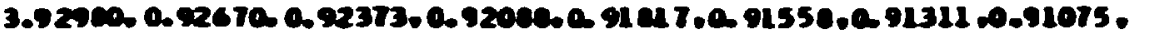

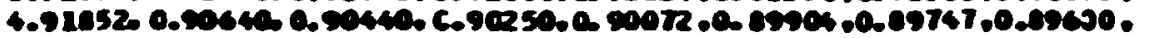

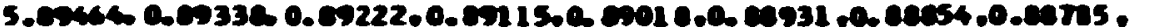

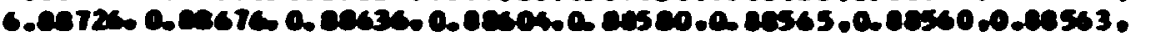

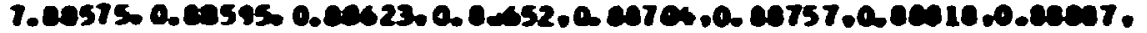

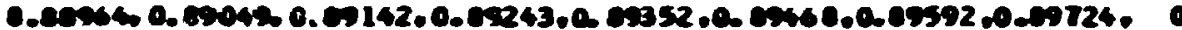

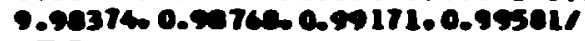

